Illinois State University

ISU ReD: Research and eData

Theses and Dissertations

4-2-2017

\title{
(re)claiming History And Visibility Through Rhetorical Sovereignty: The Power Of Diné Rhetorics In The Works Of Laura Tohe
}

Jessica Marie Safran Hoover

Illinois State University, jmsafra@ilstu.edu

Follow this and additional works at: https://ir.library.illinoisstate.edu/etd

Part of the American Literature Commons, Ethnic Studies Commons, and the Literature in English, North America Commons

\section{Recommended Citation}

Hoover, Jessica Marie Safran, "(re)claiming History And Visibility Through Rhetorical Sovereignty: The Power Of Diné Rhetorics In The Works Of Laura Tohe" (2017). Theses and Dissertations. 724.

https://ir.library.illinoisstate.edu/etd/724

This Dissertation is brought to you for free and open access by ISU ReD: Research and eData. It has been accepted for inclusion in Theses and Dissertations by an authorized administrator of ISU ReD: Research and eData. For more information, please contact ISUReD@ilstu.edu. 
(RE)CLAIMING HISTORY AND VISIBILITY THROUGH RHETORICAL SOVEREIGNTY:

THE POWER OF DINÉ RHETORICS IN THE WORKS OF LAURA TOHE

\author{
Jessica Marie Safran Hoover
}

\title{
227 Pages
}

This dissertation investigates the intricate intersections of code switching, trickster discourse and rhetorical sovereignty in the scholarship of Diné author Laura Tohe, as Tohe operationalizes survivance and alliance in complex ways, ways that "actuate a presence" in the face of ongoing attempts to render American Indian peoples absent from American rhetorical, literary, and geographic landscapes. Existing research in American Indian literatures and rhetorics often focus on the need for reclaiming rhetorical sovereignty. Yet, little work has been done to emphasize connections between the use of code switching, translation, and trickster discourse in order to give visibility to past and contemporary Diné peoples and to decolonize the Diné history. This dissertation uses decolonizing methodologies to demonstrate that Tohe's writing is an action to regain the sovereignty and visibility that has been torn from the tongues and bodies of American Indian peoples, specifically the Diné, after years of colonization, oppression, and resistance. Chapter one provides the necessary historical context of the Diné and the Navajo Long Walk, and chapter two presents an explanation for the various theoretical and critical frameworks for this dissertation. Chapter three provides an explanation about the lens through which the visibility and voice of the Diné is exacted through Tohe's use of rhetorics of survivance and alliance, as well as her attempt to decolonize the Diné history. Chapter four further explores Tohe's decolonization of the Diné history and the reclamation of her rhetorical 
sovereignty through her use of trickster and trickster discourse, as she attempts to decolonize representations of the Diné and provide her own representation of what it means to be Diné. The dissertation ends with a reevaluation of the discussions surrounding the use of American Indian texts in an introductory American literature course. Chapter five guides educators in how using a text, such as Tohe's, is beneficial to not only the promotion of American Indian texts in the classroom, but the necessity of disrupting, adding to, and maintaining our students' acknowledgment, awareness, and understanding of the significance of rhetorical sovereignty and the power of those voices of American Indian authors in claiming that sovereignty and resisting colonial attempts to silence them.

KEYWORDS: Rhetorical Sovereignty, Decolonize, Visibility, Diné, American Indian, Rhetorics, Literature, Language, Code Switching, Translation, Trickster Discourse 
(RE)CLAIMING HISTORY AND VISIBILITY THROUGH RHETORICAL SOVEREIGNTY:

THE POWER OF DINÉ RHETORICS IN THE WORKS OF LAURA TOHE

JESSICA MARIE SAFRAN HOOVER

A Dissertation Submitted in Partial

Fulfillment of the Requirements

for the Degree of

DOCTOR OF PHILOSOPHY

Department of English

ILLINOIS STATE UNIVERSITY

2017 
(C) 2017 Jessica Marie Safran Hoover 


\section{(RE)CLAIMING HISTORY AND VISIBILITY THROUGH RHETORICAL SOVEREIGNTY:}

THE POWER OF DINÉ RHETORICS IN THE WORKS OF LAURA TOHE

JESSICA MARIE SAFRAN HOOVER

COMMITTEE MEMBERS:

Christopher De Santis, Chair

Angela Haas

Kristin Dykstra 


\section{ACKNOWLEDGMENTS}

No amount of praise and no number of words can truly convey my gratitude to the many people who helped me to write this dissertation and accomplish my dream of attaining a doctoral degree. I just hope that my dedication to my teacher-scholar duties and my motivation to help others to pursue their dreams can act as a "thank you" to those who inspired me to chase my dream and grab onto it with enthusiasm and pride.

Many people have influenced my decision to pursue a doctoral degree, as they are and were my cheerleaders. I first want to thank Laura Tohe as she greatly influenced my research and academic career through her brilliant literary contributions and her influence to make the world a better and more-informed place. I also owe a great deal of gratitude to my dissertation committee members, Dr. Christopher De Santis, Dr. Kristin Dykstra, and Dr. Angela Haas. Each of these brilliant scholars gave up their time to help me compose and strengthen my research and writing. Dr. De Santis, you always encouraged me to be my best, as you challenged me to become a stronger writer and "own my words." I thank you for supporting me in finishing this dissertation and finishing my degree. Dr. Dykstra, you were instrumental in helping me write with clarity and command, and you provided me with ample feedback while challenging me to think deeper. Lastly, Dr. Haas, thank you for your insights and your guidance.

I would also like to acknowledge my parents, John and Antoinette Safran. I want to thank you two for raising me to strive for what I want, and teaching me what it means to "think for myself." You two have always been two of my biggest supporters, and I am one of the luckiest "kids" in the world for having two loving and supportive parents who taught me never to give up regardless of any inevitable and unexpected obstacles. I also want to thank my grandmother, 
Elizabeth Jobe. You always talked to me about my research and work, even though you "didn't get it." Thank you for being a listening ear.

Most importantly, I want to recognize and thank my husband, Joseph Hoover. You have always been my light in a world that can be dark and my voice of reason during my bouts of anxiety and doubt. The strength that you give me in our day-to-day lives carried over into my work, as your encouragement and support helped me finish my dissertation and graduate with a degree that has taken us on many geographical journeys. You are the foundation from which I gain my confidence and inspiration. Thank you for being my best friend, life-partner, motivator, and fan.

Lastly, I would like to remember those who are no longer with me in this tumultuous journey we call life: my grandfather Clifford Jobe, my grandfather Paul Safran, my greatgrandmother Elizabeth Pilkington, my "in-law" grandparents Paul and Lillian Funsch, and my "adopted" grandmother and dear friend Mary Ann Stephens. Each of these people knew of my quest to earn a doctorate degree, and each of these people have influenced my life and my learning in a positive way; they are my cheerleaders from up above.

J. M. S. H. 


\section{CONTENTS}

\section{Page}

ACKNOWLEDGMENTS

$\begin{array}{ll}\text { CONTENTS } & \text { iii }\end{array}$

CHAPTER I: “SEEING WITH NAVAJO EYES”: UNDERSTANDING DINÉ HISTORY, CULTURE, AND DUAL IDENTITY 1

$\begin{array}{ll}\text { My Goal and Interest } & 6\end{array}$

Overview of Navajo Nation and Diné Culture and History 11

$\begin{array}{ll}\text { The Navajo Long Walk } & 13\end{array}$

Navajo Nation Today $\quad 21$

Storytelling / Oral Traditions of the Navajo Nation 23

Background of Laura Tohe and Her Works 25

$\begin{array}{ll}\text { Dissertation Chapters } & 28\end{array}$

CHAPTER II: A DECOLONIZING FRAMEWORK AND THE NEED FOR A NATIONALIST

$\begin{array}{ll}\text { PERSPECTIVE } & 32\end{array}$

My Research Methods $\quad 32$

Decolonizing Methodologies 33

$\begin{array}{ll}\text { Sovereignty and Self-Determination } & 37\end{array}$

Cultural and Intellectual Sovereignty $\quad 42$

$\begin{array}{ll}\text { Rhetorical Sovereignty } & 45\end{array}$

Rhetorics of Survivance $\quad 46$

$\begin{array}{ll}\text { Rhetorics of Alliance } & 47\end{array}$

$\begin{array}{ll}\text { Defining Code Switching } & 48\end{array}$ 
$\begin{array}{ll}\text { Studies in Code Switching } & 51\end{array}$

$\begin{array}{lr}\text { Trickster } & 54\end{array}$

$\begin{array}{ll}\text { Nationalism } & 57\end{array}$

$\begin{array}{lr}\text { Literary Nationalism } & 58\end{array}$

$\begin{array}{ll}\text { Diné National Identity } & 61\end{array}$

CHAPTER III: (RE)CLAIMING DINÉ HISTORY AND GIVING VOICE TO SILENCED

PAST AND PRESENT DINÉ: TACTICS OF SURVIVANCE AND ALLIANCE THROUGH

CODE SWITCHING AND TRANSLATION IN LAURA TOHE'S TSÉYI'/ DEEP IN THE

ROCK: REFLECTIONS ON CANYON DE CHELLY 66

Tséyi'/ Deep in the Rock $\quad 68$

$\begin{array}{ll}\text { Diné Storytelling } & 70\end{array}$

$\begin{array}{ll}\text { Survivance } & 71\end{array}$

$\begin{array}{ll}\text { The Navajo Language } & 77\end{array}$

Past and Contemporary Diné Peoples' Visibility and Voice $\quad 80$

Stereotypes and Authenticity: Teaching Moments 92

Promoting Alliance: Teaching the Diné Language, Culture and History, and Encouraging

$\begin{array}{ll}\text { Allies } & 93\end{array}$

CHAPTER IV: SUBVERTING ERASURE ATTEMPTS AND TRANSCENDING

LIMITATIONS THROUGH TRICKSTER: (RE)WRITING HISTORY AND ATTAINING

VOICE THROUGH TRICKSTER DISCOURSE AND THE COYOTESSE IN LAURA

$\begin{array}{lr}\text { TOHE'S NO PAROLE TODAY } & 108\end{array}$

$\begin{array}{ll}\text { History of Boarding Schools } & 108\end{array}$

$\begin{array}{ll}\text { Tohe's No Parole Today } & 117\end{array}$ 
Transcending Limitations Through the Many Embodiments of Trickster

Trickster Discourse and Rhetorics

Another Layer of Trickster: Understanding the Power of Coyotesse

Speaking Back to Pratt, Reclaiming Voice and Language

Trickster Fills the Silence

Trickster Breaks the Silence

Physical, "Real," Tricksters

Tohe as Coyotesse, Again

Trickster Discourse: Speaking Back, Literally

Students or Tricksters: Shapeshifting and Survival

CHAPTER V: PEDAGOGICAL TOOLS TO BRING AWARENESS OF RHETORICAL

SOVEREIGNTY IN AMERICAN INDIAN LITERATURE: TEACHING SURVIVANCE AND

PROMOTING ALLIANCE THROUGH CODE SWITCHING AND TRANSLATION IN THE

$\begin{array}{ll}\text { INTRODUCTORY LITERATURE CLASSROOM } & 158\end{array}$

Exigency

Contact Zones, and "Unsafe" Spaces

Course Context

A Glimpse Into the Classroom

Focusing On American Indian Literature in the Classroom

Focusing on Tohe's Text

A Short Case Study of Tohe's Work

Code Switching 
$\begin{array}{ll}\text { Promotion of Alliance } & 190\end{array}$

Questioning Representations 193

$\begin{array}{ll}\text { What They Learned } & 195\end{array}$

$\begin{array}{ll}\text { NOTES } & 200\end{array}$

$\begin{array}{ll}\text { WORKS CITED } & 212\end{array}$

APPENDIX A: SUGGESTED TEXTS 226 


\section{CHAPTER I: "SEEING WITH NAVAJO EYES”: UNDERSTANDING DINÉ HISTORY,}

\section{CULTURE, AND DUAL IDENTITY}

There are 566 federally recognized American Indian Nations in North America, as of 2017, and each is distinct in its own cultures and languages. According to the National Congress of American Indians in An Introduction to Indian Nations in the United States, "the United States Constitution recognizes that Indian Nations are sovereign governments" and that "Indian Nations retain their inherent powers of self-government" (Hogg 2). The purpose of this self-government is to ensure that the various American Indian nations, with their own cultures, societies, histories, politics, and languages remain to be recognized as distinct groups. Despite this emphasis on recognition and sovereign nations, American Indians, unfortunately, continue to be "clumped together" as "Indian" or are disregarded as non-existent by the United States government. ${ }^{1}$

To begin this introduction, I will first present a history of the oppression and appropriation of American Indian identity, as I provide an explanation of how stereotypes and misnomers occur because of the ongoing colonial attempts to define, quiet, and ignore American Indian peoples by those that are non-Native. I will then give examples of how American Indians are still mistreated by the United States government, even in 2017. As mixed-blood, White Earth Chippewa cultural theorist Gerald Vizenor's work makes clear, the Indian is continually placed into the past, as a vanishing or vanished race, and one that is represented by neither his/her own culture, nor nation, but by an image that is created for him/her by hegemonic forces that sponsor colonization, assimilation, and dominance. Leech Lake Ojibwe rhetorician Scott R. Lyons too asserts that "non-Indians have had little problem lumping the hundreds of different tribes, languages, and cultures on the American continent under a single rubric, 'the Indian,' ever since Columbus arrived on these shores and announced 'Indios!' and then later designated the group a 
'race" ("Body" 148). The very concept of "Indian" is a white invention, as Vizenor explains that "the word Indian...is a colonial enactment... an occidental invention that became a bankable simulation" ("Manifest Manners" 11). This simulation aids in the pigeonholing and stereotyping of those who identify as "American Indian."

When colonial naming is imposed on American Indians, it simplifies the complexities of indigenous identities and allows stereotypes to emerge. These importunate stereotypes began with the Indian as the “savage.” In MariJo Moore's (Cherokee, Dutch and Irish) Eating Fire, Tasting Blood: An Anthology of the Great American Holocaust, Hopi scholar Matthew Sakiestewa Gilbert explains that during the late 1800s and early 1900s, "government officials, along with the public opinion of the day, viewed Indians as uneducated 'savages' who desperately needed to be saved from their 'uncivilized' and 'devil-like' ways" (78). This perspective from US government officials is what led to relocation, removal, and assimilation via boarding schools that were designed to destroy Indian identities by replacing them with EuroAmerican identities. Moreover, declaration of historic rights by the tribes, during the mid-to-late 1900s, has produced "rabid backlash against Indians in many parts of the United States"; for as recent as the last decades of the twentieth century, bumper stickers reading, "Save the deer, shoot an Indian,' were prominently featured in Wisconsin and Michigan as treaty hunting and fishing rights were successfully upheld in the courts" (Deloria "Custer" ix). More recently, in the 2000 s, these images can be seen from the same names and logos from the last decades of the twentieth century, for various sports teams in the United States, such as the Washington Red Skins, Atlanta Braves, and the Chicago Blackhawks. Despite indigenous peoples' attempts to rally against and abolish the offensive, ethnicity-based names and logos for various sports teams, the team names persist. Thus, sadly, many of these stereotypical images of "the Indian" are still 
identifiers of American Indian peoples; however, it is not just the stereotype of the savage that is harmful, but also misinformed, stereotypical view of the American Indian as "mythical.", i.e. finding and/or titling the "real" Indian. Indianness is static, unchanging, and out of history; "being" American Indian is belonging to a particular culture, society, and belief-system. It is not a "fad" or a façade. In Custer Died for Your Sins, Standing Rock Sioux Vine Deloria Jr. explains it best, in regards to people's infatuation with "what a 'real' Indian is really like," when he writes:

Indian life, as it relates to the real world, is a continuous attempt not to disappoint people who know us. Unfulfilled expectations cause grief and we have already had our share. The more we try to be ourselves the more we are forced to defend what we have never been. The American public feels most comfortable with the mythical Indians of stereotype-land who were always there. These Indians are fierce, they wear feathers and grunt. Most of us don't fit this idealized figure since we grunt only when overeating, which is seldom. To be an Indian in modern American society is in a very real sense to be unreal and ahistorical. (2)

Many Americans in the United States are exposed to these negative images and stereotyping via various media and technologies, while having little-to-no education and/or knowledge about the uniqueness of tribal groups and individuals. American Indian Nations have been silenced and pushed to the social rim by these ongoing misrepresentations and misnomers since colonization, and these attempts at silencing and eradicating American Indian sovereignty continue to persist into the present. 
One of the most recent and significant events that demonstrates the ongoing mistreatment and silencing of American Indian nations emerged in 2016 when the sovereign Nations of the Standing Rock Sioux and Cheyenne River Sioux tribes, an indigenous-led youth group, several indigenous led-camps, and the Indigenous Environmental Network came together to resist the Dakota Access Pipeline Project planned by Energy Transfer Partners to be built on Sioux treaty land (see Fort Laramie Treaties of $1851 \& 1868$ ) without consent from the Sioux and without an Environmental Impact Statement. The Dakota Access oil pipeline was originally proposed in a white community North of Bismark, but its citizens complained that the risks to their clear water were too high, and the proposed path was moved to Sioux treaty lands that the U.S. Corp of Engineers claimed as their own, which included drilling and laying pipeline through a sacred burial ground and under Lake Oahe, the Standing Rock Sioux's only source of safe water. The camps began their water protection movement in April 2016, and they were met with excessive police force in riot gear, supported by the Morton County Sheriff's office and the North Dakota governor (and supplemented with police from more than six other states). In August 2016, the Standing Rock tribal Chairman Dave Archambault and the tribal council asked a federal judge to halt construction until an Environmental Impact Statement is granted, arguing that they "were not allowed to voice their concerns and provide comments about the project's impact to their lands" (Miller). In October 2016, the federal court stated that Energy Transfer Partners had the "right to continue construction on private land," claiming that the land is owned by the U.S. Army Corp of Engineer's, when it is actually the Standing Rock Sioux's treaty and sacred land. The Standing Rock Sioux, Cheyenne River Sioux, and more than 500 North American and global indigenous nations (including the Diné) have resisted the pipeline and worked to protect Lake Oahe and the Missouri River (and downriver to the Mississippi) along with numerous 
allies, such as various celebrities, civil rights leaders, civil rights groups (e.g., Black Lives Matter), and U.S. veterans. Chairman Dave Archambault II of the Standing Rock Sioux Tribe called the coming-together of various Nations and allies "an historic occasion" as he spoke of the mistreatment by the federal government:

For centuries, the Standing Rock Sioux Tribe, and tribes across the country, have faced fundamental injustice at the hands of the federal government - which time and again took our lands and tried to destroy our way of life. Our treaties and our human rights were ignored, our interests in protecting lands and waters were considered unimportant, and our voices were not heard. It was this shared history that led tribes to come together as never before to seek the protection of our waters against the threat of the Dakota Access Pipeline. With peace and prayer, indigenous people from hundreds of tribes said: our future is too important. We can no longer be ignored. The goal was to protect these sacred waters, and to do so in the name of our children. (Archambault)

Despite the peaceful efforts by the various Nations and their allies, they have been met with excessive force by law enforcement.

The peaceful water protectors and the independent journalists covering the movement have been met with excessive police violence, such as being attacked by guard dogs, shot with rubber bullets, sprayed with water cannons in freezing cold temperatures, sprayed with mace and pepper spray, and wrongly searched, arrested, and held in cages. Chase Iron Eyes, a member of the Standing Rock Sioux tribe and the Lakota People's Law Project, explained that this treatment of American Indians and allies has 'brought back memories of the government's past treatment of Native Americans." In an interview with $C N N$, Iron Eyes summarizes: "You have a 
government agency trying to declare us trespassers on our own treaty land and threatening to penalize us, criminally charge us and possibly forcibly round us up if we don't return to the reservation" (Blau, Richmond, and Russell). This is just one example of the mistreatment endured at the hands of American government officials ${ }^{2}$; additional examples will be discussed throughout the dissertation.

In addition to experiencing subjugation, silencing, and stereotyping, many American Indians also struggle with balancing multiple identities. This notion of balancing multiple identities spurs from the mixing of the Euro-American identity with the American Indian identity, which began in the 1800s during the periods of colonization, assimilation, relocation and removal. Balancing multiple identities and cultures is a notion many American Indians identify with and share. In "This Land is Full of Stories: Navajo Histories in the Works of Luci Tapahonso," Diné scholar Robin Fast explains that American Indians, specifically the Diné, inhabit a world defined by two histories: "that of the traditional Navajo world, its origins recounted and its order established in the stories of creation; and that of colonization, a history that is perhaps most vividly represented, for many Navajos, in stories of the Long Walk period" (185). The idea of "living in two worlds" or having "two histories" means having to manipulate two distinct cultures and two languages, while surviving in the mainstream and maintaining a connection to the traditional beliefs and cultural practices, including language, of one's tribal affiliation or nation. One such American Indian Nation that has experienced this concept of twoness, as noted above, is the Navajo Nation. ${ }^{3}$

\section{My Goal and Interest}

My interest in studying Diné (Navajo) literature and rhetorics originated from my work with Diné scholar Laura Tohe in 2005-2006 and my own heritage. In 2005, I was working 
toward my bachelor's degree in the Honors Program at the University of Michigan. For my honors thesis, I was required to contact a scholar in a field of my interest and act as a research assistant for that scholar for at least a semester. My focus in my undergraduate studies was American literature, but more specifically ethnic literatures. I was raised in an ethnically diverse family. My father is Slovak. My paternal grandparents were born and raised in Slovakia and raised my father with both English and Slovak languages, as well as the Slovak traditions; he, in turn, passed his Slovak traditions onto me. My maternal grandfather was Blackfeet and Diné. His father was Siksika (Blackfeet), German and Irish, and his mother was Siksika, Diné (Blackfeet/Navajo), and German. My grandfather acknowledged his "Indianness," but he rarely spoke of it, only mentioning at times that "Blackfeet were tough; they were takers" and that is why he was "tough." He never discussed or acknowledged his Diné bloodline. My maternal great-great-grandparents gave up their affiliations to the Blackfeet Confederacy reservation, which led to them being disregarded by their Siksika reservation affiliation; because of the shame, the "giving up our land" (not physical land, but the connection to it) was rarely discussed. Because this part of my heritage was hardly mentioned, it made me interested in learning more, as an ally.

While I did my own research into my family history, my area of interest in academia quickly became American Indian literatures. When prompted to contact a scholar during my undergraduate honors thesis work, I immediately decided to locate an American Indian scholar. While perusing various scholars' academic web pages, I was intrigued by Tohe, a professor of English at Arizona State University, and her research on the Navajo Long Walk from 1863-1868. She was studying the effects of the Long Walk on women and children and the impact it had on the designs of Diné wool weavings. While I had taken history courses, the Navajo Long Walk 
was never acknowledged during discussions of the American Holocaust. After emailing Tohe and explaining my interest in working with her, she gladly accepted me as her research assistant and tasked me with finding any and all sources that I could find at local libraries (in Michigan) and the internet related to the Navajo Long Walk. I also visited Arizona State University to do more research in the ASU library and archives.

While working with Tohe, I began to analyze her poetry and narratives. Her work on the Diné philosophy and history, the boarding school experience, and uses of the language of the Diné throughout her works gave me a glimpse into a piece of my heritage that was foreign to me. As I was analyzing her work, I noticed that she not only uses the Navajo language throughout her English-dominant text, but she translates the language for the non-Navajo language speaking reader, most notably in her book of poetry, Tséyi'/Deep in the Rock: Reflections on Canyon de Chelly.

With curiosity about her decision to use both the English and Navajo languages in her work, I e-mailed Tohe on March 26, 2009 and asked her two questions. My questions and her answers (in her own words, directly from the e-mail) are below:

Q1.) What is it that you wish to convey in your poetry in your book Tséyi'/Deep in the Rock? A1.) In Tseyi, I'm trying to convey the essences of my experience with the canyon on many different levels: love and connection to place, story, history, and the mythic. I'm looking at it simultaneously in time and space. In some of the poems, I wanted to transcend present time and move into the past. Although many of my poems are longer, I do like to write short, impromptu poems or haikus using as few words as possible. I do this so I can purge my mind and soul and say exactly what I am thinking at that very moment. Doing this places me in the mind frame that my people's world changed in a moment. If they can carry with them snapshots of their home as 
they were being driven from their homeland, I can write an impromptu poem and capture that same love of place out of respect. It is easy to do while visiting the canyon, harder to do sitting at my desk.

Q2.) What role does code-switching play in the meaning of the poem?

A2.) I never really thought of this, but I think it says that some expressions can't be conveyed in English, so I use the Navajo language. I am able to see through Navajo eyes to convey what I want to say about the canyon. Seeing with Navajo eyes, you see poetry all around (Tohe, interview, 2009).

The notion of "seeing with Navajo eyes" is significant, as much of what we know about the Diné comes from the colonizer's perspective in history books and stories about the Diné. Edward Said notes that "stories are at the heart of what explorers and novelists say about strange regions of the world; they also become the method colonized people use to assert their own identity and the existence of their history" (xii). So, it is with her (re)telling of the stories of the Diné and the experiences of the Navajo Nation that Tohe resists the Americanized representations of the Diné and shows the history "through" Navajo eyes. ${ }^{4}$

I began this introductory chapter of my dissertation with a very brief background and history of America Indian struggles with sovereignty and erasure ${ }^{5}$ I did this in order to situate the need for "hearing" and "seeing" American Indian voices in various mediums: scholarship, literature, poetry, songs, and other venues. It is important for both American Indian readers and scholars, as well as non-Natives, to realize and remember that much of what has been told and represented to the general American public is not representational of the viewpoints, experiences, knowledge and contributions of most indigenous communities. To situate this assertion to my dissertation, I will refer to the words of the great-great-great granddaughter of Navajo Chief 
Manuelito and his wife, Juanita, Diné Jennifer Nez Denetdale. Denetdale argues that many nonNative authors attempt to explain the Diné's history, namely the Navajo Long Walk, "filtered through the rhetoric of American nationalist discourse that explains the experiences of people of color as a process of integration into the American mainstream" ("Reclaiming" 76). Denetdale further asserts that historians and other writers are slow to change their representations and interpretations of the Navajo Long Walk, painting it as a "beneficial" or "benign" event, or even going as far as to "justify conquest and dispossession and deny the horror, violence, and inhumane treatment of the Diné" (77). These misrepresentations and trivializations of the tragic and complex history of the Diné render both past and contemporary Diné peoples invisible and silenced. Tohe, however, combats the invisibility and silencing through her writing, as she gives both visibility and voice to past and present Diné peoples by sharing their stories and their experiences.

In this dissertation, I will demonstrate that Tohe is not only attempting to decolonize the Diné history through her works, but she is doing so in order to regain her rhetorical sovereignty. It is in this process of establishing her rhetorical, ${ }^{6}$ intellectual, ${ }^{7}$ and cultural sovereignty ${ }^{8}$ that Tohe grounds her efforts toward decolonization through strategies of survivance ${ }^{9}$ and alliance ${ }^{10}$. Tohe does not just do this through her story telling in her poetry, but by her focus on the Navajo Long Walk, and most notably her use of code switching and translation, and trickster discourse. By investigating Tohe's writing, I attempt to demonstrate that her writing is an action to regain the sovereignty and visibility that has been torn from the tongues and bodies of American Indian peoples, specifically the Diné, after years of colonization, oppression, and resistance. With this dissertation, I aim to contribute to Denetdale's call for scholars "who have begun the process of 
remapping and reclaiming, as well as (re)writing" the "territory, geographical, and cultural" spaces that have been written by those in power ("Reclaiming" 10).

\section{Overview of Navajo Nation and Diné Culture and History}

The Navajo have been given various names throughout their existence; however, they call themselves "Diné” which means, "the people." They also name themselves "Náhookah Diné (Earth Surface People) and Bilá 'ashdla' (Five-Fingered Ones)" (Denetdale "Reclaiming” 10). "Navajo" is an imposed name that represents the colonization and removal the Diné experienced in the 1800 s, while "Diné" is representational of pre-colonization and one-ness with the homeland of the Navajo Nation, or rather Dinétah or Diné Bikéyah, ${ }^{11}$ which means "Navajo Land or Navajo Country" (Denetdale “Reclaiming” 10). In 1969, the Navajo Tribal Council officially designated this land the "Navajo Nation." The Navajo Nation today covers over 27,000 square miles across Arizona, New Mexico, and Utah. Currently, more than 250,000 Diné reside within and outside the borders of the Navajo reservation. The Diné focus on a matrifocal family and a matrilineal society and are the largest recognized Indigenous group in the United States.

For my dissertation, it is necessary to understand the complex historical experiences of the Diné, so I include in this historical telling of Diné history information that helps to contextualize Diné literature and rhetorics. When the Diné first settled in "Dinétah," the land that they inhabited was barren and had very few roads for travel. However, it was bounded by four sacred mountains: Sisnaajiní in the east, Tsoodził in the south, Dook’o'osłíłd in the west, and Dibé nitsaa in the north. These mountains are significant for the Diné, as they aided in hiding many Diné during the relocation and removal of American Indians by the United States during

the 1800s. The Diné based their decisions or actions on the feel or the emotion of the four sacred mountains. According to Diné political and spiritual leader, Barboncito: “Our grandfathers had 
no idea of living in any country except our own...When the Navajos were first created four mountains and four rivers were pointed to us, inside of which we should live, that was to be our country and was given to us by the first woman of the Navajo tribe" (qtd. in Iverson 7-8). These mountains provided security, warmth, and habit for the Diné. Before the United States upset the balance of the Diné way of life, ${ }^{12}$ the Spanish had introduced many new elements into the life of the indigenous peoples of the Southwest. For the Diné, the impact was double because they were absorbing much of the culture of the Pueblos as well.

The Diné were and are known as pastoral and agricultural peoples. For the Diné economy, the most important by-product of the Spanish colonies in New Mexico was the introduction of horses and sheep, the smooth non-oily wool of the Spanish sheep proved ideal for weaving (Kluckhohn and Leighton 961). The horses were beneficial to the Diné, as they "transformed the Navajos into a military force that ably resisted and counteracted Spain and then Mexican invasions" (Denetdale "Reclaiming" 11). Besides herding, weaving, hunting, and farming, the Diné were also dependent on raiding for much of their economic well-being, as they raided the Spanish and the Pueblos and sent parties into northern Mexico (13). In addition, the Diné had continual land conflicts with the Hopi, as they were closely located near the Diné lands. However, this raiding was spurred by the removal of various tribes by the United States begun in the mid 1800 s, when the federal government diligently worked to remove indigenous peoples from their tribal lands under a removal policy that would make land available for the EuroAmerican settlers.

The most conflict came from the Diné resenting the Spanish colonization attempts. Navajo Chief Manuelito's great-great-great-granddaughter, Diné Jennifer Nez Denetdale, in Reclaiming Diné History: The Legacies of Navajo Chief Manuelito and Juanita, explains that 
"tension, conflict, and peace marked the colonial period as Navajo relationships with Pueblo peoples, the Spaniards, the Mexicans, and then the Americans, shifted along a continuum of kinship and peace to conflict and war" ("Reclaiming" 11). The arrival of the Americans in 1846 then escalated significant conflict between the Diné and other American Indian Nations, the New Mexicans, and the Americans. The Diné saw the Americans in the same lens as the indigenous Mexicans saw the Spaniards, as colonizers that perpetuated the slave trade between the Diné and New Mexicans, as Diné women and children were used to enhance the colonial economy. In addition to the violence between the Diné and the New Mexicans, the Americans too were eager to build a route to California and steal natural resources from the Diné lands, which caused unrest within the Navajo Nation. However, it was when the Americans decided to build a fort in the heart of Dinétah in 1851 that tensions increased. ${ }^{13}$

\section{The Navajo Long Walk}

In 1863, the Americans waged an all-out war against the Diné with the intent to not only relocate, but completely eradicate them. A significant event that affected the Diné was forced displacement, as they were "rounded up" by the United States government and forced to leave their homes. In September 1862, General James Henry Carleton assumed command of the Department of New Mexico. In Santa Fe, Carleton found an old friend to help him "fight Indians," and force them to assimilate. This friend was Kit Carson, who had scouted for Carleton in the earlier Apache campaigns. Carson was commissioned field commander and given orders to "bring the Indians in," as Carleton wrote: "The Navajo Indians have got to be whipped" (Iverson 51). Carleton attacked the Mescaleros and in less than three months conducted some four hundred of them to the reservation Carleton had marked out one-hundred miles away. It was in the Pecos River valley at a place where "a circular grove of cottonwood" trees supplied the 
name "Bosque Redondo." This is where Carleton and Carson forced many tribes to relocate, including the Mescalero Apaches. The men's attention quickly turned to assimilating the Diné. For the Diné, Carleton decided that they would have the same fate as the Mescaleros' at Bosque Redondo.

The Long Walk took place under an act that forcibly relocated thousands of American Indians to distant miles away from their original homelands. The Diné did not want to leave, and Manuelito, the leader of the tribe's resistance, ignored the first proposition. According to American Indian scholar, Peter Iverson, author of Dine: A History of the Navajos, the rest of the Diné balked at the idea of exchanging their homeland of centuries for the "sterile Pecos bottoms three hundred miles east" (199). Angry and frustrated by the Diné's lack of cooperation, Carleton explained a plan to the commander of Fort Wingate on June 23, 1863: “"Tell them they can have until the twentieth day of July of this year to come in-they and all those who belong to what they call the peace party"' (199). Once the day arrived and many of the Diné did not cooperate with Carleton's plans, they were titled hostile and were treated as such. Carleton placed Carson in charge, along with one thousand of his men, and they invaded the Navajo Nation.

About twelve-thousand Diné refused to leave, so Carson waged a war, during which he devastated the Diné's crops and flocks, their means of survival. Carleton saw the imprisonment of the Diné "as absolutely necessary" (199). According to Carleton, at their "“new home the Navajo would soon acquire new habits, new ideas, new modes of life, and the children would learn to read and write, and the rest of the Navajos would learn the art of peace and the truths of Christianity"' (9). After Carson had been placed into the Navajo Nation's lands, many Diné were frightened and began to collect their sheep and horses in order to get out of Navajo Nation. Southern Diné joined the Gila Apaches; some western residents, led by Manuelito, sneaked 
down into the Grand Canyon, while others went to Havasupai or to the ravines of the Little Colorado, and some migrated to Diné sacred mountains. In the fall of 1863, Carson, also known by the Diné as Bi'éé Eichii' i, which means "Red Shirt," with a force of Army regulars and New Mexican volunteers, began a scorched-earth campaign designed to drive the Diné from their land and break their spirit, by burning crops, orchards, and homes, destroying wells, and slaughtering livestock (Denetdale "Reclaiming" 71). Deprived of food and shelter from the winter weather, the Diné faced starvation; although many escaped entirely by fleeing west or north, and others held out for as much as a year. In the eighteen months following Carson's campaign, thousands of Diné surrendered; as they did so, they were marched hundreds of miles to Fort Sumner, in eastern New Mexico, and this tragedy was called the Navajo Long Walk.

The Navajo Long Walk was not a "walk," but rather a "forced march driven by harshness and cruelty" (Iverson 51). In his book, Navajo Long Walk: Tragic Story of a Proud Peoples Forced March from Homeland, Diné Joseph Bruchac, along with Diné editor Shonto Begay, explains that the Diné walked a total of over 470 miles. American Indian scholar Lawrence W. Cheek, author of The Navajo Long Walk, states that the military records indicated that approximately 11,468 Diné were marched (18). The Long Walk has been dubbed as part of the American genocide against American Indians, as Laura Tohe asserts that "the Long Walk, the Trail of Tears, the Dakota incarceration, and other death marches like it are part of America's holocaust” (“Hwéeldi Bééhániih” 82). While Tohe’s above statement summarizes what many Diné, as well as other American Indians, have written, she can also be considered a pioneer in regards to the idea of the Long Walk being affiliated with the American Indian genocide, as her research and writings on the Navajo Long Walk are significant in the genres of poetry, prose, and song, which aids in bringing awareness of the Navajo Long Walk. 
On March 6, 1864, the Diné began the Long Walk to the Bosque Redondo on the banks of the Pecos River in New Mexico. In Spider Woman Walks This Land, American Indian scholar Kelli Carmean explains that:

[T]here were actually a series of long walks, taking different routes, led by different military men, and composed of differing numbers of Navajo. . . The walks averaged about 12 or 13 miles a day, making the nearly 500- mile march last just over a month. Conditions varied greatly ... with some military men being exceptionally cruel, shooting anyone who could not keep up. Some were intent on making the Navajo suffer miserably, making them march many miles out of their way to humiliatingly parade them through the streets of Santa Fe. (18-9)

Bruchac explains that the 470 miles marched led the Diné to Bosque Redondo. The Diné refer to this place as Hwéeldi or the land of suffering. According to Tohe, "the pain and suffering the [Diné] ancestors endured was so nearly unbearable that they named Fort Sumner, where they were starved, raped, exploited and killed, Hwéeldi: the place of extreme hardship where the Diné nearly took their last breath”(“Hwéeldi Bééhániih” 79). They also suffered disease, slave-raids by Comanches and Kiowas, extreme weather, grief and despair. More than a quarter of those who made the Long Walk died en route or at Bosque Redondo, where they were killed by "smallpox and other illnesses, depression, severe weather conditions, and starvation" (Tapahonso 7). In Bighorse the Warrior, Diné Tiana Bighorse retells her father, Gus Bighorse's story. Bighorse lived through the period of the Long Walk, as he avoided being removed. While hiding, he recalled the following: "“[t]he enemy is some soldiers from Washington. They want to get our land. That's why they're killing all these Navajos. [Other survivors] tell me the soldiers chopped 
all the corn and peaches down and burned them. They tell me that my father's relatives got killed trying to stop them—-protecting the corn and peaches"' (13). Further, the elderly, the sick, and pregnant women were shot on the trail. In 1973, a Diné tribal elder named Howard W. Gorman told a story to author Lawrence Cheek about his ancestors' experiences during the Navajo Long Walk. This quote is an excerpt from that story as told to Cheek, a scholar of the Navajo Long Walk:

My ancestors were on the Long Walk with their daughter, who was pregnant and about to give birth. Somewhere beyond Butterfly Mountain on this side of Belen, as it is called, south of Albuquerque, the daughter got tired and weak and couldn't keep up with the others...not long after they had moved on, they heard a gunshot from where they had been a short time ago. (Cheek 26)

Those who were not killed by the elements or starvation were also shot by the American soldiers if they did not "keep up." The alleged intent of this uprooting and imprisonment was to end Diné raiding, protect them from other tribes, and force them to assimilate as farmers on the EuroAmerican model, while making their homeland available for white settlers (Fast 195-6). Bighorse and others who escaped captivity, hid and lived in the Chuska Mountains and in crevices of Canyon De Chelly during the four years of removal. Most of the Diné who were not removed were men or warriors, as they resisted the removal process with success. Many of these Diné men, including Chief Manuelito, were important resistors who helped to establish the peace treaties that were sought during the fourth year of the Diné's incarceration at Bosque Redondo. Those who were captured and moved by the US military made their living at Bosque Redondo for nearly five years in conditions that were devastating and cruel, as Denetdale explains that 
rations were "rancid" and "unfit to eat," and clothing and blankets were not adequate to survive harsh weather ("Reclaiming" 75). Because of this treatment, of the approximately 11,000 Diné who were marched to Hwéeldi, 2,500 died (75).

Finally, late in 1868, peace commissioners General William T. Sherman and Samuel Tappan decided that Carleton's plan was unworkable and negotiated a treaty that was signed by the leading Diné headman on the day of its presentation. The treaty process began on May 28, 1868, and lasted three days with two Indian Peace Commissioners, Lieutenant Sherman and Tappan, and seven Diné Chiefs and two interpreters. The proceedings occurred at Bosque Redondo, at Fort Sumner in the Territory of New Mexico. The seven Chiefs present during the first day of the proceedings included Delgadito, Barboncito, Manuelito, Largo, Herrero, Armijo, and Torivinio. When Sherman asked the Chiefs what it would take to bring peace, Barboncito explained that the Diné needed their homeland to sustain their inner peace and way of life. Barboncito then agreed that as long as the Diné were allowed to return to their homelands, they would abide by the rules set forth by the United States Government (75).

On June 1, 1868, Manuelito and other Diné leaders signed the "last treaty" between the "Navajo Nation and the Americans" (75). A piece of the Treaty of 1868 is as follows:

The United States agrees that the following district of country, to wit: bounded on the north by the 37 th degree of north latitude, south by an east and west passing through the site of old Fort Defiance, in Canon Bonito, east by the parallel of longitude which, if prolonged south, would pass through old Fort Lyon, or the Ojo-de-oso, Bear Spring, and west by a parallel of longitude about $109^{\circ} 30^{\prime}$ west of Greenwich, provided it embraces the outlet of the Canon-de-Chilly, which canon is to be all included in this reservation, 
shall be, and the same is hereby, set apart for the use and occupation of the Navajo tribe of Indians. (qtd. in Iverson 326)

Despite the displacement, and although they were only able to "claim only a portion of the land they once inhabited," the Diné were "joyful" and able to return to their place within the four sacred mountains (Denetdale "Reclaiming” 76). Further, The Treaty of 1868 required that Diné children between the ages of six and sixteen attend schools in English education. The Treaty states:

In order to insure the civilization of the Indians entering into this treaty, the necessity of education is admitted, especially of such of them as may be settled on said agricultural parts of this reservation, and they therefore pledge themselves to compel their children, male and female, between the ages of six and sixteen years, to attend school; and it is hereby made the duty of the agent for said Indians to see that this stipulation is strictly complied with. (Fixico "Treaties" 553)

The treaty required the Diné children to receive obligatory education for the purpose of assimilation.

Despite being back at their homeland, the Long Walk had influenced the Diné's way of life. Hunting and gathering changed because the Diné took on the life of farming, as the treaty influenced a farmer lifestyle and an individualist worldview by granting land to individual Diné; this was different from the community-minded Diné way of life pre-Long Walk. The Diné began to raise sheep, goats, horses, and cattle and used artisan skills in weaving and silversmithing to supplement their new lifestyle. As livestock grew, so did weaving and trading. According to 
Iverson, "As early as 1883 , traders bought more than 1.3 million pounds of Navajo wool, perhaps three hundred thousand sheep pelts, and one hundred thousand goat hides" (79).

During World War II, the Diné suffered again under U.S. Indian policies during the 1930s and 1940s when they were forced to reduce their livestock by fifty percent because of overgrazing. This mandated stock reduction decreased the number of animals grazing on the reservation by more than half, which "drastically altered the relative distribution of livestock." In most cases, the number of animals permitted was too small to support a family. Further, federal officials also attempted to persuade the Diné to accept the Indian Reorganization Act (IRA). The Diné, however, rejected the IRA because they linked it to livestock reduction, much to the dissatisfaction of Indian Commissioner John Collier (Iverson 145). Although the Navajo Nation rejected the IRA, the Diné were "forcibly subjected to government rule based on Western democratic principles" (Denetdale "Chairman" 13). These principles called for the Diné men to fill leadership roles. As anthropologist Christine Conte and Diné attorney Genevieve Chato note, this Western form of government is patriarchal and has undermined Diné women's traditional rights including land-use rights, property and livestock rights, and primary care and control of children; a legacy of governance that remains in place today (13). Then, in the 1950s, the Diné children were sent off of the reservation and into boarding schools. The boarding schools pushed Western values and ideals, such as "proper" gender roles, which encouraged males in power roles and women in inferior roles; the opposite of the Diné way of life. Returning to the reservation, Diné men took leadership roles in the Diné government, while women assumed lower positions, such as secretarial and caregiver. Like Euro-American women, Diné women were expected to demote themselves to the domestic realm, with little political or economic 
power - a significant shift from the previous matriarchal and matrilineal positions they held in the pre-colonial Navajo Nation.

\section{Navajo Nation Today}

The Navajo Nation has survived many conditions of colonialism, including subjugation, relocation and removal, extermination, and forced assimilation. Today, the Diné exist in postand ongoing-colonial conditions, while also retaining their own pre-western traditions and customs. The Navajo Nation still operates under a government created by U.S. federal officials and struggles to claim its sovereignty "in every sense of the word" (Denetdale "The Long Walk" 106). Although the Navajo Nation relies on a number of strategies, such as cultural events and rhetoric about tradition, to draw links between a traditional Diné political system and the modern government, it has always faced Diné suspicion and criticism (106). Regardless of the setbacks and tragedies that the Navajo Nation has endured, they have been able to hold on to a large part of their ancestral culture and traditions. One of the best ways that the Diné have found the ability to "hold onto" their culture and historical ties to pre-colonial Dinétah, is to honor those who were lost during the Navajo Long Walk. On June 4, 2005, a Bosque Redondo memorial was erected at Fort Sumner. Also, the Heard Museum in Phoenix, Arizona houses much respected art and weavings of the Diné. The museum is in addition to the memorial; these are just two ways in which Diné peoples can present or access their history and cultural expressions.

Presently, according to the official Navajo Nation website, the Navajo Nation now is "larger than 10 of the 50 states in America" ("Navajo"). The Navajo Nation is striving to uphold a feasible economy for an ever-increasing population that is over 298,200 Diné, per the 2000 Census, and sits on 17.3 million acres. More than half of the Diné population are spread throughout urban locations, such as Los Angeles, Phoenix, and Albuquerque, although many 
Diné, like Tohe, as well as fellow Diné Tapahonso and Rex Lee Jim, visit "home" to retain their kinship with the land, while the other half lives "on lands formerly inhabited by their ancestors" (Denetdale "Reclaiming" 13).

The Diné have managed to uphold many of their cultural-specific traditions and values, as well as their language; however, despite the size of Diné Bikéyah and the large population of the Navajo Nation, they are still limited in their rhetorical and cultural sovereignty. Diné sovereignty is restricted and denied by the U.S. policies and the U.S. government, as there is a constant threat to the Diné's traditions and language retention. Denetdale explained that the Diné face unvarying challenges to their way of life, but they remain strong in sharing their traditions with the next generation:

The Navajo [Nation] share the concern of other indigenous nations about the loss of language and the erosions of tribal traditions even as we continue to look to our own traditions for answers to issues and problems. We experience some of this country's highest rates of unemployment, violence toward women and children, alcoholism, and poverty. Nevertheless, Navajo exhibit resilience and determination to retain traditional beliefs and values. In many sectors of our society, Navajo parents, teachers, scholars, counselors, Navajo Nation employees, and others are committed to conveying our traditions to the next generation. (14)

Even though Denetdale is discussing the conditions surrounding the Diné in 2007, to assert their resilience, valuable works of Diné thought continue to contribute to the Diné intellectual tradition into the year 2017. This dissertation will investigate how the Diné's, specifically Tohe's, thoughts, ideas, and use of their language are helping to transform how Diné people have 
been represented and contribute to how the Diné can decolonize the past, present, and future through their writing and storytelling.

\section{Storytelling / Oral Traditions of the Navajo Nation}

Shawnee, Sac \& Fox, Muscogee Creek and Seminole Donald Fixico explains that "narrative and oral tradition are essential tools for building a bridge between...two interpretations of history" ("The American Indian" 23). For the Diné, sharing stories is vital to maintaining their traditions and culture, and bringing visibility to their history. They also distinguish that certain stories are only to be shared at a specific time, and/or with specific people. According to Tohe:

One must carefully use thoughts and words, for they have great potential. I came to learn that this might have caused the people to withhold stories of the Long Walk; the pain and suffering the ancestors endured was so nearly unbearable that they named Fort Sumner, where they were starved, raped, exploited and killed, Hwéeldi: the place of extreme hardship where the Diné nearly took their last breath. ("Hwéeldi Bééhániih" 79)

The passing down of stories is how the Diné keep alive the memories of their past and remind them of their bright futures, as the passing of stories is what helps the Diné with their remembrances. Denetdale argues that the Navajo Long Walk is a "watershed in Navajo history" and a spark for stories that the Diné tell within their "clans and families" ("Reclaiming" 12). Diné Luci Tapahonso too makes it a point in her work to keep this tradition alive, most notably in her poem "In 1864," as Iverson notes, "Luci Tapahonso would not forget. She would tell the story to the next generation, who would tell it to the next... a story of survival and continuation" (35). This dissertation will focus on Tohe and how she is in dialogue with other Diné writers in 
order to use writing to (re)claim rhetorical sovereignty. While Iverson mentions Tapahonso above, my focus for this dissertation will be on how specifically Tohe demonstrates survivance and alliance in her writing. She is a significant author, on which to solely focus, as her research and writing surrounding the Navajo Long Walk has been groundbreaking in Diné literature, and she is currently using her position as the Navajo Nation's Poet Laureate to spread awareness and legitimize Diné writings to regain intellectual, cultural, and rhetorical sovereignty.

Although they endured great hardships, the Diné believe that the Long Walk made them better individuals, and Tohe's work epitomizes this endurance and survivance. In addition, they are aware of their unity and that helps them to promote humanity to the rest of the world, as Tohe does through her writings. Cheek sums up the heart of the Diné best: "The irony ...of the Long Walk is that it preserved Navajo identity instead of destroying it. The Navajos returned to their land with a new and deeper bond to it, and the stories tightened...the bond" (57). Further, Tohe in her article "Hwéeldi Bééhániih: Remembering the Long Walk" explains that understanding the colonization, removal, and violence against the Diné is necessary to understand the connections to the limitations of U.S. policies:

The Long Walk, the Trail of Tears, the Dakota incarceration, and other death marches like it are part of America's holocaust, and each deserves a place within the larger story of America. To gloss over or to omit the costs of colonialism is an injustice, not only to those whose ancestors were imprisoned but to the future generations who will want to know the past. To speak of these injustices is a way to heal from these wounds. These stories hold connections to current U.S. foreign policies that have already deeply impacted this country. (82) 
Stories have aided the Diné in the retention of their beliefs, traditions, and culture despite past and present assimilation and colonization attempts. American Indian scholar Elizabeth Archuleta, in “'I Give Your Back': Indigenous Women Writing to Survive,” writes: “Our journeys through writing represent a form of activism because our collective narratives demonstrate that traditions are being renewed, revitalized, or questioned. Writing provides directions to help the lost find their way home" (7). This idea of "home" relates to the convergence of land, identity, and memory that is evident in the Diné oral history, specifically Tohe's work. "Home" also relates to the sense of kinship and belonging between the Diné and the land of the Navajo Nation, especially during the Navajo Long Walk. According to Wyandot Clifford Trafzer, the "surrender of the Navajos and their subsequent 'Long Walk' to Hwéeldi ... is remembered by the Diné as the most significant time in their past. ... It is the period from which Navajo time is measured" (169-70). This tradition of storytelling is continued by elders whose ancestors went to Bosque Redondo, and by others, such as Tohe, who narrate the traumas experienced by those who did not, but who still suffered loss, violence, and dislocation during American Indian relocation and removal, and colonization; their stories explicate the relationship between the people and their land and venerate the suffering, survival and resistance of the Diné. One of the most active Diné survivors and resistors, via her use of writing and the Diné language, is Laura Tohe.

\section{Background of Laura Tohe and Her Works}

Diné Laura Tohe is a part of the Navajo Nation, and a scholar of the Navajo Long Walk and Navajo/Diné history. She earned her Bachelor of Arts degree in Psychology from the University of New Mexico, her Master of Arts degree in English from the University of Nebraska, and her Ph.D. from the University of Nebraska. She is currently an Associate 
Professor of English at Arizona State University and resides in Mesa, AZ. Tohe was born in Fort Defiance, Arizona, and was born to the Tsenabahi Łnii, which means the "Sleepy Water People clan," and born for the Tódích'ínii, which means the "Bitter Water clan." Tohe grew up on the reservation in Crystal, New Mexico, near the Chuska Mountains on the eastern border of the Diné/Navajo homeland and attended both boarding schools and public schools in Albuquerque, which greatly influenced most of her writings, as storytelling was an important part of her upbringing. Her most well-known works are No Parole Today (1999), Sister Nations: Native American Women Writers on Community (2002), her book of poetry Tséyi'/Deep in the Rock: Reflections on Canyon de Chelly (2005), and her newest book Code Talker Stories (2012).

A poet, writer, and librettist, Tohe's work has also been published in various scholarly and literary journals. She has read her poetry in the U.S., Europe, and South America. Her chapbook of poetry, Making Friends with Water, was translated into modern dance and music by The Moving Company in Omaha, Nebraska. Tohe also wrote the commissioned libretto for Enemy Slayer: A Navajo Oratorio for the Phoenix Symphony's 60th Anniversary that made its world premiere in Phoenix in February 2008. It received rave reviews by the Arizona Republic and was called "a triumph" by Opera Today. She has also served as a panelist in open forum and review panels, is a member of the National Caucus Board of the Wordcraft Circle of Native Writers Storytellers and serves on the Advisory Board for the Wicazo Sa Review. Most significantly, Tohe was named Navajo Nation's Poet Laureate in August 2015, and will serve as poet laureate from 2015-2017. The aim of designating a chief poet is to support other Diné writers and artists, and to emphasize their contributions to Diné culture. I discuss Tohe's abovementioned contributions to writing, literature, and history in order to show her active participation in bringing the Diné, both physically and intellectually, to the forefront. 
While Tohe is a well-known Diné author, there are relatively few critical studies of Tohe's works, despite the increasing awareness and critical acclaim for her poetry, especially by linguist Anthony K. Webster who has written various scholarly articles in regards to her code switching. In addition, Tohe's works are taught in colleges and have been anthologized. Despite the minimal attention that her works have received academically, when Diné authors Luci Tapahonso and Rex Lee Jim are mentioned, as well as Native American authors Louise and Heid Erdrich, and Sherman Alexie, Tohe's name is included with these prominent authors in edited collections. This can be seen in the various articles by Webster (2004 and 2006) as well as in her and Heid Erdrich's compilation of Native American works in Sister Nations: Native American Women Writers on Community (2003). It is appalling that Tohe has received such minimal recognition in the literary community (outside of the American Indian communities), and that she is still understudied, as she has been emergent in the national scene and should be visible through her literary contributions; yet, she is still invisible on many levels, which is why this dissertation aims to bring her contributions, in regards to regaining rhetorical sovereignty to light, to visibility.

Tohe attempts to find herself, and make her identity as Diné, as well as her fellow Diné, visible through her writings and ideas. She asserts: "I believe that we as Indian people have to reclaim what was beaten out of us and what was nearly stolen from us: our voices, our stories, our songs, and most important, our language" (qtd. in Bataille 311). Tohe also believes that her works as a whole contribute to her growth as a woman, as a Diné, and as a part of her heritage: "I hesitate to say that I make the invisible visible, because Diné women were always invisible to ourselves and to other Native people. Our invisibility came as a result of colonization. I reclaim power through the stories and poems that I write" (311). These two claims made by Tohe 
demonstrate the necessity for her works to be analyzed and her contributions to Diné sovereignty, and even American Indian sovereignty writ large, to be recognized, which is what this dissertation aims to do.

In each of Tohe's aforementioned works, she establishes her rhetorical sovereignty through the use of code switching and translation, as well as trickster rhetoric, and uses it to not only decolonize Diné thought and the history of the Diné, more specifically the Navajo Long Walk, but also to bring visibility to past and present Diné peoples. Lyons defines "rhetorical sovereignty," as "the presence of an Indian voice, speaking or writing in an ongoing context of colonization and setting at least some of the terms of debate" ("Rhetorical" 462). Rhetorical sovereignty cannot, of course, be disassociated from political sovereignty, and it has been the struggle to achieve political sovereignty that has been the goal of much American Indian writing and speaking; to emphasize rhetorical sovereignty, as Lyons does, is to recognize that much of the battle for American Indian sovereignty has "taken place at what we might call the colonized scene of writing: a site of contact-zone rhetoric in its fullest sense" (453). Lyons goes on to argue that "One way of approaching this site is to find in American legal, political, and cultural discourses recurrent, yet ambivalent, assaults on Native sovereignty answered by recurrent, yet subordinate, defenses and redefinitions of the same by Indians" (453). Tohe, through her writing, is one Diné voice that answers those assaults on Diné sovereignty as she uses code switching and trickster discourse to decolonize Diné representations.

\section{Dissertation Chapters}

In Chapter Two of this dissertation, I will explain my methodology and methods. I use methodologies that foreground traditional indigenous knowledge and that promote selfdetermination and decolonization (Smith 117). Decolonizing methodologies is an alternative 
approach to research that challenges traditional Euro-American practices that have historically silenced indigenous knowledges. Through this methodology, the analysis of Tohe's work on (re) writing and (re) righting Diné history confirms that a tradition of Diné rhetorics has survived colonization attempts to make them absent and invisible. I will also explain the perspective of Navajo Nationalism and demonstrate how Tohe adds to the scholarship on the Navajo national identity, as she operationalizes survivance in complex ways, ways that "actuate a presence" in the face of ongoing attempts to render American Indian peoples absent from American rhetorical, literary, and geographic landscapes.

Next, in Chapter Three, I argue that Tohe not only adds to the decolonizing work of Navajo Nationalism, but she also demonstrates survivance and alliance through her (re)claiming her rhetorical sovereignty in her works, most notably Tséyi'/Deep in the Rock: Reflections on Canyon de Chelly. It is through her use of poetry and stories that she gives voice and visibility to historical and contemporary Diné peoples. Tohe uses her story-telling surrounding the Navajo Long Walk and the language of the Diné to (re)tell, and attempt to decolonize, the Diné history. She also promotes alliance by teaching the Navajo language through her translations for the nonNavajo speaking reader.

In Chapter Four, I further demonstrate Tohe's decolonization of the Diné history and her reclamation of her rhetorical sovereignty through her use of trickster and trickster discourse. There are many contradictions and ambiguities that exist in colonial spaces and by using trickster discourse, and her role as Coyotesse, Tohe is able to move between the "two worlds" of both the North American culture and language and the Diné culture and language, as she attempts to decolonize representations of the Diné and provide her own representation of what it means to be Diné. The concept of trickster and trickster discourse also provides Tohe a means to provide 
lessons on the Navajo language and demonstrate how the Diné survived colonization through her reworking of the English and Navajo languages.

Finally, in Chapter Five, I focus on the significance of examining pedagogy and how to use Tohe's work of Tséyi': Deep in the Rock in the writing classroom in order to promote discussions of autonomy, sovereignty, and the connections between identity and language. In 2012, Lisa King posited that following: "the need for Native texts in the classroom connects in part to a larger ongoing discussion regarding multiculturalism and the recognition of multiple voices in the composition classroom. While multiculturalism in pedagogy has made some progress via bringing those voices habitually marginalized to the attention of students, the rhetorical 'hows' and 'whys' of these voices and the texts through which they speak are not frequently addressed" (King 210). To help bridge this gap in the classroom, I offer a way to continue reevaluating the discussions around using American Indian texts in an introductory American literature course. Specifically, I show how to teach students about rhetorical sovereignty while building alliances between American Indian authors and scholars, and nonAmerican Indian instructors and students. I draw on the work of Scott Lyons and Malea Powell, and on their concepts of "rhetorical sovereignty" and "rhetorical alliance," respectively. I address how these concepts can be used as an approach for using American Indian texts in an introductory American literature course, and explain how we can focus on both sovereignty and alliance in the classroom to help students not only understand the American genocide, but also provide examples of how American Indian authors use language as a means of sovereignty and alliance (i.e. teaching the students the language). First, I will briefly review the exigency for a discussion concerning pedagogy, multiculturalism, the contact zone, and using American Indian texts in an American literature classroom. Next, I will provide examples from my own 
experience that demonstrates the need for discussions surrounding the relocation, removal, assimilation, and present-day stereotyping surrounding American Indian peoples with students before engaging with American Indian texts. Finally, I suggest a method of using rhetorical sovereignty and rhetorical alliance as a means to assist students with not only understanding the reasoning behind the use of particular language(s) by American Indian authors in their respective works, but also understanding how some American Indian authors are demonstrating survivance and promoting alliance. I will also use a short case study, using Laura Tohe's Tséyi'Deep in the Rock: Reflections on Canyon de Chelly as an example. This chapter will guide educators in how using a text such as Tohe's is beneficial to not only the promotion of American Indian texts in the classroom, but the necessity of disrupting, adding to, and maintaining our students' acknowledgement, awareness, and understanding of the significance of rhetorical sovereignty and the power of those voices of American Indian authors in claiming that sovereignty and resisting colonial attempts to silence them. 
CHAPTER II: A DECOLONIZING FRAMEWORK AND THE NEED FOR A NATIONALIST PERSPECTIVE

In Chapter One of my dissertation, I briefly explicated the historical tensions between the US and the Diné to help understand the complexities and sovereignty housed within Tohe's rhetorical choices in her writing. It is imperative for a reader (both Native and non-Native) to understand the context and history in which any author is writing, most notably, an American Indian author who is challenging and (re)claiming her rhetorical, intellectual, and cultural sovereignty through her writing, such as Tohe. To complement, this chapter will function in two ways. First, I will explain my methodology and demonstrate how the tropes of survivance, alliance, trickster, and the practice of code switching function through the methods that I will use (literary and rhetorical analyses), and coincide with the theories of rhetorical, intellectual, and cultural sovereignty that I will employ in later chapters. Second, this chapter will outline the discussions surrounding American Indian nationalism, and explain why the nationalist perspective is important when reading American Indian texts, including texts by Diné authors, and most notably, Tohe whose scholarship adds to the Diné nationalist perspective.

\section{My Research Methods}

As discussed in the introduction, my interest in expanding the study of Diné (Navajo) literature and rhetorics began in 2005-2006 as I worked with Diné scholar Laura Tohe as her research assistant. Ever since, I have immersed myself in studying her works: No Parole Today, Sister Nations: Native American Women Writers on Community, her book of poetry Tséyi'/Deep in the Rock: Reflections on Canyon de Chelly, and her newest book Code Talker Stories. While I have also studied Diné authors Luci Tapahonso and Rex Lee Jim, I have focused my research specifically on Tohe because of her use of code switching in her work. 
For this dissertation, I rely on both primary and secondary research information. For my primary sources, I have interviewed Tohe in regards to her use of code switching in her writing. As for secondary research, I consulted scholarly literary, rhetoric, and historical documents that help me to frame my research and support my assertions. My methods include a rhetorical analysis and literary analysis of Tohe's scholarship. My research centers on three of her four major works: No Parole Today, Sister Nations: Native American Women Writers on Community, and her book of poetry Tséyi'/Deep in the Rock: Reflections on Canyon de Chelly. While Code Talker Stories is equally important, unlike her aforementioned works however, it is not a creative or poetic work; it is non-fiction, as she focuses on the Diné code talkers via interviews, stories, and research into their contributions during World War II. I focused my research solely on her works in which she uses code switching, as these works provide me a window into the use of the Diné language for the purpose of (re)taining and (re)claiming intellectual, cultural, and rhetorical sovereignty. Later in this chapter, I will explain how the tropes of survivance, alliance, trickster, and the practice of code switching function through the methods that I use in this dissertation.

\section{Decolonizing Methodologies}

In my dissertation, I use decolonizing methodologies, an alternative approach to research, that support and privilege indigenous knowledge and that promote self-determination, decolonization, mobilization, healing, and transformation (Smith 117). The title of Linda Tuhiwai Smith’s Decolonizing Methodologies echoes Ngugi Wa Thiong'o's 1986 “Decolonizing the Mind." It expands on the Kenyan writer's thesis that colonialism did more than enforce control over peoples' lands and resources through military conquest and political dictatorship. Imperialism also dominated the emotional and sovereign mindset of the colonized and has continued to do so long after independence was gained. According to Tuhiwai Smith, writing 
from the position of the colonized Maori of New Zealand and a professor of education and Maori development at the University of Waikato, New Zealand, colonialism is far from being eradicated. Her work paves the way for both colonizers and the colonized to understand that decolonization is an ongoing process that requires dissociation from the cultural limitations forced on a peoples' cultural, social, political and linguistic sovereignty. This is relevant to American Indian studies, as she argues that "practices linked to the last century, and the centuries before that, are still employed to deny the validity of indigenous peoples' claim to existence, to land and territories, to the right of self-determination, to the survival of our languages and forms of cultural knowledge, to our natural resources and systems for living within our environments" (1). Tuhiwai Smith questions the principle that Western research was/is collected for the greater good of serving all of mankind: the ways in which data were/are collected, reflect(ed) less the cultural and social realities of the colonized, than fictitious Western constructions of gender, race and class. Decolonizing methodology, then, is a way to combat this continued representation.

According to Tuhiwai Smith, a decolonizing methodology is a "framework of selfdetermination, decolonization, and social justice" (4). The principal objective of Smith's project is to speak to indigenous (and non-indigenous) researchers as they produce scholarship in concurrence with the interests and desires of those communities "who have chosen to identify themselves as indigenous" (5). This framework privileges indigenous perspectives, while attempting to rupture “imperialism's dehumanizing imperatives which were structured into language, the economy, social relations and the cultural life of colonial societies" (26). This dismantling of imperialistic effects on indigenous sovereign knowledge is acted on by indigenous researchers and "other researchers committed to producing research knowledge that documents social injustice, that recovers subjugated knowledges, that helps create spaces for the 
voices of the silenced to be expressed and 'listened to,' and that challenge racism, colonialism and oppression" (198).

While Tuhiwai Smith resists the silencing of indigenous voices and histories, in Borderlands/La Frontera Chicana scholar Gloria Anzaldúa resists the colonial imaginary. Anzaldúa enacts a battle against the colonial binaries that force an "either/or" identity, as opposed to a "both/and" perspective. This resistance that Anzaldúa creates is the new mestiza which celebrates the occupying of multiple spaces. She explains that:

(t)he new mestiza copes by developing a tolerance for contradictions, a tolerance for ambiguity....She learns to juggle cultures. She...operates in a pluralistic mode....The future depends on the breaking down of paradigms...the straddling of two or more cultures. By creating a new mythos - that is, a change in the way we perceive reality, the way we see ourselves, and the ways we behave-la mestiza creates a new consciousness. $(80)$

It is through this new consciousness that Anzaldúa rebukes Western intellectual thought for turning American Indians into objects of study and making it reprehensible to speak their own language and trust their own ways of knowing. This silencing, both literal and metaphorical, is the root of violence, and instead of celebrating the juggling of multiple borders, it instead makes those on the border the abject. She goes on to explain that ethnic identity is wrapped up in language; thus, those on the border attempt to create a language in which "they can create their own identity too, one capable of communicating the realities and values true to themselves-a language with terms that are neither espanol ni ingles, but both. We speak a patois, a forked tongue, a variation of two language" (76). 
It is not just language that must be decolonized, but history of a people as well. To bring my focus toward American Indian histories, more specifically the Diné, Diné historian and author Jennifer Denetdale argues that there must be a transformation of how Diné peoples and their history are represented in writings by both Diné and non-Diné authors. In Reclaiming Diné History: The Legacies of Navajo Chief Manuelito and Juanita, Denetdale critically analyzes Western perspectives of Diné history and promotes a research methodology that reclaims Diné intellectual tradition, (re)values Diné philosophy, and advocates for Diné sovereignty. Through her indigenous approach toward oral tradition to discuss Manuelito and Juanita, she demonstrates how contemporary Diné scholars can discuss, interpret, and analyze Diné history for both the Diné and non-Diné alike.

She is concerned with both recognizing and promoting the acknowledgement of the sovereignty of the Diné peoples and privileges the Diné intellectual tradition. Denetdale explains this goal in the following excerpt:

My ongoing research projects acknowledge the nature of colonialism and its consequences for our society, and at the same time reaffirm the value of our traditions and practices. By critiquing works that refuse to acknowledge the colonial nature in which we continue to live and then advancing studies that privilege a Diné worldview I hope to contribute to the betterment of our communities, for the Diné believe in the power of stories to transform, to move mountains. ... Utilizing oral traditions to write Diné history requires changes in our approaches so that we become cognizant of community involvement and sensitive to Navajo needs. (45) 
It is through her works that Denetdale provides an indigenous space, or rather a paradigm, which scholars, both Native and non-Native, can use to maintain respect for indigenous rights and sovereignty when writing about indigenous histories.

While this methodology, in the subsequent chapters, will benefit American Indian studies, most notably Diné literature and rhetorics, it also has the potential to extend theories of cultural, intellectual, and rhetorical sovereignty to understand how American Indian writers, more specifically the Diné, use code switching, translation and trickster rhetorics to attain sovereignty.

\section{Sovereignty and Self-Determination}

In the disciplines of American Indian literatures and rhetorics, American Indian sovereignty does not simply mean "equality," or having agency or a voice that democracy would sustain. According to indigenous Quechua scholar Sandy Grande, “American Indians have been engaged in a centuries-long struggle to have what is legally theirs recognized (i.e., land, sovereignty, treaty rights). As such, indigenous peoples have not, like other marginalized groups been fighting for inclusion in the democratic imaginary, but rather for the right to remain distinct, sovereign, and tribal peoples" (144). Being a sovereign nation comes with the inherent right to self-rule and self-govern, just like any other sovereign nation. The problem is that the U.S. government does not treat American Indian nations as sovereign, but rather as domestic dependent Nations.

For Native nations, a close relationship with the federal government is an unavoidable byproduct of colonization. Unfortunately, throughout history, the federal government has at every opportunity sought to limit the exercise of sovereign tribal powers. Since Geronimo's surrender and the official termination of the Indian Wars in 1871, the United States government 
has limited tribal sovereignty through "a rhetorical process of definition and redefinition" (Cobb "Understanding" 120). Lyons has termed this idea of definition and redefinition "rhetorical imperialism."

"Rhetorical imperialism" is "the ability of dominant powers to assert control of others by setting the terms of debate. The terms are often definitional, that is, they identify the parties by describing them in certain ways" (Lyons "Rhetorical" 452). Lyons provides examples of this process by explaining: “From 'sovereign' to 'ward,' from 'nation' to 'tribe,' and from 'treaty' to 'agreement,' the erosion of Indian national sovereignty can be credited in part to a rhetorically imperialist use of writing by white powers, and from that point on, much of the discourse on tribal sovereignty has nit-picked albeit powerfully, around terms and definitions" (452-3). While the discourse on tribal sovereignty has certainly "nit-picked" around terms and definitions, these very terms or definitions of tribal sovereignty have real, noticeable consequences in the everyday experiences of Native nations; for, it is through these same terms and definitions that Native nations must live with limitations on their abilities to exercise sovereignty and live as they choose (Cobb "Understanding" 119).

For Native nations, concepts of government and culture are linked. The concept of government or even self-government does not and cannot adequately express or "assuage the needs of a spiritual tradition that remains very strong within most tribes and that needs to express itself in ways familiar to the people" (Deloria and Lytle 14). Likewise, Lumbee David Wilkins argues that tribal sovereignty "can be said to consist more of continued cultural integrity than of political powers and to the degree that a nation loses its sense of cultural identity, to that degree it suffers a loss of sovereignty" (21). Sovereignty then is, in other words, cultural continuance. While a national identity is a part of the United States' understanding of its own sovereignty, the 
United States does not view tribal cultural integrity as a "natural part of an inherent sovereign but instead as a criterion, a quality that Native nations must prove for their sovereign status to be recognized" (Cobb "Understanding" 121). Thus, Cobb argues that "cultural integrity can function not as the act of indigenous self-definition that it is, but instead as a way for the colonizer to define and control the colonized" (121). Complementing this idea of definition and control, White Earth Chippewa and Choctaw scholar Clara Sue Kidwell and Alan Velie, English professor at the University of Oklahoma, explain cultural continuity as: "a requirement for federal recognition for tribes . . if American Indians cannot demonstrate their cultural distinctiveness within American society, Congress can simply terminate its government-togovernment relationships with tribes and deny their sovereignty, as happened during the termination era of the 1950s" (62).

Some could argue that the very definition of sovereignty is not political-focused, but focused only on concepts of power and self-regulation. ${ }^{14}$ This is false. When considering sovereignty, through the lens of American Indian nations, sovereignty is very much political. In Native American Studies, Kidwell and Velie posit that "although sovereignty is an inherent right stemming from aboriginal occupation of the land by self-governing groups of people, the special political status of tribes in contemporary American society depends upon their acknowledgement of the US government. This relationship is political, not cultural" (11). This focus on the political side of sovereignty is a reflection of the influence of nations onto other nations, most notably the United States' effect on tribal nations. This can be seen as Kidwell and Velie further explain that the process for tribal nations wanting to achieve federal recognition is multifaceted and includes seven steps, which are provided in the Federal Acknowledgment Act of 1978 (11). The Act explains the basic criteria as follows: 
Evidence to be relied upon. . . shall include one or more of the following: 1.) Repeated identification by Federal authorities; 2.) Long-standing relationships with State government based on identification of the group as Indian; 3.) Repeated dealings with a country, parish, or other local government in a relationship based on the group's Indian identity; 4.) Identification as an Indian entity by records in courthouses, churches or schools; 5.) Identification as an Indian entity by anthropologists, historians, or other scholars; 6.) Repeated identification as an Indian entity in newspapers or books; 7.) Repeated identification and dealings as an Indian entity with recognized Indian tribes or national Indian organizations. (Prucha "Documents" 290)

In other words, many tribal communities identify themselves as "American Indian," and may be recognized by outsiders as "American Indian," based on cultural traditions and language, yet these communities will not be federally recognized.

As can be seen above, while a nation's sovereignty is inherent, its ability to fully extend that sovereignty is based on the recognition, acknowledgment, and respect other nations accord it (Cobb "Understanding" 117). However, the term "sovereignty" does involve the notion of practical power in addition to the recognition of sovereign nations. In American Indian Sovereignty and the U.S. Supreme Court: The Masking of Justice, Wilkins asserts that the practical powers include, but are not limited to the following:

the power to adopt its own form of government; to define the conditions of citizenship/membership in the nation; to regulate the domestic relations of the nations' citizens/members; to prescribe rules of inheritance with respect to all personal property and all interest in real property; to levy dues, fees, or taxes upon citizen/members and 
noncitizens/nonmembers; to remove or to exclude nonmembers of the tribe; to administer justice; and to prescribe the duties and regulate the conduct of federal employees. (20)

While the term "sovereignty" may encompass political-legal definitions, sovereignty for American Indians also includes the colonized's sense of unity against the colonizer that has taken language, history, and culture away from the voices and bodies of the sovereign nations.

Closely related to the theories of sovereignty is the significance of self-determination. Self-determination, in American Indian literatures and rhetorics, is looked upon as having control of one's own destiny. In his hallmark work, Custer Died For Your Sins: An Indian Manifesto, Deloria explains that "Indian people... have a chance to re-create a type of society for themselves that can defy, demystify, and educate the rest of American society" (268). While this explanation is rooted in the 1960s, it is still very applicable to today's sovereign nation's struggle for intellectual sovereignty and self-determination. Moreover, in Power and Place: Indian Education in America, Muscogee scholar Daniel Wildcat argues that there is both good and bad in culturally conforming to Western society, but urges that the focus should begin with "attentativeness with the relations around us [tribal nations], whether they be typically understood as economic, political, ecological, or spiritual" (138). Wildcat alludes to the resilience of American Indian nations, and the validity of a focus on the "old ways" that preserve tribal traditions and knowledge construction that is separate from the dominant society's institutions (7). This attentiveness to community and tradition provides a ground for a nation's sovereignty and self-determination, which ultimately helps a nation to establish cultural continuance.

The notion of cultural continuance is further explained in "Understanding Tribal Sovereignty: Definitions, Conceptualizations, and Interpretations," as Chickasaw Amanda Cobb 
asserts that sovereignty allows a nation "to determine its own way of life, and to live that life- to whatever extent possible—free from interference" (118). The idea of being "free from interference" creates a space for a nation to thrive, or rather to attain cultural continuance, as the very concept of sovereignty is not only politic-based, but also rooted in culture. It is because of this deep connection between sovereignty and culture that American Indian nations must work to attain cultural and intellectual sovereignty.

\section{Cultural and Intellectual Sovereignty}

Filmmaker Beverly Singer (Santa Clara) explains that cultural sovereignty involves "trusting the older ways and adapting them to our lives in the present. . . [Native] films and videos are helping to reconnect us with very old relationships and traditions. Native American filmmaking transmits beliefs and feelings that help revive storytelling and restore the old foundation" (qtd. in Cobb 127). In other words, Singer asserts that practicing cultural sovereignty entails using American Indian traditions as a plan for the future of American Indian sovereignty by making the old traditions part of present-day life. Singer's explanation is similar to Vine Deloria, Jr.'s work, as Deloria focuses on the alteration of tradition in contemporary American Indian life. As Osage Robert Warrior points out, "The return to tradition ... cannot in Deloria's analysis be an unchanging and unchangeable set of activities, but must be part of the life of a community as it struggles to exercise its sovereignty.... To understand what the 'real meaning' of traditional revitalization is, then, American Indians must realize that the power of those traditions is not in their formal superiority but in their adaptability to new challenges" (50). Unless the traditions, or "old ways," of American Indian nations are modified to present-day life and modern goals, the Nations risk becoming caught between living in the past, and/or living in a "non-Indian" world. 
In Tribal Secrets: Recovering American Indian Intellectual Traditions, Warrior argues that "to believe we can live free from and untainted by the rest of the world is to unwittingly play a parochializing, monolithic Anglo-versus-Indian game, the rules of which have been set up for failure" (115). In other words, it is only by making American Indian cultural values and traditions part of their contemporary and self-determined lives that American Indians can avoid this toxic game of either/or. Being sovereign requires "reflection" and without it, they risk "unconsciously mimicking the larger society, and, to echo Deloria, where is the self-determining in that?" (Cobb "Understanding" 127). The idea of the either/or is further explicated in "Cultural Sovereignty and Native American Hermeneutics in the Interpretation of the Sacred Stories of the Anishinaabe," as San Manuel Band of Mission Indians Endowed Chair of Native American Studies, Lawrence W. Gross argues that "in a scenario in which Native Americans achieved sovereignty over their land and politics, would that accomplishment have any functional meaning if, at the same time, Native Americans were fully assimilated into the culture of the dominant society?" (Gross 127).

The notion of cultural sovereignty is not a past concern of tribal nations; it is still a struggle in present day, in various forms of political, social, and cultural influences. An example of this can be seen in the 2015 State of the Band Address, as Mille Lacs Band of Ojibwe Chief Executive Melanie Benjamin, focused on the theme of cultural sovereignty: "cultural sovereignty is our inherent right to use our values, traditions, and spirituality to protect our future. It goes much deeper than legal sovereignty, because it's a decision to be Anishinaabe, to not just protect a way of life, but to practice living Anishinaabe, every day" ("Mille"). Though Benjamin addresses Anishinaabe practices, this explanation of cultural sovereignty is applicable to every tribal nation that is currently struggling to maintain a sovereign identity. 
One way to establish or (re)claim cultural sovereignty is through language. Writing, or sharing cultural background and history through writing, is one way of ensuring that a sovereign nation's culture does not continue to be appropriated by non-Natives in irresponsible ways. This not only aids in the process of self-definition, but also assists with ensuring cultural continuance (Cobb "The National Museum" 502). The plurality of this term extends through treaty rights, land rights, identity, Native intellectual traditions, cultural revitalization, language, education, and more, including storytelling. ${ }^{15}$

All of these extensions of American Indian intellectual work actively promotes community renewal and adds to the American Indian intellectual tradition. In addition to cultural sovereignty, Warrior urges American Indian nations to engage in another transformative practice, which he calls "intellectual sovereignty." Intellectual sovereignty is based on the notion of sovereignty as process of a beginning, or a (re)claiming. Warrior contends that, "it is now critical for American Indian intellectuals committed to sovereignty to realize that we too must struggle for sovereignty, intellectual sovereignty, and allow the definition and articulation of what that means to emerge as we critically reflect on that struggle" (53). The attainment, or (re)claimation of intellectual sovereignty empowers American Indian scholars by providing a means to chart their own path of sovereignty through writing and intellectual work. As opposed to writing for or writing to the colonizers, intellectual sovereignty allows for a means to "writ[e] forward" (Cobb "Understanding" 128). Warrior argues that part of intellectual sovereignty is American Indians' awareness of the importance of also “choosing carefully whom... [they] invite into the sovereign space that is... [their] intellectual praxis" (123). So, by centering the American Indian critical practice within the framework of intellectual sovereignty, American Indian nations are able to "enter the dialogue with both a pro-Indian awareness of [their] own 
strength and an openness to what the experiences of others have to teach [them]" (124). Echoing Warrior's reaction, Creek-Cherokee Craig S. Womack, in Red on Red: Native American Literary Separatism, focuses on the idea of self-representation: "the ongoing expression of a tribal voice, through imagination, language, and literature, contributes to keeping sovereignty alive in the citizens of a nation and gives sovereignty a meaning that is defined within the tribe rather than by external sources" (14). While cultural and intellectual sovereignty provide a means of expanding the definition of sovereignty to break away from oppressive, Western practices that attempt to silence and rewrite the histories of sovereign American Indian nations, rhetorical sovereignty too is a transformative tool with which American Indian writers can attain a voice that has long been silenced through Western thought and writing practices.

\section{Rhetorical Sovereignty}

In "Rhetorical Sovereignty: What Do American Indians Want from Writing" Leech Lake Ojibwe rhetoric and composition scholar Scott Lyons tells us that what American Indians want from writing is the ability to pursue rhetorical sovereignty, or the "inherent right and ability of peoples to determine their own communicative needs and desires, to decide for themselves the goals, modes, styles, and languages of public discourse" (449-50). Lyons provides us with a demonstration of how rhetorical sovereignty is part of the decolonization work of American Indians, as writing provides a means for regaining the sovereignty that has been stolen from American Indian peoples after years of colonization, subjugation, and resistance.

Lyons defines sovereignty as rhetorical because most of the debate over sovereignty rests in written and oral discourse by Natives and non-Natives alike. However, Lyons suggests that we move away from using texts about American Indians to texts by American Indians to understand rhetorical practices. Treaties, political documents, and written oral stories all provide the means 
of constructing how American Indians use(d) writing to make meaning and express their sovereignty through public discourse.

Cultural, intellectual, and rhetorical sovereignty are different transformative tools from which American Indian nations can thrive within both cultural continuance and attempting to decolonize their histories. While transformative, the different theories of sovereignty also help frame the tropes of rhetorics of survivance and rhetorics of alliance.

\section{Rhetorics of Survivance}

Writing provides a means for redressing the sovereignty that has been stolen from American Indian peoples after years of colonization and subjugation. This is established through the means of exercising rhetorical sovereignty and acts of survivance, or what mixed-blood, White Earth Chippewa cultural theorist Gerald Vizenor and mixed-blood, Indiana Miami-Eastern Shawnee rhetoric scholar Malea Powell explain are acts of both survival and resistance. Rhetorics of survivance resist the imposition of being absent and invisible in the colonial imaginary and texts that attempt to define, quiet, and ignore American Indian peoples. As Vizenor's work makes clear, the Indian is placed into the past, as a vanishing or vanished race, and one that is not represented by his/her own culture, nor nation, but by an image that is created for him/her by hegemonic forces that sponsor colonization, assimilation, and dominance. However, Vizenor explains that American Indian peoples and "their stories actuate a presence, not an absence" ("Fugitive"14).

Powell extends Vizenor's theories on rhetorics of survivance as she investigates the rhetorics of resistance + survival among late nineteenth and early twentieth century American Indian rhetors, Sarah Winnemucca (Northern Paiute), Charles Eastman (Santee Dakota), Susan La Flesche (Omaha), and Andrew Blackbird (Harbor Springs Ojibwe/Odawa). Drawing on 
Lyons's argument to frame "Rhetorics of Survivance: How American Indians Use Writing," Powell demonstrates how Winnemucca and Eastman used rhetoric to both resist and survive colonization and imperialism and how doing so worked to assert a presence instead of an absence, thereby transforming themselves from object-status to subject-status. Powell asserts that American Indian texts must be examined to distinguish the important rhetorical tactics they use and establish how American Indians have used public discourse in order to recast more diverse and empowering American Indian identities and forge new stories and alliances.

\section{Rhetorics of Alliance}

Powell expands on her rhetorics of survivance work by explaining how integral alliances are to both American Indians and non-Natives. In her article "Down By the River, Or How Susan La Flesche Picotte Can Teach Us About Alliance as a Practice of Survivance," Powell evidences how Omaha physician, spokeswoman, and public health activist, La Flesche Picotte, used alliance and adaptation tactics in her writing to bridge gaps between American Indian and Western cultural and rhetorical traditions. One of Powell's goals is to "make visible the fact that some of us read and listen from a different space, and to suggest that, as a discipline, it is time we all learn to hear that difference" ("Rhetorics" 398). If we pay attention to the rhetoric and listen, as responsible citizens, Powell suggests that "we can begin to reimagine ourselves, our pedagogies, our discipline in relation to a long and sordid history of American imperialism. That we will not shirk from the hard work implied by stories - like the new histories and theories being offered" by American Indian rhetorics (428). In order to be able to listen and engage in the ways that rhetoric of alliance offers, there must be intellectual engagement from both the colonizer and the colonized, or the insider and outsider to the intellectual community. To do this, Powell states that we must envisage "a usable past in which Native peoples' writings (and 
African American, and Chicano/Latino and Asian American, et cetera) aren't just included but are, instead, critically important" ("Down" 41). She also explains that:

We need a new language, one that doesn't convince us of our unutterable and ongoing differences, one that doesn't force us to see one another as competitors. We need a language that allows us to imagine respectful and reciprocal relationships that acknowledge the degree to which we need one another (have needed one another) in order to survive and flourish. We need, I would argue, an alliance based on the shared assumption that "surviving genocide and advocating sovereignty and survival" has been a focus for many of the people now on this continent for several centuries and, as such, should also be at the center of our scholarly and pedagogical practices enacted in the United States. (41)

For this dissertation, I will show how Tohe's creative work demonstrates this alliance. Tohe uses her poetry and prose to promote alliance and educate potential allies as she uses code switching and the history of the Navajo Long Walk as means to provide awareness and education for both the Native and non-Native reader.

\section{Defining Code Switching}

In this search for a "language that allows" us to form relationships that demonstrate our need of one another in order to "survive" and flourish, many writers of color, including American Indian authors, have utilized the rhetorical trope of code switching. Martha Cutter, professor of Africana studies, and editor for the Journal of Multi-Ethnic Literature for the United States, posits that writers of color live and write on the border between languages (13). It is through code switching that writers of color can "more thoroughly interrogate the relationship 
between the 'dominant' discourse and its bastardized, hybridized, and revolutionary others" (13). In other words, code switching allows a space for a new language to emerge. Cutter, in her article, "Translation and Alternative Forms of Literacy," argues that ethnic American writers sometimes find something previously lost in the silences of the "ethnic parent or in a language in which they no longer have fluency, even as they assimilate into the dominant culture" (7).

When discussing code switching, it is necessary to realize that there are several definitions. Code switching can be the usage of bilingualism, or rather the switching of languages, as it displays a combination of two languages in a text (Boeschoten 355). For example, in a predominately-English text, an author might include the usage of various Spanish terms or phrases sprinkled throughout the writing. Code switching is also referred to as the usage of words and structures from more than one language or linguistic variety by the same speaker within the same speech situation (Callahan 5). Although this definition is mainly in reference to linguistic speech, this definition can also be applied to written text. Linguists Sandra Schecter and Robert Bayley, in their article "Language Socialization Practices and Cultural Identity: Case Studies of Mexican-Descent Families in California and Texas," argue that code switching has generally been explored as a phenomenon in which speakers switch back and forth between two separate languages and dialects, to include or exclude other participants, to portray a particular nuance, or to establish solidarity. For this dissertation, however, I use the term "code switching" as it is used by professor of Native American literary studies Holly E. Martin (2005), as she states that:

Codeswitching between...English and a Native American language, creates a multiple perspective and enhances the authors' ability to express their subjects. Also... writers lay claim to the languages of their communities and resist the dominance of English by 
proposing that these languages can accompany English in the creation of works of US literature. (403-4)

In "Code-Switching in U.S. Ethnic Literature: Multiple Perspectives Presented Through Multiple Languages," Martin (2005) studies how code switching is used in Chicano literature, claiming that one must understand the conditions for code-switching and its usage in a Chicano setting before one can understand Chicano literature (405). Since the 1970s, almost all Chicano and Chicana authors use code switching in their texts. However, they may do so for differing reasons. Gloria Anzaldúa asserts that she expects those who do not know the language to meet her "halfway" in understanding her language (qtd. in Martin 405). According to Martin, Anzaldúa uses code switching in her writing for rhetorical purposes, as she uses language to "emphasize, illustrate, and bring alive... her heritage" (Martin 406), whether understood by outsiders or not. Martin also explores authors who use code switching between languages other than English and Spanish. According to Martin, "authors who are bilingual in English and another language other than Spanish, such as Chinese or a Native American language, have a more difficult task if they wish to code switch" (410). Readers from the United States cannot be expected to know a Chinese or a Native American language, i.e., Navajo, as much as they can be expected to be familiar with Spanish. Thus, Martin concludes that non-Spanish or non-English authors must use code switching sparingly in their works (410). Martin states that code switching results from a conscious decision to create a desired effect and to promote the validity of the author's heritage language (403). Martin's definition is not one of a linguistic lens, but one of cultural, social, and literary lenses that allows us to see the complex ways that writers of color, specifically American Indian authors, use code switching with the intent of (re)claiming rhetorical sovereignty. 
Though I am using Martin's definition of code switching, which is not a definition rooted in the field of linguistics, it is important to note that there have been numerous linguistic studies, in addition to rhetorical studies, that investigate the dominant discourse's effect on those "bastardized" discourses that are not considered "mainstream."

\section{Studies in Code Switching}

Studies of code switching and its function have focused on Italian-Americans, ChineseAmericans, African Americans, Native Americans, and Latino Americans, etc. In both spoken and written texts, an important function of code switching is that it displays a sense of identity with an author's ethnicity or culture (Buell 97). Despite the broad spectrum of ethnic backgrounds, each of these language groups demonstrate a strong "language choice and code switching [which] figure as the most important, and prominent, linguistic strategies in negotiation of ethnicity" (de Fina 380).

Anna de Fina, in her article "Code-switching and the Construction of Ethnic Identity in a Community of Practice," (2007) discusses the language use of Italian-American males observed during an all-male card-playing club called Circolo della Briscola, analyzed from 2002 to 2003, during an ethnographic study done by de Fina, as she examines code switching as a signal of group solidarities. She interviewed club members, and made video and audio recordings of games and other types of interaction between the men (375). De Fina found that the meanings and functions of code switching, in relation to ethnicity, are complex, as there is a "stable relationship between the uses of the language variety spoken by the ethnic group and the expression of in-group ethnic solidarity" (380).

Agreeing with de Fina is Adrienne Lo. Lo's study consisted of analyzing data from a study consisting of three men's conversations, which were videotaped in Los Angeles, California 
in 1995. One man was Chinese American, another was Korean American, and the third African American. Lo found that the function of code switching was used to demonstrate co-membership in a language community (Lo 462). Most of the time when code switching was used, the act and form of code switching demonstrated a social identity within a group and ultimately within a language community. Lo also found that the code switches used by the men had connections to each man's identity in their respective ethnicities, and that many times the code switching left a section of their audience unsure of the meanings of various words. Some of the code switching made the conversation incomprehensible, as the men would use "deliberately opaque outgroup talk" (473). Lo concludes that code switching projects category memberships for each of the participants and "the outgroup talk contextualizes these stances as characteristic of a given ethnic category" (475).

There are also studies that focus on the use of code switching in the fields of composition and rhetoric. Geneva Smitherman's Talkin and Testifyin: The Language of Black America (1977) is one such study. In her book, Smitherman makes a significant impact in understanding Black English by setting it in the larger context of Black culture and societal life style. In addition to defining Black English, by its unique structure and distinct lexicon, Smitherman argues that the Black dialect is set apart from traditional English by a rhetorical style which reflects its African origins. Denise Troutman adds to the discussion of Black English in the edited collection Sociocultural and Historical Contexts of African American English (2001). Troutman's “African American Women: Talking That Talk" highlights the social constructions of African American women's speech patterns as they are not the same as white women's speech or black men's speech; each group has their own sociocultural influences on their language usage. Vershawn Ashanti Young $(2009 ; 2013)$ and Arnetha Ball also investigate the social constructs of code 
switching when those of color speak or write. Young argues that code switching can be viewed as a "racial compromise" in terms of language and representation in the mainstream discourse and/or with non-Blacks. Ball, on the other hand, claims that code switching can be seen as a form of "resistance," as code switching, similar to the trickster tradition, "embodies a gesture of ideological independence" (qtd. in Gilyard 169).

As can be seen above, there have been studies surrounding the use of code switching in linguistics, composition, and rhetoric in regards to various ethnic groups. However, there has been a limited focus on the use of code switching in American Indian writing, especially when it comes to viewing code switching through the lens of rhetorical sovereignty. Some American Indian authors do employ code switching in their works, such as Turtle Mountain Chippewa Louise Erdrich. Although she translates her Anishinaabe language use in some of her novels, she does not in Love Medicine, but she does provide enough context for non-Anishinaabe speakers/readers to understand. Diné Luci Tapahonso also code switches throughout her three books of poetry, A Breeze Swept Through (1987), Sáanii Dahataat: The Women are Singing (1993), and Blue Horses Rush In (1997); however, unlike Erdrich in Love Medicine, she does translate some terms for the non-Diné speaking reader.

On the other hand, some scholars do not wish to use translations or code switch at all; some choose to write specifically in the Diné language. Diné author Rex Lee Jim is one such author. Jim's all- Diné collection Saad (1995) does not use the English language at all, from the Table of Contents to the page numbers. However, in Jim's book of poetry Duchas Taa Koo Dine: A Trilingual Poetry Collection in Navajo, Irish and English, he does incorporate the English and Irish languages, but not with the Diné language. Each poem is written in Diné, English, and Irish, separately. Other Diné authors, in addition to Tapahonso and Tohe, who also 
utilize code switching in their works include: Esther Belin in From the Belly of My Beauty (1999), Norla Chee in Cedar Smoke on Abalone Mountain (2001), Rutherford Ashley in Heart Vision 2000 (2001), and Hershman John in I Swallow Turquoise for Courage (2007). Though some of these authors', notably Tohe's, writing has been significantly analyzed using a linguistic framework by scholars, such as Anthony Webster, ${ }^{16}$ I do not know of any scholarship that analyzes Tohe's work with the lens of indigenous rhetorical theory (investigating the use of rhetoric in an indigenous text), and it most certainly needs to be, as her writing encapsulates the push for decolonization in Diné literary, societal, and cultural history.

\section{Trickster}

I will be analyzing code switching's connection to trickster rhetoric. In Other Destinies: Understanding the American Indian Novel (1994), Choctaw-Cherokee and Irish scholar Louis Owens, explains that code switching is a trickster move (109). Further, in Mixedblood Messages: Literature, Film, Family, Place (2001), Owens states that "the role of trickster is to dismember all constructions that impose definitions and limit possibilities" (86). However, the literary concept of trickster has a variety of interpretations. These interpretations vary depending on the intent, audience, and the culture that trickster is contradicting and from which it comes (Vizenor "Manifest Manners" 170). Cherokee Jace Weaver posits that it is necessary for trickster to "cross the line" in order to subvert expectations and disrupt social norms ("Other Words" 257). Trickster's disruption of society's norms is not to cause undue emotion or strife, but to encourage acknowledgement of a society's oppressive nature.

In rhetoric and literature, trickster can be used as a means of establishing voice and being heard in, and disrupting, the mainstream discourse. One way that Native writers can enter public discourse is the practice of trickster hermeneutics. Trickster Hermeneutics is the "interpretation 
of simulations in the literature of survivance, the ironies of descent and racialism, transmutation, third gender, and themes of transformation in oral tribal stories and written narratives" (Vizenor "Manifest Manners" 15). Vizenor names the practice of trickster hermeneutics rhetorical, as he suggests that Native writers must understand the rhetorical landscape they are entering and invent texts that upset what is there. In this respect, trickster hermeneutics is more than an exercise in reading and interpretation. Rather, it is inventional and it relies on a set of topos from which the trickster can "liberate the human mind" (15). Because of this idea of disruption, trickster has a "political significance" (Vizenor "The Heirs" 166). In his essay "Trickster Discourse," Vizenor argues that the "tribal trickster is a liberator and healer in narrative, a comic sign, communal signification and a discourse with imagination" (187). However, trickster can also be used as a way of voicing skepticism about "nationalist narratives of tribal sovereignty" and any narrative that is complicit with the history of colonialism.

While Vizenor is often cited in regards to trickster, Indigenous Canadian authors, such as Canadian-Cree Tomson Highway, Cherokee-Greek Thomas King, and Scots-Irish American and Mohawk Beth Brant must be acknowledged for their contribution to indigenous studies, more specifically, the use of trickster, or rather mythical figures that could be deemed as trickster, in their works. In Canada, Highway is one of the most well-known spokespersons for the trickster world-view theory. He claims that "Christ is to Western culture as the trickster is to Native culture" (qtd. in Hannon). Highway's plays The Rez Sisters (1986) and Dry Lips Oughta Move to Kapuskasing (1989) encouraged the idea of trickster's centrality in the Native worldview; however, his focus on trickster also focuses on the idea of "two-ness," as he acknowledges the two-spirited person within not only indigenous culture, but also urban culture. Similarly to Highway, Brant approaches the idea of two-spirit through trickster, in her book Mohawk Trail 
(1992). In her poem "Coyote Learns a New Trick," she also investigates the idea of trickster being tricked by reversing the role of Coyote by beginning the story with a female coyote. King too uses the Coyote figure in his works as a method of viewing two-ness in terms of audiences and directions of trickster, as he uses trickster as a celebration of difference, as well as a tool to question colonial history and Western discourse, as can be seen in his works "The One About Coyote Going West" (1996) and A Coyote Columbus Story (1992). Through trickster, King not only ridicules Western ethnocentrism, but also the colonial history in North American that has shaped dominant perceptions of American Indian nations.

Trickster represents a plurality. This plurality can be seen in the work of Jay Cox. Cox and Barbara Babcock explain that "[trickster] knows no bounds, lives in a world before/beyond classification, and is always in motion, [as trickster is] timeless, universal, and indestructible...Mythical and primordial, [a] champion of possibility and enemy of spatial, temporal, and cultural boundaries" (99).

Kristina Fagan (NunatuKavut, the Labrador Metis Nation) offers another lens from which to view trickster in indigenous rhetorics and literary studies. In the introduction of Troubling Tricksters: Revisiting Critical Conversations, Fagan explains the ebb and flow of trickster theory. She argues that the study of trickster has been appropriated in various forms, by various writers, who would adopt the idea that trickster was "hiding" in every indigenous authors' work, and as such trickster would become synonymous with "Indianness" in the 1990s (5). This comparative approach was dangerous, as a writer could explain an indigenous author's work without extensive research into the complex history of that particular indigenous nation; she also explains that some writers would make the author himself or herself trickster, and then ignore the agency of the indigenous author and only focus on that critic's ideals. 
However, according to Fagan, much has changed since the peak of trickster criticism in the 1990s, as more indigenous scholars joined the academy and created a new lens from which to view American Indian literature; these scholars then adopted an approach to literature that focuses on the grounding of indigenous peoples in cultural, political, and historical landscapes. These scholars use the lens of American Indian, or indigenous, literary nationalism to focus on the specificity of the cultural and historical in indigenous literature, as opposed to the "essentializing" and "generalizing" of previous lenses of trickster. One such scholar is Craig Womack. Womack argues that while many indigenous nations, as well as European, American, African American, and Asian cultures have characters, in their works, that resemble trickster, trickster did not originate in American Indian stories. He argues that trickster is a "trope rather than a reality" in American Indian cultures (“American Indian Literary Nationalism" 70).

In this dissertation, I will demonstrate how Tohe works to decolonize Diné history and reclaim her rhetorical sovereignty through her use of trickster and trickster discourse. Contradictions and ambiguities exist in colonial spaces and by using trickster discourse, Tohe is able to move between the "two worlds" of both the North American culture and language and the Diné culture and language, as she provides her own representation of what it means to be Diné.

\section{Nationalism}

Trickster criticism is influenced by the recent work of nationalist critics who have called for ethical literary studies that are responsible to Indigenous people and communities.

Discussions on the significance and meaning of American Indian nationalism is not new to American Indian Nations, or to the Navajo Nation, specifically. The trend toward Nationalistic literary work in American Indian studies is influenced by the ongoing colonization of American 
Indian peoples, appropriation of American Indians identities, and inaccurate generalizations about diverse American Indian literatures—among other things

The constructions of nationhood and nationalism are a part of the twentieth and twentyfirst century American Indian experience, or rather, struggles. According to Diné author Lloyd Lee: "Nationalism in the western context is defined as the policy of asserting the interests of one's own nation, viewed as separate from the interests of other nations or the common interests of all nations. It is a desire for national advancement or independence. In the Navajo context, it is a realization of a western political identity. Navajo nationalism is about common ideology, customs, institutions, and the controlling of a territory" ("Reclaiming Indigenous" 40). It is because of these deeply rooted historical tensions and struggle for sovereignty, as well as competing nationalisms, that it is necessary to view American Indian literature through the lens of literary nationalism.

\section{Literary Nationalism}

A nationalist approach to American Indian literary works is a vital tool through which to protect the Native culture, or "way of life" against what Weaver refers to as "pericolonialism," the "thorough, pervading nature of settler colonialism ... that, for indigenes, must be gotten under, around, or through" (39). The nationalist focus demands that American Indian intellectual and critical traditions be used as the primary lenses through which to read American Indianauthored literature. This nationalist lens is necessary as a way to overturn centuries of cultural appropriation and erasure by Euroamericans and to (re) claim American Indian sovereignty and preserve American Indian communities and nations. Embodied in the works of Crow Creek Sioux Elizabeth Cook-Lynn, Osage Robert Warrior, Cherokee Jace Weaver, Creek-Cherokee Craig Womack and Cherokee Daniel Heath Justice, the body of scholarship under the rubric 
American Indian Literary Nationalism (AILN) ${ }^{17}$ has impacted how I think about American Indian writers and texts. Over the past thirty years, scholars have attended to the relationship between American Indian literature and cultural sovereignty, and in the past fifteen years, following the publication of Womack's Red on Red: Native American Literary Separatism, this dialog has expanded. In Red on Red: Native American Literary Separatism (1999), Womack, emphasizes the ways in which texts and authors make political involvements in drives for cultural sovereignty as he states his ideals for "a literary criticism that emphasizes Native resistance movements against colonialism, confronts racism, discusses sovereignty and Native nationalism, seeks connections between literature and liberation struggles, and, finally, roots literature in land and culture" (10). Womack argues that "this criticism emphasizes unique Native worldviews and political realities ... and attempts to find Native literature's place in Indian country, rather than Native literature's place in the canon" (11). In its emphasis upon worldviews and rooting literature in "land and culture," Womack calls for a nationalist criticism, and his critical framework introduces the possibility of literary separatism, which he uses as power against a U.S. literary canon that has upheld colonial hegemony over American Indian texts and their authors, not only excluding them, but also appropriating them when their messages can be opportunely used for a particular purpose in the "dominant" culture. It is these inclinations to homogenize and appropriate American Indian nation experiences, privilege certain forms of writing, and observe certain political alignments over others (dominant society government vs nation or tribal government), and foreground culture and identity at the expense of politics, power and nationhood that American Indian literary nationalism intercedes. To these ends, Weaver, Womack, and Warrior assert, in their co-authored preface to American Indian Literary Nationalism (2006) their admiration for the work of Simon Ortiz 
Acoma Pueblo scholar and poet Simon Ortiz, in his 1981 essay, "Towards a National Indian Literature: Cultural Authenticity in Nationalism," asserts that rather than be overcome and immersed by the impositions of Euro-American culture, Native peoples shaped "creative response[s] and development[s]" which he identifies as "the primary element of a nationalistic impulse to make use of foreign ritual, ideas, and material in their own — Indian — terms. Today's writing by Indian writers is a continuation of that development" (254). ${ }^{18}$ He writes:

It is because of the acknowledgment by Indian writers of a responsibility to advocate for their people's self-government, sovereignty, and control of land and natural resources and to look also at racism, political and economic oppression, sexism, supremacism, and the needless and wasteful exploitation of land and people, especially in the U.S., that Indian literature is developing a character of nationalism which indeed it should have. (11-2)

Ortiz also notes that as many writers address the political dimensions of their work, they also acknowledge "a responsibility to advocate for their people's self-government, sovereignty, and control of land and natural resources; and to look also at racism, political and economic oppression, sexism, supremacism, and the needless and wasteful exploitation of land and people, especially in the US. [ . . Consequently,] Indian literature is developing a character of nationalism which indeed it should have" (259). Ortiz and other authors advocating for Indigenous nationalism stress the importance of the oral tradition as cultural expression, passed on through generations and replicating the values of a culture. They also emphasize the prominence of being attentive concerning abuses of power, both imposed from outside of one's culture and even from within one's nation or tribe. 
In American Indian Literary Nationalism, Weaver, Womack, and Warrior continue the strong assertion of a nationalist approach to American Indian literature for which Ortiz provided the foundation. Weaver, Womack, and Warrior explain that "nationalism" is a term that includes the notion of sovereignty, or rather, a nation's "power" to self-govern, "to determine its own way of life, and to live that life — to whatever extent possible - free from interference" (Cobb "Understanding" 118). However, nationalism is also "culture, self-determination, experience, and history that is central to understanding the relationship between the creative expression of Native American literature and the social and historical realities that such expression embodies" (Weaver, Womack, and Warrior xv).

\section{Diné National Identity}

Upon reflecting on recent introspections on Indigenous nationalism, these emphases help to illuminate a Diné literary nationalism, as American Indian nationalism might best shape readings of Diné texts for the ways they allow readers (including Diné, other indigenous persons, and non-Natives) to recognize and affirm Diné rhetorical, cultural, and intellectual sovereignty. While my dissertation focuses solely on the works of Laura Tohe, who was just named poet laureate for the Navajo Nation in 2015, the works of many influential Diné writers are now being published and receiving deserved critical attention. Some of these Diné authors include Luci Tapahonso, Gloria Emerson, Irvin Morris, Rex Lee Jim, Hershman John, Sherwin Bitsui, Orlando White, Esther Belin, and Archie Carr. It is important to note that these texts can be read both for their literary endeavors as well as how they offer insight into social and historical conditions - in ways that are meaningful to Diné readers, and, in ways that might push nonNavajo readers to read Diné-authored texts not just through the lens of Euroamerican critical tools and against artistic expectations shaped by the Western canon, but for the significant and 
challenging insight these works offer into a contemporary Indigenous culture. As mentioned above, Ortiz and scholars including Womack, Weaver, Warrior, Heath Justice, Cook-Lynn, and Lisa Brooks have contributed significantly to the shaping of nation-based theories of reading literature for its contributions to the cultural sovereignty, respectively, of Muscogee Creek, Osage, Cherokee, Acoma, Lakota, and Abenaki peoples. Diné identity and cultural sovereignty is also foregrounded in the work of Diné scholar, Lloyd Lee.

I now turn to current discussions of Navajo nationalism and cultural identity as they might provide a foundation for reading Diné texts. While much has been written about Diné aesthetics, linguistics, and epistemology, largely by ethnographers and linguists, less critical attention has been given to Navajo nationalism, especially how Diné literature and rhetorics factor into efforts to (re)establish rhetorical, intellectual, and cultural sovereignty. Recent texts by Diné scholars Lee, Miranda Haskie, and Denetdale identify aspects of a Diné worldview that offer a framework for interpreting how Diné-authored works communicate culturally significant concepts. In a series of essays published over the past four years, Lee effectively grounds the discourse of Indigenous nationalism in the particulars of the Navajo Nation. In "Navajo Cultural Identity: What Can the Navajo Nation Bring to the American Indian Identity Table?," Lee refers to several features of the Diné worldview, which are central to Diné identity. Historically, those features included grounded knowledge of "worldview, land, language, and kinship" (92). Lee also determined an additional breadth of contemporary Diné identity: namely, "pride in being Navajo and respect for their ancestors' ability to survive colonialism" (92), which he further elaborates as "the utmost respect for their ancestor's ability to survive the prison camp at Bosque Redondo" (96). This respect to the ancestors calls for the Diné, according to Lee, to do the following: establish a definition of "Navajo Nationhood, educate the Diné youth, and change the 
current government structure; all of which will help with determining self-sufficiency in the Navajo Nation (Lee "Reclaiming Indigenous" 103).

While Lee does not call for extensive rebuilding of pre-colonial governing institutions, in his article, "Reclaiming Indigenous Intellectual, Political, and Geographic Space: A Path for Navajo Nationhood," he does describe the systems of governance that were diminished by invasions of Spanish, Mexican, and American colonial powers, which builds a platform for his vision of an alternative Diné political system: "Navajo society can incorporate some historical aspects of governance along with using the creative mind to imagine a government that encourages harmonious cooperation, coexistence founded on respect for autonomy and the principle of self-determination" (107). Lee argues that the current Diné government system is rooted in American values and ideals, which benefits the "colonizer" (105). Diné writer Reid Gomez has also expressed the need for Native people to think about sovereignty in terms of the people's ability to think, speak, and act on their homelands: "When we practice an intellectual spiritual sovereignty, we step outside those narratives [the ideologies of the conquerors] and work from within our own worldviews and from our own origins and migrations." As these examples suggests, Diné peoples are beginning to reconceptualize the meaning of Diné selfdetermination and how they can ensure its manifestation, as Lee argues that the Diné people need to show the U.S. government that the Navajo Nation can exist within the political boundaries of the United States, while practicing self-determination (107).

Part of this self-determination entails sustaining the language of the Diné. In his article "The Future of Navajo Nationalism," Lee declares that over the next several generations the Diné can significantly change how they imagine the Navajo Nation as well as "what it means to have self-determination" as he outlines a path that calls upon changes in thinking as well as 
changes in institutions of education, economic development, governance, and, most importantly, language. Lee explains that "language has become pivotal to the people because everything about Navajo society, such as the prayers, songs, ceremonies, and rituals, is based on how the people interact, analyze, and synthesize the way of life through language" (93). Studies by Deborah House, in Language Shift among the Navajos: Identity Politics and Cultural Continuity, as well as Diné Evangeline Parsons-Yazzie in her essay "Perceptions of Selected Navajo Elders Regarding Navajo Language Attrition," among others, have documented how the Navajo language is currently in decline.

Lee explains that according to the 2000 U.S. Census, there are more than 120,000 Navajo-language speakers on the reservation, and only 32,000 are below the age of seventeen ("The Future of Navajo" 65). While the existence of the Diné language is questionable, many Diné argue that language is what makes one part of the Navajo Nation. Steve Johnson, who was interviewed in Lee's article, defines Navajo cultural identity as the ability to speak the Diné language. Johnson is a thirty-seven-year- old graduate of the University of New Mexico who was born on the reservation and spent half of his life there. For Johnson, speaking the language is what "makes a Navajo person distinctly Navajo." Parsons-Yazzie also interviewed Diné elders concerned about the loss of the Diné language. Elders view the Diné language as a language of "compassion, unification, and love, and feel that the younger Navajo generations are turning their backs on their language and culture" (87). One elder states that belief with the following translation: "In order to know Navajo values, one has to know the Navajo language." For many elders in Parsons-Yazzie's study, Navajo cultural identity is contingent on the ability to speak the language, as they believe that a Diné person "should and must know how to speak the Diné language and that language helps a person have a strong connection to their identity" (87). Lee 
argues that "many, if not all, Navajo people would agree" with Johnson's perspective that the "language, culture, lifestyle, and thinking processes are core characteristics for Navajo cultural identity" ("Navajo Cultural Identity" 94).

It is important to note the significance of language within the cultural identity of the Diné peoples, as it is the language on which I focus, in the following chapters, within my analysis of Tohe's works, namely through the focus on the use of code switching and trickster discourse in Tohe's writing. Lee, among other Diné scholars, claim that the connections between language and the Diné cultural identity are synonymous. ${ }^{19}$ Further, Lee argues that "the people need to show the U.S. government that the Navajo Nation can physically exist within the political boundaries of the United States and, at the same time, practice true self-determination" (Lee "Reclaiming Indigenous" 107). Through her writing, Tohe creates a physical space for not only the Navajo Nation, but also establishes a space in which both worlds can exist through her use of code switching, translation, and trickster discourse.

Lee asserts that "for centuries Indigenous peoples in this hemisphere have raised powerful voices of resistance to the unjust treatment and outright genocide they have received at the hands of colonizers. This resistance has been, and continues to be, manifested through a variety of rhetorical venues: speeches, stories, poems, songs" (Lee "The Future" 89). In Chapter Three, I will consider how Tohe resists this colonization and uses her writing, storytelling of the Navajo Long Walk, and code switching between English and Diné to (re)claim her cultural, intellectual, and rhetorical sovereignty. 
CHAPTER III: (RE)CLAIMING DINÉ HISTORY AND GIVING VOICE TO SILENCED

PAST AND PRESENT DINÉ: TACTICS OF SURVIVANCE AND ALLIANCE THROUGH

CODE SWITCHING AND TRANSLATION IN LAURA TOHE'S TSÉYI'/ DEEP IN THE

ROCK: REFLECTIONS ON CANYON DE CHELLY

"We, as Native intellectuals, have both a right and an obligation

to challenge the colonial dominance of our history, whether it be sociocultural,

political, artistic, linguistic, or legal" - Jack Forbes, "Intellectual Self-Determination and

Sovereignty" (19).

"Writing is a way for me to claim my voice, my heritage, my stories, my culture, my people, and my history" - Laura Tohe, No Parole Today (xii).

Canyon de Chelly or Tséyi' is a place of sacred reflection for the Diné. 'The rock," as it also called, is in the heart of "Dinetah," or rather the Navajo Nation. It is also the place where many Diné hid from the United States during the "round-up" of the Diné that was led by Kit Carson from 1863-1868. As discussed in the introduction to my dissertation, this attempt at enforced assimilation is called the Navajo Long Walk. The United States (U.S.) government marched thousands of Diné from Arizona to New Mexico, over 300 miles, to relocate the Diné to Bosque Redondo. This was done so that the U.S. could take over the Diné's land and livestock, and force relocation, removal, and assimilation. "The rock," or rather the canyon, contains the stories, voices, memories, hardships, and successes of both past and present Diné peoples. While tourists flock to this destination for its beauty, the Diné and the canyon have a kinship, one that is not visible to anyone that is not Diné. Tohe brings awareness to this relationship and legitimizes the history buried within the canyon walls through her stories and her use of code switching. 
After years of being "invisible" in the eyes of the U.S. society and the U.S. government, as discussed in previous chapters, it is through her poetry and stories that Tohe gives voice and visibility to both historical and contemporary Diné people. This visibility is enacted through her use of the Diné language, as it is code switching that provides Tohe with a tool to re-tell history through rhetorics of survivance, as she teaches the reader (both Native and non-Native) about the Diné's surviving history, land, culture, beliefs and values. It is also through rhetoric of alliance that Tohe invites the reader to learn the Navajo language in order to promote awareness of the Diné's continued existence and language, as history, story, and rhetoric work together to bridge zones of "cultural" experience.

As discussed in the last chapter, I use the term "code switching" as it is used by professor of Native American literary studies Holly E. Martin (2005):

Codeswitching between...English and a Native American language, creates a multiple perspective and enhances the authors' ability to express their subjects. Also...writers lay claim to the languages of their communities and resist the dominance of English by proposing that these languages can accompany English in the creation of works of US literature. (403-4)

In this chapter, I focus on how Tohe is using her code switching between the English language and the Navajo language to demonstrate rhetorics of survivance and teach the reader the Navajo language. With code switching, I also use the term "translation." I use "translation" to mean the instances when Tohe provide the English "version" of a Navajo term, for the non-Diné speaking reader. Tohe also experiments with more than one translation strategy in this particular collection, as she also uses translation as a pedagogical activity that promotes alliance because, at 
times, she withholds certain information to make the reader act as researcher. In most of Tohe's poetry and short stories, when she writes in Navajo, she provides an English translation for the Navajo word or phrase; however, there are instances when she does not provide a translation. It is important to note that I am not translating any Navajo terms from Tohe's works; Tohe does this for the reader through her poetry and storytelling. In this chapter, I am going to specifically focus on Tohe's book of poetry Tséyi'/Deep in the Rock: Reflections on Canyon de Chelly (2005). This poetic compilation represents Tohe's reflections while visiting Canyon de Chelly.

\section{Tséyi'/ Deep in the Rock}

In the beginning of her book, Tohe states that she visited the canyon when she was in college, but she did not appreciate its beauty back then as she does now, as an adult with a family of her own:

I never visited the canyon as a child, even though I grew up on the other side of the mountain from it. In college my roommate and I drove to the Junction Overlook and marveled at the view. I have a photo of her with the wind blowing in her face, sitting on the sandstone rocks. In another photo my grandmother is wearing a red blouse and standing near the rim of White House Overlook. That day is clear in my mind because we drove home over the dusty, washboardy rez roads through Sawmill. It was autumn and the piñon trees were dropping their nuts. As we drove through the forest, my grandparents told the stories they knew of Tseyi. (xiii)

Although she had not visited the canyon many times, the connection to it was still strong through her cultural connection to "the rock," through her ancestral past. Tohe goes on to talk about the pull of her ancestors: "It was during my visits to my parents' home in Mexican Springs that I 
first heard the canyon calling. 'Hágo, hágo.' Come here, come here, came a powerful voice, one that I could not ignore" (xiii). This calling is what inspired Tohe to write about the canyon and the life around it: "[T]hese poems evolved from the canyon's voice - the stories in and around the rock walls, the sounds of the animals and trees - and in the movements of light, wind, and water" (xiii). This book of poems encapsulates her thoughts, feelings, connections, and experiences with and of Canyon de Chelly and she shares these connections through her storytelling and the agency that she gives nature, as she gives voice and movement to these elements.

In the introduction of her book of poetry, Tséyi', Tohe explains to the reader that Tséyi' housed the Diné, and both the Diné and the land accepted each other; the land and the Diné have a mutual recognition, a deep connection through history and ancestral memory. "By the 1860s," Tohe writes, "the Diné had firmly placed their roots in the bottomlands, planted their cornfields and peach orchards, and raised their flocks of sheep. The canyon had accepted The People. In turn, the Diné had found agreement with the canyon, where they could build their homes, raise their families and live a harmonious life based on hózhó" (xiii). To many of the Diné who embrace traditional values, storytelling is a core practice by which to teach children the important principles necessary to live well. For these people, living well is grounded in the concept of "sa'a naghai bik'e hozho." This is a key Navajo philosophy, "one that is very difficult to accurately translate into English... Stories are the means by which many Diné have constructed the meaning of life, of human beings, and of the universe: they are the means by which this knowledge is passed on" (Farella 1984). This kinship between the Diné and Canyon de Chelly was threatened in 1864 when the U.S. Calvary, led by Kit Carson, forced the Diné from their home - from their land and livestock. This tragic event greatly influenced the Diné's 
storytelling. This storytelling is influenced by the land's being an active member in its relationship with the Diné, as it is the land that holds the memories of past Diné, which in turn informs the relationship with present Diné.

\section{Diné Storytelling}

Most of the storytelling that occurs in Dinetah, or Diné bikéyah, ${ }^{20}$ is told in the Navajo language; however, this changes depending upon the storyteller, the time, the place, and the context. Further, Tohe explains that certain information cannot or should not be shared with certain audiences. She writes:

One must carefully use thoughts and words, for they have great potential. I came to learn that this might have caused the people to withhold stories of the Long Walk; the pain and suffering the ancestors endured was so nearly unbearable that they named Fort Sumner, where they were starved, raped, exploited and killed, Hwéeldi: the place of extreme hardship where the Diné nearly took their last breath. ("Hwéeldi" 79)

The trauma surrounding the tragedy of the Navajo Long Walk still affects the Diné in the twentyfirst century. In "The American Indian Holocaust: Healing Historical Grief," Maria Yellow Horse Braveheart (Hunkpapa, Oglala Lakota) and Lemyra M. DeBruyn explain that because of the effects of colonization, such as massive losses of land, lives, and culture, there is a "chronic trauma" and "unresolved grief" that spans through a nation's generations (60). However, the stories shared within a nation, specifically the Diné, help to "heal" the lasting trauma and grief; the stories that do get shared about the Long Walk remind the Diné about the survival and endurance of the Navajo Nation. 
For the Diné, as discussed in Chapter One of this dissertation, storytelling is essential to the survival of their oral tradition. Tohe explains that storytelling is part of the "oral tradition of indigenous peoples ... stories impart values, language, memories, ethics and philosophy, passing them to the next generation. A lot of people think of storytelling as just entertainment for kids, but for the Diné it helps maintain tradition and language" (qtd. in "Storytelling"). While this storytelling is part of the oral tradition, today, it is now part of the Diné's written rhetorical sovereignty. This ownership is seen in the preface to Tohe's poem "In Dinétah," in Sister Nations, as she writes: "In the people's memory are the stories / This we remember... "Ałkidąa adajiní nítęę; / They say long time ago in time immemorial" (100). ${ }^{21}$ She asserts that it is their memories that will be shared; not the colonized Western fugitive poses offered by non-Natives. ${ }^{22}$ Tohe promotes this idea of Diné memory through her code switches between the English and Navajo languages in her poetry and short stories.

\section{Survivance}

In this chapter, I will argue that by using code switching in her works, Tohe is engaging in rhetorics of survivance, or what Vizenor and Powell explain are acts of resistance and survival. "Survivance" denotes the need for both resistance and survival; to resist an imposition of being absent and invisible in the colonial imaginary and to survive the ongoing colonial attempts to define, quiet, and ignore American Indian peoples. As can also be seen through recent examples of colonization attempts, Vizenor's work makes clear that the "Indian" is placed into the past as a vanishing or vanished race; one that is represented by neither his/her own culture, nor nation, but by an image that is created for him/her by hegemonic forces that sponsor colonization, assimilation, and dominance. Powell extends Vizenor's theories on rhetorics of survivance as she investigates late- nineteenth and early-twentieth-century American Indian 
rhetors, Sarah Winnemucca (Northern Paiute), Charles Eastman (Santee Dakota), Susan La Flesche (Omaha), and Andrew Blackbird (Harbor Springs Ojibwe/Odawa). In "Rhetorics of Survivance: How American Indians Use Writing," Powell demonstrates how Winnemucca and Eastman used rhetorics to both resist and survive, and how doing so worked to transform themselves from object-status to subject-status, to assert a presence instead of an absence. It is through her use of language, more specifically code switching, that Tohe demonstrates the acts of surviving and resisting by asserting presence in the face of pressures suggesting death and absence.

Before I explain how Tohe's works demonstrate survivance, and transformation from object-status to subject-status, it is important to understand the aforementioned attempts to define, quiet, and ignore American Indian peoples writ large, in the context of our current society. One example of these attempts to define and ignore American Indians can be seen through the use of stereotypical sports mascots. In an interview with American journalist and political commentator Bill Moyers titled, "The Absence of Native American Power," Spokane/Coeur d'Alene Sherman Alexie talks to Moyers about feeling "lost and insignificant inside the larger culture," and how his culture's "lack of power" is illustrated in stereotypical sports mascots. Alexie argues that "At least half the country thinks the mascot issue is insignificant. But I think it's indicative of the ways in which Indians have no cultural power. We're still placed in the past. So we're either in the past or we're only viewed through casinos...I know a lot more about being white than you know about being Indian" (Moyers). Alexie touches on what many American Indian nations struggle with in terms of representation, stereotypes, and striving to survive within the dominant culture. In addition, Diné student Amanda Blackhorse, in her May 2016 speech to her fellow classmates at Many Farms High 
School, expressed her frustration with struggling with racism: "When we leave the reservation . . . there is a lot of racism. We've learned to just deal with it and say, 'It's not a big deal' ... We need to confront it. We need to address it now ... We are at a time that we're saying, 'We're not going to take it any more!'” (Yurth). Blackhorse was one of the petitioners in the 2005 lawsuit against Pro Football to cancel trademark protection for the Washington, D.C. NFL team's stereotypical name and logo. The case is presently making its way through the appeal process and will likely end up in the Supreme Court, according to Blackhorse (Yurth). Though she has continued to be outspoken about racism and representation, she has dealt with much backlash, as some argue that she should "get over it" and she should "worry about her own life." Both Alexie's and Blackhorse's tactics of bringing awareness to the appropriation of American Indian peoples displays that these struggles continue into our present-day of 2017.

In addition to stereotyping, there are instances of "writing" the "Indian" in the past. This can be seen in some examples of U.S. history books, as American Indian histories are either glossed over or non-existent. In her article, "Hwéeldi Bééhániih: Remembering the Long Walk," Tohe explains that the history she was taught "exalted American imperialism and nationalism. Not one mention was made of the other -ism, colonialism. The Long Walk and the other death marches of indigenous peoples in the United States were omitted in all my history textbooks" (78). Tohe further explains that "Trails of blood led from the Dine ${ }^{23}$ homeland to Hwéeldi. Those who were fortunate enough to escape Kit Carson and his soldiers hid wherever they could and protected themselves however they could. These are the kinds of stories that were omitted in the textbooks, but the older people remembered how violent and dangerous that era was" (80). Making this specific to the Diné today in the twenty-first century, on the Navajo Nation's Facebook page titled "Dine Bikeyah," a post by the administrator reads as follows: "I understand 
the Rez schools(sic) librarians are gathering this summer to evaluate library books and may throw out all the Americans history books out(sic) or may donate to smithsonian(sic) / Rez schools evaluation???” (“Dine Bikeyah"). In response to this post, Tohe wrote the following:

The NN [Navajo Nation] has many wonderful writers who aren't known within their own community, let alone schools on the NN. This sounds like an opportunity for schools and administration to offer works written by our own writers. The $\mathrm{NN}$ is the only indigenous nation to award a Poet Laureate which means we value and honor our writers. Dine writers' work should be taught in the Rez schools as part of the curriculum. ("Dine Bikeyah")

Tohe's response showcases her efforts, through her own writing as well, to bring the Diné's triumphs, against colonization, to the forefront. In "Diné Culture, Decolonization, and the Politics of Hózhǫ,” Larry Emerson (Tsénahabiłnii, Tó'aheidlíínii, Hoghanłání and Kii’yaa’áanii) explains that "contemporary Diné decolonization resists English-only U.S. history that skips over Native American experiences" (59). This can be seen in the Navajo Nation's decision to focus on the Diné history, from their own writers, as opposed to the history supplied to them through U.S. history books. To further combat this “skipping over” the American Indian nations' histories, Powell suggests that American Indians need to write their own histories. However, she warns the following: "But we cannot, we must not, write these as 'other' histories, magnanimously included alongside the 'real' history. As Craig Womack reminds us, these aren't some 'branch waiting to be grafted onto the main trunk ... [they] are the tree, the oldest [and most persistent dis- courses] in the Americas"” (7). Sadly, while these histories may be the "oldest" in the Americas, they are often "othered" or ignored. 
While some American Indians use interviews, Facebook, and graduation speeches to bring awareness, others use fashion. In the article "Navajo Fashion Designer Uses T-Shirts To Illustrate Native Life," author Stina Sieg explains how Diné fashion designer Jared Yazzie uses fashion to bring awareness of the mistreatment and misrepresentation of American Indian peoples ${ }^{24}$ Yazzie is a part of the current renaissance of American Indian fashion called Native Fashion Now, which showcases 70 designers that travel the country, bringing awareness through their fashion. Yazzie's goal is to remind "non-Natives that Native American still exist" (Sieg). To do this, he places slogans on t-shirts that assert an American Indian presence in the larger, dominant culture. Some examples of his slogans are: "Native Americans Discovered Columbus," "Uncle Scam," "Protect - Native Woman Protestor," and "Water is Life."

Yazzie's message of "Water is Life" is referencing the maltreatment of the Diné's water supply and land in the present-day; one would not think that an American Indian nation would have to deal with an inhumane issue such as lack of clean water. However, yet another example of these ongoing attempts to silence or ignore American Indian nations, more specifically the Navajo Nation, is the Diné's struggle with having clean water from which to drink and grow their crops in 2015. In the article "Navajo Nation Mourning, Pleading for Help After Toxic Mine Spill Contaminates River," Avianne Tan explains how a team of Environmental Protection Agency (EPA) workers accidently released 3 million gallons of waste-water containing lead and arsenic, from the gold mine in Silverton, Colorado. The spill affected the Navajo Nation's water supply as the water turned orange from contaminants, and the state of New Mexico had to declare a state of emergency. Though the situation was dire for the Diné, the reaction of the EPA was slow. While the EPA argued that they had to work slowly out of "caution," then-Diné President Russell Begaye said the slow response was deliberate and that the people within the 
Navajo Nation were "weeping every day" and in "dire need of clean water" for drinking and sustaining their crops. Begaye further lamented that "The Animas River and the San Juan rivers are our lifelines. Water is sacred to us. The spirit of our people is being impacted" (Tan). Begaye begged for help, explaining that the two personnel sent to "help" the Diné would not provide answers nor ensure that the water was safe to drink and/or use for their crops. This lack of support affected the Navajo Nation's ability to drink clean water, use the water for their crops and livestock, and affected their tourism, which cost the Navajo Nation thousands of dollars. Begaye took his anger a step further by writing an opinion article in The Daily Caller titled, "Federal Government Lets Navajo Nation Down After EPA Mine Spill." Begaye wrote the following:

[The] Navajo Nation is used to historical mistreatment by agencies of the federal government, but the inadequate and delayed response to the contamination of our rivers and the utter lack of accountability takes that sentiment to a whole new level. When that threat became reality, they waited nearly two days to inform the Nation that a spill had occurred, then waited six full days to take responsibility and apologize. The EPA's eventual "response" was to provide our communities with tanks of impure water for our livestock and crops. And now, FEMA is denying our request for a declared state of emergency. Our people have suffered immeasurably due to the reckless actions of the EPA and other responsible parties (who have yet to be held accountable), and the government's failed response to this crisis only adds insult to injury. Our irrigation systems are still shut down, and our analysis shows that the water is not yet safe for consumption or crop irrigation. The Navajo Nation's Environmental Protection Agency has found lead, arsenic, mercury, chromium, cadmium and beryllium, contaminants 
known to be toxic to humans and animals, still present in our rivers. Our people and our land are devastated. With high unemployment on the Navajo Nation and almost all Navajo families relying on subsistence farming, our lack of access to clean water to grow our crops is catastrophic. (Begaye)

I included this weighty passage, in its entirety, as it poignantly demonstrates the mistreatment of the Navajo Nation, as well as displays a specific example of a political and cultural attack on the Diné's well-being in the twenty-first century. ${ }^{25}$ It is the continuance of the faulty notion that American Indians only exist in the past, as well as the ongoing cultural, political, and economical attacks against American Indian nations, as some of the examples show above, that encourage American Indian authors to demonstrate survivance in their works.

\section{The Navajo Language}

Tohe is one of these authors that establishes survivance in her writings, as she reveals the Diné's survivance through her poetry. Vizenor explains that American Indian peoples and "their stories actuate a presence, not an absence" ("Fugitive Poses" 14). Vizenor's elucidation is applicable to Tohe, as Tohe's work operationalizes survivance in complex ways, ways that "actuate a presence" in the face of ongoing attempts to render American Indian peoples absent from American rhetorical, literary, and geographic landscapes. Tohe is engaging in these rhetorics because she is reclaiming her rhetorical sovereignty through her poetry. She reclaims her sovereignty by writing in both Navajo and English. The engagement in rhetorics of survivance, most importantly, demonstrates the Diné's survival through their language.

The fact that Tohe uses the Navajo language is, alone, demonstrative of survivance because the use of the Navajo language is actually in decline. As discussed in the last chapter, according to the 2000 U.S. Census, nearly 300,000 people identify as Navajo. In the census, 
178,014 people identified themselves as speakers of Navajo, with roughly 120,000 of those identifying themselves as speakers of Navajo and as residents of the Navajo Nation (Webster "Don't Talk About It" 401). Less than half of those who reside in the Navajo Nation can speak the Navajo language. In A Seat at the Drum, Pechanga tribal chief Mark Macarro explains why he took the time to teach himself his tribal language: "[Language] is really a key to the soul of the culture ("Revitalizing"). To connect the idea of language's connection to the "soul of culture," to the Diné, they are in danger of losing their culture due to the declining use of the Navajo language. While the Navajo language is widely spoken (in fact, it is spoken in every state in the U.S.) by a significant number of speakers, Diné scholars Tiffany Lee (2007) and Ancita Benally (Benally and Viri 2005) point out that the language of the Diné (Navajo) is an endangered language. It is threatened in the sense that the younger generations of the Diné are not learning the language at a rate that will protect the sustained usage of the language. Also, despite a number of efforts over the years, literacy in Navajo is still rather limited (Webster "Don't Talk About It" 401). In an article from Indian Country Diaries titled "Revitalizing Native Culture," the author argues that the "death of a Native language matters most because that language is part of the rooted identity of the members of that tribe. The loss of the language means that ceremonies are no longer performed in the language. Stories are no longer told. Even if the stories have been translated into English, much of the meaning has been lost. There are concepts that don't translate into English" ("Revitalizing"). If the traditional tribal stories are no longer able to be told, a nation will lose a part of its history, a part of its culture.

This significance of losing the Diné language makes the use of code switching significant in the writings of Diné authors, specifically Tohe, as it is a way to "save," or rather, reestablish the importance of the Navajo language in Diné culture; for, presently, most of the elders today 
understand and speak only Navajo, while most of the generation under 30 speaks only English. ${ }^{26}$ Even though the Navajo language is being taught at schools on the reservation as a second language, it is rapidly disappearing as the tribe's native language. Many Diné feel that language preservation and revitalization is one of the most important issues the Navajo Nation faces today (Benally). This conversation has arrived at the moment where activity to promote survivance must be envisioned/taken.

Some Diné authors, like Tohe, use the Navajo language in their writing. American Indian literature scholar, Susan Brill, argues that the Navajo language is used in many of their stories "to move their reader-listeners into the Navajo worlds of those stories, even when those stories are predominantly in English. The use of the Navajo language firmly roots the stories within a Navajo world - be that world of the mythic, the everyday, or, in many cases, both" (135). Tohe's decision to incorporate the Navajo language within her English-dominant works contests the boundaries and representations of Western literatures and rhetorics and provides her with a tool to give voice to the Diné community and demonstrate her survivance, as her usage of the Navajo language demonstrates the Navajo Nation's survivance attempts, in the twenty-first century.

In Chapter One of my dissertation, I noted that Tohe explains that she used the Navajo language in her writing because it allowed her to "see through Navajo eyes." Before she could do this, Tohe had to learn how to write in Navajo. While she could speak the language, she could not write it; so, she attended Diné College, the Navajo tribal college, to learn to write Navajo (Webster "Tséyi' First"). Her desire and motivation to learn how to write in Navajo, helps her to convey the Navajo perspective and "see" through "Navajo eyes." Diné historian Jennifer Nez Denetdale argues that the oral tradition, particularly storytelling and/or narratives, are "valid forms of historical production" (“Remembering” 81). Denetdale further explains, "Recently, 
oral traditions have been examined to illuminate Indigenous peoples' perspectives on the past. If we view oral traditions and history as cultural constructions embedded in social processes, we discover that the meaning of the past differs across cultures and raises questions about the authority we continue to give to documentary evidence"(81). As Denetdale's quote helps to demonstrate, culture and history are connected, and the analysis of rhetoric in storytelling helps to flesh out those connections, as rhetoric aids in bridging culture and history rather than dividing them into ostensibly "different" aspects of experience. Tohe uses the power of storytelling to recollect and acknowledge the voices of the Diné people, which will be discussed below.

\section{Past and Contemporary Diné Peoples' Visibility and Voice}

Her ability to write in two languages enables Tohe to use the power of storytelling to remember and bring validity to the voices of the Diné people. Significantly, these voices, mostly, come from those who perished during the Navajo Long Walk. ${ }^{27}$ She gives these non-survivors identities, emotions, and voices, which gives them the visibility that was denied to them via Westernized representations of the Navajo Long Walk. It is through her stories of the Navajo Long Walk and the struggles and tragedies surrounding Diné bikéyah ${ }^{28}$ that Tohe demonstrates survivance by code switching to emphasize the voices and history of the Diné, which are rooted in the Navajo Nation. This can be seen in Tohe's book of poetry Tséyi' / Deep in the Rock: Reflections on Canyon de Chelly, as Tohe shares stories about the canyon, Tséyi' or Canyon de Chelly "as it is known on tourist maps" (Tohe xiii). Tohe personifies the canyon itself - she gives voice to the canyon. She explains: "It was during my visits to my parents' home in Mexican Springs that I first heard the canyon calling, 'Hágo, hágo,' Come here, come here, came a powerful voice, one that I couldn't ignore" (xiii). Tohe's personification of the canyon is her first step in demonstrating survivance; for, despite years of oppression and colonization the 
canyon has retained its voice, as have the Diné. However, most powerful is that she references the voices of her ancestors, those that lost their lives during the Navajo Long Walk. She writes: “...there was much more to what we were seeing. We knew that there were stories embedded in and around Tséyi'"' (xiii). These voices are embedded in the rock walls of Canyon de Chelly, and they were calling to her, "hágo, hágo." By personifying the canyon and acknowledging its voice, she gives homage to those whose stories are found within its rock walls.

Here I provide a brief recap of events discussed in greater length in the introduction to this dissertation. The Navajo Long Walk was a removal attempt in 1863-1868, carried out by the U.S. government, to eradicate the Diné. When Kit Carson ordered the Diné to leave Dinétah, their homeland, many Diné hid within the walls of Canyon de Chelly, as the canyon shielded them. Others hid their belongings, such as pottery and jewelry, in the caves within the canyon, with the hopes of returning to Dinétah. Though over 10,000 Diné were relocated and/or lost their lives during the Long Walk, their voices, their stories, are housed within the canyon, and Tohe brings awareness of their existence, of their stories. The voice that can be heard from the canyon comes from the history of the Diné or rather the Diné "who inhabit it today and of the people who came before" (xiii). This personification of the canyon and the "hearing" of its voice demonstrate that the Diné voice can be and should be heard. The canyon, and the voices embedded in it, act as a source of history and a symbol of survivance for the Diné, as well as a muse for Tohe, which she uses to bring awareness of the Diné's continued existence and survival in our present-day.

This survival is further demonstrated in her poem "Jiní," when Tohe directly translates the Navajo term "jiní" to the English phrase "they say," as she writes: "Jiní, they say. We accept jiní as part of our stories on simple faith. It's not important who said it, but that it was said...Our 
stories begin and end with jiní" (11). While Tohe is retaining the Diné connection to the word "jiní," she is also letting the non-Diné speaking reader see that "they say" is the English equivalent. The "they" are the Diné who were not allowed to have a voice during the 1860s. This poem demonstrates that regardless if they were heard in the past, they have stories that influence the present. They have history and they should be heard (Hoover 180). Tohe enables those silenced Diné to have their voice through her writing, as she writes: "our stories." They are not being told for the Diné; rather, the Diné are telling their own stories, and Tohe is the conduit. This (re)telling is further seen in Tohe's poem "Refugees in Our Own Land," as she translates the following for the reader: "Shiyáázh, my son, fusses in his cradleboard" (17). She continues: “Shhh, shee'awéé', shiyázhí, shhh.” Hush baby, my beloved, hush,” as she translates for the nonNavajo speaking reader once again. It is important that Tohe translates for the reader, as she is teaching the non-Diné speaking reader the Navajo language, but the context in which these translations and code switches are used are most significant. This translation also exists in a complex social place, as Tohe had to teach herself the language and younger Diné do not all speak it, so the non-Diné speaker could easily be from her own community.

While "they say," "my son," and "hush baby, my beloved, hush" do not seem to be directly connected to the Navajo Nation, they are. Tohe's explanation of "they say" is housed within a poem that remembers the past and demonstrates a respect for what was said by Diné ancestors - it represents a pre-colonial nation (Hoover 180). Further, the mother and son in her poem "Refugees in Our Own Land" are victims of the Navajo Long Walk. "My son" and "hush baby, my beloved, hush" is dialogue used within a poem titled "Refugees in Our Own Land," which portrays a strong, rhetorically-powerful title that demarcates not only a connection to the Navajo Nation, but a struggle to maintain a connection to the land of the Diné amidst adversity 
and violence. The translations are used to display a picture of relocation and assimilation, as the speaker is coddling her child while "Monster Slayer's archenemy rises again to pull us off the rock where we've taken refuge since winter's approach" (Tohe 17). Though the poem about the mother and son is just one story about those annihilated during the Navajo Long Walk, or rather those who were attempting to hide within the canyon, it is a significant story. This is not just a poem about a mother and a son, but about a people being torn from land that is theirs - a mother, a past that will be forced to fight for sovereignty in the future, her son. Tohe uses rhetorics of survivance to depict a mother resisting and attempting to survive for her son, as is her use of the translations to provide that vision for the audience.

Despite the relocation and removal attempts by Carson and the US government, and the death of many Diné, the history and culture of the Diné survived, as did the Navajo Nation. Tohe uses rhetorics of survivance to demonstrate a strong nation and land that endured relocation and removal, as she directly or indirectly translates terms that are specific and significant to the land of the Navajo Nation. One example of survivance is in the poem "Deep in the Rock." Tohe writes: "Deep in the rock, crows make echoes, gáagii, gáagii. Their name is pure /onomatopoeia. Gáagii / are everywhere" (9). The Diné word "gáagii," is connected to the English term "crows." In Navajo Land, Navajo Culture, Diné historian Robert S. McPherson explains that, "a medicine man, said that coyote, wolf, crow, and mountain lion were all hunters and friends of Navajo hunters. The crow cries ahead and tells the hunter where the game is located" (25). Though the crows aided in hunting and survival, as well as communicated with the Diné in the past, in her poem, Tohe tells the reader that now the gáagii "[pick] up the remains of what humans / leave, even the stuff not intended for them, like the boxer shorts stolen from / the clothesline" (Tohe 9). As this excerpt demonstrates, the gáagii are still here. In addition to their continued presence, 
they are strong enough to take what they want, even if it is not intended for them. This idea of strength can be a nod to the Diné that continue to live and engage in their culture, despite the outside forces of the larger, dominant society, that was not "intended for them." Like the gáagii, however, the Diné are not deterred, and also like the gáagii they are "everywhere, and are taken for granted" (9). "Taken for granted" is a reference to how the Diné, while the largest American Indian nation in the country, are often ignored or othered, as can be seen from the maltreatment by the US government in regards to their water supply in 2015, and their culture is often appropriated by those outside the culture for entertainment or fashion. This appropriation is seen through the May 2016 Urban Outfitters case, as well as the numerous Halloween costume options labeled "Naughty Navajo" or "Princess Navajo Indian Woman," which are sold for entertainment purposes during Halloween. ${ }^{29}$ These appropriations and misrepresentations hide or ignore the continued existence of Diné and their extensive contributions to the larger, dominant culture that disrespects their culture. The Diné's rich history is "taken for granted," through their fashion/jewelry, pottery, and the fact that the Diné are our firefighters, doctors, lawyers, teachers, and other significant figureheads in the United States, which is mirrored in Tohe's reference to the gáagii as she writes: "If they were to / leave, they would be missed" (9). If the Navajo Nation were to cease or disappear, the impact would be felt within the dominant culture, just as the loss of the gáagii would affect the ecosystem and land of the Navajo Nation. Like the gáagii, who are hidden because of the dominant view or size of the canyon, the Diné too are hidden because of the dominant society, but both the Diné and the "gáagii are everywhere," and are significant. Interestingly, gáagii or the crow is also seen as a trickster figure in the Diné culture. Guy H. Cooper, in "Coyote in Navajo Religion and Cosmology," states that "raven (or crow, the Navajo do not distinguish the two) is linked with coyote in myth" as a trickster-culture hero 
(188). Cooper also states that hunting is also a form of "trickery requiring cunning" (188). This level of cunning and cultural heroism can be viewed in two ways. The first way is that the metaphor of the gáagii hiding "deep in the rock" references those Diné that hid, bravely yet frightened, in the canyon during the genocide conducted during the "round up" of the Navajo Long Walk, as it took cunning to survive an attack on their land, their culture, and their homeland. Further, those that hid survived, and were able to "pick up the remains" of the Diné culture and "carry" it into the present for contemporary Diné peoples to continue to survive physically and culturally, despite resistance and persecution. This survival and strength too displays elements of trickster; for, in Mixedblood Messages: Literature, Film, Family, Place, Choctaw-Cherokee and Irish scholar Louis Owens states that "the role of trickster is to dismember all constructions that impose definitions and limit possibilities” (86). The gáagii evade expectations and constructions by taking what is "not intended for them," much like the Diné that are successful in retaining their culture and language amidst adversity in a culture that was "not intended for them" via relocation, removal, and assimilation. The second way to view this cunning and cultural heroism is that, presently, Diné authors are "crafty" in engaging with their cultural views and beliefs in a Westernized culture, much like Tohe with her decision to code switch and include the Navajo language in an English-dominant text.

Not only is the image of the crow seen as trickster, but also is the very act of code switching. In Other Destinies: Understanding the American Indian Novel, Owens explains that code switching is a trickster sign (109). ${ }^{30}$ Tohe's act of code switching, especially in this poem, is significant not just because the crow represents an image for rebellion and strength, but also because Tohe's act of code switching redefines both her own and the Diné's sovereignty and numerous political, economic, social, literary, and personal possibilities by using the Navajo 
language in an English dominant text, which mirrors the Diné culture in the larger, American culture. Furthermore, in American Indian Rhetorics of Survivance: Word Medicine, Word Magic, Ernest Stromberg alludes that trickster stories can rewrite history, as well as aid in a fight for self-determination and self-definition. Thus, the above example shows Tohe's use of rhetorics of survivance through not only her use of the Navajo language in her English-dominant text, which makes her a "subject within [the dominant discourse], not just a victim subject to it" (Powell "Rhetorics" 425), but she also depicts survivance through the image of the crow and her engagement in trickster rhetorics through her code switching. Tohe asserts her active, Diné presence through the representation of the crows, and is, in a sense, telling the reader: "like the crows, we are still here.”

Perhaps as a connection to the Diné, or even Natives in whole, as they are here - present, not absent, and yet are ignored and taken for granted, this assertion demonstrates Tohe's "active sense of presence over absence, deracination, and oblivion" (Vizenor "Survivance" 39). Tohe's connection between the Diné and the crows' and trees' sustained presence in the land represents a continued and active presence by the Diné; for, according to Vizenor, "the presence of animals, birds, and other creatures in native literature is a trace of natural reason, by right, irony, precise syntax, literary figuration, and the heartfelt practice of survivance" (12). This survivance can further be seen in the following line: "Deep in the rock, the tamarisk and monkey-egg trees have dug in to prevent / erosion. Like the Diné, they refuse to leave" (Tohe 9). This line appears simplistic in its imagery of the trees being rooted in the earth; however, this is a very complex line that denotes the survival and the "roots" of the Diné in the past and in the present. "Like the Diné" who hid within the canyon to evade relocation and removal, or rather the "erosion" of their culture and home, the "tamarisk and monkey-egg trees" are symbolic of the Diné of the past 
who did not leave the canyon, as well of those who were forced to physically leave, but whose culture remained intact to teach and share stories with the Diné of the present. The most significant part of this excerpt is the speaker's declaration that: "Like the Diné, they refuse to leave." The trees are rooted in the canyon and refuse to cease, as do the Diné. This resistance can be seen in the survival of the Diné despite the Navajo Long Walk's tragic implications on the Navajo Nation; however, this survivance can also be seen in the existence of the Diné, presently, most notably through Tohe's use of the Navajo language. Though there were assimilation attempts to eliminate the Diné's culture and replace their language with English, Tohe's use of the Navajo language in her English-dominant text displays a rhetorical act of defiance against the assimilation, relocation, and removal that the American Indian Nations faced in the nineteenth century; for, "despite hundreds of years of pressure, first from American colonists then from Euroamericans, Natives did not disappear" (Powell "Rhetorics" 427).

American Indians, most specifically the Diné, did not disappear because they never left. This presence, instead of the imposed absence suggested by Western rhetorics, is further depicted in Tohe's poem "On the Round Belly of the Earth" as she encapsulates the invasion of the unwanted visitors on the Diné land. She writes:

The Germans, Swedes, Danes, and Eastern Europeans that / flooded this country brought with them the fury to own the land. First by the force / of themselves, opening the earth and dropping seeds into her, they realized the / abundance of the land and wanted more. The plane turns southward and toward / home, where my mother buried my umbilical cord so that my spirit would remain / tied to Nahasdzáán, the earth. (1) 
Tohe translates "Nahasdzáán, the earth" for the reader because she is not only sharing the history of the Diné land and establishing the continued presence of the Diné in a land that was "flooded" by those trying to take the land and eradicate the Diné, but she also emphasizes the Diné's deep connection to Nahasdzáán, the earth, as the Diné peoples' umbilical cords have been buried at the canyon. Hypothetically, even if the Diné had been fully removed from the earth during the Navajo Long Walk, they would still survive, still exist, because of their connection to the land. Regardless of the attempts of oppression, colonization and removal, the land still belongs to the Diné and the Diné presence is felt both physically and spiritually (through the voices of their ancestors) in the land. These voices can be found through the cultural connection to the land. The Navajo creation story explains that when the Diné emerged and were birthed into the Glittering World, they came through the "umbilical center of the earth mother, Nahasdzáán [italics used by the author]. She provides for all living things; she sustains life ... The Diné philosophy teaches that we humans depend on Nahasdzáán and that she must be cared for and respected; our survival depends on it" (Tohe "Hwéeldi" 81). After the umbilical cord falls off the baby, it is buried in the earth near the baby's home. The burial ensures that the child will "never become lost, that the child will remain tied to Nahasdzáán. These beliefs remained in the minds and hearts of the people who were forced out of the homeland" (81). During the Navajo Long Walk, even when the Diné were imprisoned hundreds of miles away in Bosque Redondo, the land within the Navajo Nation, more specifically the four sacred mountains, was still there for them. They were still tied to their homeland, and still surviving, despite physical removal by the US government. Not only does the earth help the Diné to survive through its water, livestock, etc, but it also helps the Diné to resist erasure as it holds the very life force of the Diné born in the Navajo Nation, and Tohe makes the reader aware of this through her code switch. 
Tohe continues her focus on the importance of the Diné's connection to land, as well as the need to hear the voices of past and present Diné, in her poem "A Tree Grows near the Road." The poem has two stories that are told separately and sequentially. The first story gives voice to a past Diné woman, enduring the Navajo Long Walk in the canyon in 1864. The second story gives voice to a present day (when Tohe composed this poem, the "present-day" was 2005) Diné woman who watches tourists tromp on the very ground where Diné blood was spilt by the US government in the 1860s. Tohe begins her poem with a depiction of the tourists that visit the canyon: “...trucks and jeeps used to run tourists / in and out of the canyon - half-day, all-day tours, cameras click, / coconut sunscreen / with SPF 30 fills the air" (Tohe 13). While the tourists are clicking their cameras, taking pictures of the beauty of the rock, they are oblivious to the stories embedded in the stone. Tohe, however, reminds the reader, disrupts the tourists' narrative, and gives voice to the "woman who got away" (13). Tohe tells the woman's story for her, since she was silenced during the Navajo Long Walk; this silencing of the woman, and Tohe's telling of the woman's story, can be seen in the following excerpt: "Someone shudders in that tree that reaches across the dirt trail. It is a woman / driven from her home. Her husband and children scorched, along with the corn / and peach orchards. The sheep slaughtered. Below the horse soldier paces / back and forth, back and forth. She sees horse prints in the sand burying hers" (13). While we do not hear the woman's name, and "someone" is not even gendered anymore at this stage of the poem, the context of the poem is rooted in the fact of "someone's" existence and presence. It is also significant that she uses the term "someone," as she is telling this person's story, which brings this person's history and experiences to the forefront; this story is not glossed over or ignored. 
By Tohe writing "someone" and "her husband and children," she is giving this woman a voice, she is telling her story. She survived. She is also creating an image, for the reader, of the devastation of the Navajo Long Walk through her use of "scorched" to describe this woman's family and her land. While Tohe includes images of the past, more specifically the Navajo Long Walk, she also depicts the canyon as a present-day, tourist "hot-spot," as she writes: "Brown Diné women sell soda and turquoise jewelry / near the grove of cottonwoods at Antelope House / Tourists must love the authenticity of "Real Indians" (13). Like the gáagii referenced in her poem "Deep in the Rock," who are hidden in the canyon, from the people's view, the history and pain of the Navajo Nation is also hidden in the canyon, and is ignored by the tourists. The women themselves and their goods may be on display but the history and pain are not. They are visible but not visible in the way that Tohe would hope -- not visible in their admirable "survivance." Tohe reminds the reader of this history, these voices, as she writes: "This canyon...demands the price / of memory and the stories of jiní. So remember, this place where the tree arches / over the road represents the flow of the water and the woman who got away" (13). While Tohe is giving voice to the woman who survived the Navajo Long Walk, the juxtaposition of the past (Navajo Long Walk) and the present (tourists visiting Canyon de Chelly) also demonstrates resistance on two levels. The first level is the woman (past) who survives, resists the devastation of the relocation and removal, even though her family perished. The second level is the resistance of the Diné women to not succumb to the Westernized version of "the Indian." The Diné women, at Canyon de Chelly, are aware of the expectations of the tourists; they know what representations of "the Indian" that the tourists are expecting to see: headdresses, beading, and/or turquoise jewelry. Because they know of these expectations, they use the jewelry, according to Tohe's poem, to create a paradoxical slippage between object and 
subject. While the Diné women "play" the role of the "object," with their turquoise jewelry on display in the shops at the canyon, they are actually the "subject," and the tourists are the "objects." This is also a function of trickster discourse, as trickster demonstrates who/what is visible and to whom. This flip-flop of subject and object status is possible because it is the tourists who believe this authenticity is demonstrated through the jewelry, but it is not. The true authenticity of the canyon lies within the tragic history and the various stories embedded in its walls. With the jewelry, the Diné women are resisting. They are resisting because it is the Diné who poke fun at the idea of how the tourists "must love the authenticity of Real Indians." In this poem, the tourists are being represented and appropriated, not the Diné. Because of this reversal in appropriation, the Diné are able to resist the Westernized representations of "the Indian."

The incorporation of "soda" and "turquoise jewelry" also depicts Tohe's understanding of what is expected of the Western view of the "Indian-ness" of the canyon -a land that holds the sacred memories and pain of the Diné - as a tourist attraction. Furthermore, her awareness of how the tourists must love the "authenticity of 'Real Indians"” not only demonstrates her awareness of the expectations of the visitors of the canyon, but also how the audience of her poetry will respond to her sarcasm and observations. She writes this to evoke a response from the reader, as she places "Real Indians" in quotation marks and capitalizes the phrase - she is critiquing the beliefs about "authentic indianness" that her audience and the tourists may hold about American Indians (Powell "Rhetorics" 415). They are brown. They are selling turquoise jewelry. They are on "Indian" land. They must be authentic. The "authenticity," however, lies in the heart of the Dinétah - the canyon's memories of the Diné and the tragedy of the Navajo Long Walk. While this is all potentially "visible," the culturally and historically uninitiated tourists do 
not see what is there in the space with them, so presence and absence co-exist. Tohe brings these assumptions and expectations to the forefront, while also giving voice to those who perished.

\section{Stereotypes and Authenticity: Teaching Moments}

"A Tree Grow Near the Road" is the only poem in which Tohe emphasizes representation and stereotypes surrounding the Diné, or even American Indians writ large, as she writes:

"Tourists must love the authenticity of 'Real Indians."” Diné authors are aware of these racist stereotypes about Diné - for example, that all Navajos are poor, live on reservations only, or are alcoholics. In his article “"Don’t Talk About It': Navajo Poems and Their Ordeals of Language,” Anthony Webster explains that "a number of Navajo poets have pointed out the tension involved in simply ordering a beer at a border town bar or restaurant. The moment you order that beer, they tell me, you can be seen as confirming Anglo stereotypes" (408). Webster further explains that Diné authors are also aware of outsiders' expectations that "trivialize and exoticize them." Outsiders' expectations are reflective in Tohe's poem as she describes the actions of the "brown, Diné women" making jewelry at the canyon, and the acknowledging that the "tourists must love" the 'Real Indians.'”

It is not surprising that Diné authors are aware of the multiple tensions surrounding them as Diné; they experience tensions from outside, non-Diné expectations and even tensions from other Diné as well. ${ }^{31}$ The fact of multiple perspectives also echoes the complications of Tohe's decision to provide translations, as it is not only outsider/non-Diné who might need translations but also Diné audiences; her potential audience is multiple, not neat and binary, in perspective.

This notion of authenticity and representation, as well as appropriation, is still prominent in the twenty-first century as the Diné recently became outraged by author J.K. Rowling's appropriation of the Diné legend about Skinwalkers. In the Diné storytelling tradition, a 
skinwalker is similar in form to trickster coyote, owl, fox, wolf, and so forth, but they are more powerful, and the association is that with a medicine man or a witch, and the intent is for evil and harm. ${ }^{32}$ Rowling's cultural appropriation of the Diné story for the purpose of her work surrounding a new "Harry Potter" story, which was not yet in print, angered Adrienne Keene, a Cherokee writer who created the Native Appropriations online forum, as she wrote that the skinwalker legend "has a deep and powerful place in Navajo understandings of the world." "It is connected to many other concepts and many other ceremonial understandings and lifeways. It is not just a scary story" (qtd. in Gibson). Diné writer, Brian Young, also sent out a message on Twitter, stating: “Yo @ JK Rowling, my ancestors didn’t survive colonization so you could use our culture as a convenient prop" (qtd. in Gibson). Events that took place even after the publication of Tohe's book demonstrate the ongoing relevance of her rhetorics of survivance and her emphasis on the (re)telling of the Diné history that much more powerful and relevant. However, coming back to her poem "A Tree Grows near the Road," the act of her speaking directly to a particular audience who is learning the Navajo language, is equally significant. She is taking the time to educate and teach multiple audiences while also promoting alliance.

\title{
Promoting Alliance: Teaching the Diné Language, Culture and History, and Encouraging
}

\begin{abstract}
Allies
When I use the term "alliance," I am referring to Powell's explanation of rhetoric of alliance. Alliance is a tactic of survivance. This alliance is attained through becoming allies, not "competing individuals," who are "working toward the survival of our shared community" (Powell "Down" 42). To become an ally does not mean that one has to become like the other culture or group; actually, the fact that Tohe speaks to multiple audiences in her writing demonstrates this idea of multiple audiences and allies. An ally embraces the differences and
\end{abstract}


works with the other culture or group to have a shared understanding, a shared community. In her article "Down by the River, or How Susan La Flesche Picotte Can Teach Us About Alliance as a Practice of Survivance" Powell explains that we "must share some understanding of one another's beliefs. We don't have to believe one another's beliefs, but we do have to acknowledge their importance, understand them as real, and respect/honor them in our dealings with one another" (42). In order to "deal with each other" in a respectful and meaningful way,

we need a new language, one that doesn't convince us of our unutterable and ongoing differences, one that doesn't force us to see one another as competitors. We need a language that allows us to imagine respectful and reciprocal relationships that acknowledge the degree to which we need one another (have needed one another) in order to survive and flourish. (41)

This new language is created by Tohe in her poetry as she uses the Navajo language with the English language. She does not use one or the other; she uses both. More specifically, she uses both to teach the reader about the Diné's history, land, culture, beliefs, and traditions, and give voice to both past and contemporary Diné peoples. Moreover, code switching provides her with a tool to not only re-tell a history that has been skewed or ignored by the Western culture, but also a tool through which she can encourage allies, ones that will learn about and appreciate the Diné's continued existence.

While I have discussed the significance of her code switching throughout the duration of this chapter thus far focusing on her code switching and translation of single words and short phrases, the next examples that I will discuss demonstrate an extensive use of code switching through Tohe's distinct translation tactics, as she code switches and translates full sentences and 
paragraphs. Tohe uses translation as a tool for a transformative pedagogy, one that pursues the goal of alliance across difference. Tohe's promotion of alliance can be seen in her poem "Many Horses." On the surface, the poem reads as if the speaker visits the mountain and then leaves. While this reading can be indicative of Tohe being called to the canyon by her ancestors, it is the use of her code switching and translation that is most important, as Tohe emphasizes the Diné creation story and repeats the English version of "mountain" six times and the Navajo version five times. (These versions change, depending on the action, as can be seen below). The following excerpt shows her code switching and full translation of these code switches:

Dził bich 'i’ yishááł...I am approaching the mountain Dził bikáá' haashā...I am ascending the mountain Dził bikáá' naashá...I am walking on the mountain Dził bąąhdōō 'adaashááh...I am descending the mountain Dził bits'ąajị dah diishááh...I am leaving the mountain. (7)

Tohe uses ellipses to guide the reader to a translation of the Navajo phrases. These phrases also read as if they are learning tools, or progressions, in a language class, which is interesting as Tohe took a course on writing in Diné and so she is teaching the reader what she learned as well. As the action changes (i.e. walking, descending, leaving, etc), as does the Navajo translations, while the English versions of "the mountain" remain the same. Tohe clearly knows that her audience includes non-Diné speaking, or rather reading, readers, as she is outwardly teaching them the Navajo language. These teachings can be for the non-Diné reader, or it is also accurate to assume that she may also be teaching other Diné the language as well, as the younger generations use the Navajo language less and less. This example clearly demonstrates rhetoric of 
alliance, as Tohe is sharing knowledge with her audience, be they Diné or non-Diné, as she is encouraging the reader to become an "ally"; one whom works "toward the survival" of his/her community and the Navajo Nation (Powell "Down" 42). Tohe's sharing is especially important, as Powell asserts that, in regards to ceasing a struggle between languages and cultures, we "need a new language, one that doesn't force us to see one another as competitors" (41). Using both English and Navajo languages creates that "new language" as both propose their meanings and translations for the audience.

While alliance is obviously present, so is her rhetoric of survivance. In addition to the above code switching and translation, Tohe also references the Diné creation story when she shares that the "Diné spiraled into this world protected with a song" (Tohe 7). Tohe's inclusion of the Diné entering this world, along with her repetition of "mountain" is important to note because the Diné creation story includes metaphors and distinct references to Canyon de Chelly and the four sacred mountains. ${ }^{33}$ The four sacred mountains were created for the Diné, as a place chosen for them

by the Holy People where Sisnaajiní rises to the east, Tsoodził rises to the south...Dook'osłííd rises to the west, and Dibé Ntsaa rises to the north. The stories of time immemorial are full of references to these mountains, and so are the ceremonial songs and prayers. These are the mountains that would guard the Diné, where prosperity and growth could exist, where hózhó, spiritual balance, could prevail—until the Spanish, the Mexicans, and the American soldiers arrived. (Tohe "Hwéeldi" 81-2)

In her article "Hwéeldi Bééhániih: Remembering the Long Walk" (2007), Tohe explains that she believes it was the mountains that sustained the "hearts and spirits of the Diné and helped to 
bring them back. The mountains resonate with spirituality and are part of the stories of the mythic migration. Tsoodził, Mount Taylor near Grants, New Mexico, was one of the first mountains the people saw upon their return" from Bosque Redondo (82). Though Tohe does not include the creation story or the cultural stories surrounding the mountains, she does mention them, or rather, hints at them. Her allusion to the stories of the sacred mountains and the creation story portrays survivance, as the stories are continuing to be shared. However, most importantly, these elements of survivance also promote alliance because, as I mention above, she does not share the full creation story, nor does she disclose the Diné's cultural stories about the sacred mountains, but her mention of them are posed to spark an interest for the reader. She is not preventing the reader from knowing about these elements of the Diné's culture; rather, she is alerting the reader to the stories' existence. From there, it is up to the reader to research and learn. Tohe provides the translation for the reader; however, with her translation, she is making the reader responsible to research and learn the Diné's history and culture, by not divulging details. She is demanding that the reader take the extra step to learn, but she does offer guidance for the reader, which is her attempt at alliance.

Tohe continues her promotion of alliance in her poems "Female Rain" and "Male Rain." What makes these poems unique is that they are both written entirely in the Navajo language and then a translation of these poems is written entirely in English. These English translations are, physically, placed next to - not above or beneath -the Navajo versions. This positioning could demonstrate a potential parallel suggesting equality. Again, Tohe is demonstrating her awareness of both audiences, Diné and non-Diné by including both languages, which aids in her teaching the Navajo language, but she is also visibly placing the languages on equal terms, by situating the Navajo language to be just as prominent as the colonial discourse of the English language, as 
the versions are side-by-side. It can be argued that Tohe separates the Navajo-speaking reader from the non-Navajo speaking reader with her separate versions. She may blatantly separate these two versions of the same poem to demonstrate the solidarity and communal connection that the Diné culture has with the earth and rain at the specific place of Canyon de Chelly. She may also be trying to teach the non-Navajo speaking reader the Navajo language, as she does not code switch, but rather includes an English version and a Navajo version of the poems. While the reader may get a piece of information about the Diné culture, while reading strictly from the titles of the poems, which alerts to the reader that there is male and female rain, again, the reader is forced to do research to learn more about the Diné culture, if the reader wishes to understand the details that Tohe provides. Through her specific translations, Tohe uses the English language to share stories that reveal a Diné perspective and that assert Indigenous knowledge, which demonstrates survivance; however, she too promotes alliance as she, like in her poem "Many Horses," does not disclose what is male rain or female rain, nor does she disclose why these rains are significant to the Diné culture, but she does bring awareness, which encourages the reader to want to learn more.

This teaching, or rather an extended invitation to learn about the Diné culture, can be seen as both poems give reference to the Diné creation story in regards to the heroic twins Child of Water and Monster Slayer. Though Tohe does not explain this use of the creation story to the reader, if one looks closely at the references in the poems, there are connections to the creation story in these poems. Her allusion to the creation story can first be seen in the English version of the poem "Female Rain," which is as follows: "Female Rain / Dancing from the south / cloudy cool and gray / pregnant with rainchild / At dawn she gives birth to a gentle mist / flowers bow with wet sustenance / luminescence all around" (Tohe 26). ${ }^{34}$ The female rain sustains the way of 
life for the Diné at the canyon, both in the past and presently, and also did so during the beginnings of Dinétah, as Child of Water helped to create the Diné way of life. While "Female Rain" portrays the idea of nurturing and sustaining the Diné existence, through references such as "birth," "pregnant," and "sustenance," the poem "Male Rain," on the other hand, represents another layer of sustaining the Diné, as the tone is one of the survival and fierceness of the Diné, or rather enemy slayer or Monster Slayer. This survival can be seen in the following, English version of the poem: "Male Rain / He comes riding a dark horse / angry malevolent cold / bringing floods and heavy winds / Warrior rain having a 49 night / then rides away leaving his enemy behind" (27). The tone of survival can be seen through the references of "riding a dark horse," which gives the element of saving or fighting for those in need. Also, "leaving his enemy behind" demonstrates that the warrior, or rather Monster Slayer, fights the battle and then leaves, returning when needed to once again defend the Diné. In the article "Universal Truths, Ancient Wisdom," Diné Marley Shebala explains that the "Navajo history is one of surviving dangerous times and powerful enemies," beginning with the story of heroic twin brothers who "defeated the monsters that inhabited Dinétah, the Navajo homeland" (Shebala). Shebala also explains that after the twins won the battle in the beginning of the Diné history, they faced another battle when they returned home, because "when they returned home: [they experienced] a vast inner torment that emptied their lives of happiness. Nightmares, hopelessness and emotional numbness separated them from their loved ones" (Shebala). Like the twins, the descriptors Tohe uses in both poems also represent dichotomies, which are in reference to the twin brothers Child of Water and Monster Slayer. These dichotomies can be seen through the "light" or "life" representations in "Female Rain," such as "cool," "gentle mist," and "luminescence," which emphasizes life, or Child of Water. On the other hand, the references of "dark," "angry," 
malevolent," and "cold" gives the tone of "darkness" or "death," which emphasizes the emotions and outcomes of battle, of Monster Slayer. Both Child of Water and Monster Slayer needed to be present to save and create Dinétah in the beginning of the Diné's creation. This "saving" by both Child of Water and Monster Slayer connects to the idea of "two-ness" that Tohe promotes, as she includes the two versions of the poems with the two languages of English and Navajo, while sharing the story of the two heroes in the Diné creation story. So, the question becomes: why does Tohe share these poems in a book about Canyon de Chelly? Tohe includes these poems, about the Diné rain at Canyon de Chelly because just as the Diné were sustained during their creation, they too survived the Navajo Long Walk. Tohe's depictions of rain in the poems demonstrates survivance, because Child of Water and Monster Slayer had to defend the Diné during their creation while they fought the enemy and won Dinétah, and then they had to fight another monster: the US government during the Navajo Long Walk. The rain at Canyon de Chelly (the place of both battles), whether it is a gentle mist or a thunderstorm, is a reminder of those battles, both of which failed to erase the Diné's existence. Like the rain (and the crow and trees she mentions in her poem "Deep in the Rock"), the Diné are still here, still present. Further, Tohe demonstrates that it is through these dualities, "female and male, sky and earth, love and war, light and darkness" that the Diné are able to survive, as she explains, "if we are to survive, we must find a way to achieve balance and harmony in this world" (Tohe xiv). It is through these balances and dualities that the Diné were able to return to Dinétah and start over after the Navajo Long Walk.

In all but two cases, Tohe uses a consistent strategy to provide translations with her code switches; in other words, she is cognizant to provide the English "version" for the non-Diné speaking reader. She accomplishes these translations through using a comma or an ellipsis to 
guide the reader from the Navajo word or phrase to the English translation of the word or phrase. However, she does not provide a clear translation throughout her poetry for two words. These words are "Diné" and "Hwéeldi." Though she does not translate "Diné" in her poetry, she does provide ample explanation about the Diné or "the people" in the preface to her poems. It is in the beginning of the poetic compilation that the reader is able to understand that the Diné are "the people," her people. Further, in her poem, while Tohe does not provide a direct or an indirect translation of the term, with commas or ellipsis as mentioned above, the reader can still understand that the term "Diné" is connected to a group of people or a person. For example, in her poem "Jiní," Tohe writes: “'It's best to take time to listen to the stories and not be in a hurry,' the Diné elder / says" (11). The phrase "Diné elder" allows the non-Navajo speaking reader to make the connection that the term "Diné" is connected to a person. Also, she mentions a "Diné woman" in her poem "Echoes" and "Brown Diné women" in "A Tree Grows near the Road." It is with her explanation in the preface to her poems, and how she is using "Diné" in her poetry that the reader is able to understand the term and why it is being used. Furthermore, by not directly translating "Diné," Tohe is encouraging the reader to want to learn more, perhaps research why she uses the term "Diné" as opposed to "Navajo." 35

The most significant Navajo word that she does not directly or indirectly translate is "Hwéeldi." By not providing a "sufficient" translation, she is resisting expectation and encouraging the reader to research the term in order to attain understanding. ${ }^{36}$ She uses this term one time in her entire book of poetry. The only time she uses the term is in her short poem, “What Made This Earth Red?" as she writes:

What made this earth red? These rocks red? Was it the light from earth / and sky to remind us at day's end of the color of our births? Is it all the / trails we took upon 
ourselves or that were forced upon us, beginning / with our blood trails to Hwéeldi and back? (3)

"Hwéeldi" is what the Diné call their relocation place of Bosque Redondo, also known as Fort Sumner. However, Tohe does not share the meaning of this term; meaning, she does not guide the reader with a comma or an ellipsis to the translation of "Hwéeldi." Throughout this chapter, I focused on what translations and details Tohe includes in her poetry; however, also important to consider in regards to her rhetoric of survivance is what she does not say. Perhaps it is because the memories, meaning, and pain behind the term cannot be fully translated into an English translation that she does not provide a translation for the reader. Fellow poet and Diné Luci Tapahonso, explains that "there are things that can be said in each [language] that cannot be said in other [languages]" (qtd. in Brill 136). In other words, some Diné words cannot accurately be expressed in English, and/or the potential translator resists the act of seeking those words, refusing translation: one of multiple gestures that together project survivance. Webster too claims that code switching allows the self to be reflected in the creative work, and that "we do not say something new, rather we insert ourselves into the implicated and entangled history of our language" ("Code switching" 2). ${ }^{37}$ The term "Hwéeldi" does, indeed, have an "entangled history"' as it represents a deep history of struggles with violence, loss, removal, and forceful relocation during the Navajo Long Walk (Hoover 182). Yes, Tohe can use the term and the reader can research it to understand what is meant by it; however, can the reader really understand why the phrase "Hwéeldi" is used? Meaning, even if Tohe had provided a translation for the term, which loosely means "a place of great suffering," could the reader even begin to understand the entangled history of such a term? Will the reader, unless he/she is Diné, understand the depth and emotions behind the term? In other words, perhaps Tohe's refusal to 
translate also generates a new meaning, a meaning that goes beyond any dictionary equivalent of the word.

When the Diné use the term "Hwéeldi," they are referencing an actual place. This place is called Bosque Redondo or Fort Sumner; however, regardless of the physical name of the place, the emotional/metaphorical name of the place is Hwéeldi. This phrase is tied to the numerous murders, rapes, beatings, starvings, and other abuses that happened in 1864, when 8,354 Diné were forced to walk from Dinetah to Bosque Redondo, in southern New Mexico, a distance of three-hundred miles. They were held there for four years until the U.S. government declared the assimilation attempt a failure. More than 2,500 Diné died of "smallpox and other illnesses, depression, severe weather conditions, and starvation" (Tapahonso 7). "Hwéeldi" displays the pain and suffering the Diné endured during their incarceration at Bosque Redondo; thus, it is considered a place of "great hardship," according to Tohe (qtd. in Webster "From" 540). This can be seen as she writes in her poem: "What made this earth red?...Is it all the trails we took upon ourselves or that were forced upon us, beginning with our blood trails to Hwéeldi and back?" (Tohe 3). The very image of "blood trails" provides a tone of significant loss and violence. She also uses the term "forced," which depicts a violent removal, not a peaceful relocation. On another level of her use of the term "Hwéeldi," in addition to promoting awareness and allies, she is also testifying: "look what we have been through, and yet, we are still here" (Cobb "The National" 502), as can be seen as she writes "to Hwéeldi and back. She also mentions that there are "trails" that "we took upon ourselves," which sends a message of sovereignty and power over their own history and existence.

By not providing a translation for "Hwéeldi," Tohe may be holding the meaning of the term sacred. What I mean by this is that she is not disclosing details of the forced removal to 
those that are not insiders. ${ }^{38}$ Though she shares the stories and voices of the Diné from the past throughout her poems, this term may only be able to be understood by one who is Diné, not an outsider to the Diné culture. ${ }^{39}$ An outsider can look on a map, and see the words "Bosque Redondo" and "Fort Sumner," but the Diné look at the same map and see "Hwéeldi." In the beginning of this chapter, I noted that the Diné do not typically share stories about the Navajo Long Walk because of its emotional and violent memories. Tohe explains that "one must carefully use thoughts and words, for they have great potential" ("Hwéeldi" 79). In this case, perhaps Tohe's actions suggest deferred translation for some readers; those who are ready to learn about it and don't already know can put in the effort to cross this most difficult of divides. Tohe further explains the reasons why the Diné tend to hold back stories of the forced relocation. She states:

I came to learn that this might have caused the People to withhold stories of the Long Walk; the pain and suffering the ancestors endured was so nearly unbearable that they named Fort Sumner, where they were starved, raped, exploited, and killed, Hweeldi: the place of extreme hardship where the Dine nearly took their last breath. The response to such death and violence was to not speak of it in any casual way. (79)

Although her book of poetry is in no way "casual," the poem is questioning why the earth is red, which is alluding to not only the beauty of the canyon, but also to the blood that stained and continues to stain the walls of the canyon from the Navajo Long Walk. Because of the questioning of why it is red, and the allusion to violence, perhaps she did not feel as though further details or a translation of the term was necessary. Regardless of Tohe's reasoning for not including a translation for the term, the use of it in her poem will spark an interest in the reader, 
which promotes awareness. She is teaching the reader, while also encouraging the reader to want to learn more, to do research to learn about the Navajo Long Walk, a significant event in the Diné culture. Tohe explains that knowing about the Navajo Long Walk is vital for all audiences, regardless of culture:

Although the Long Walk happened more than a hundred years ago, it is still with us. We must know what happened and we must remember. It is part of Dine history, as it is part of American history. The Long Walk, the Trail of Tears, the Dakota incarceration, and other death marches like it are part of America's holocaust, and each deserves a place within the larger story of America. To gloss over or to omit the costs of colonialism is an injustice, not only to those whose ancestors were imprisoned but to the future generations who will want to know the past. To speak of these injustices is a way to heal from these wounds. (82)

As Tohe states above, the Navajo Long Walk is not just a part of the Diné history; rather, it is also a part of the American history. Because of this, both audiences need to be included, need to learn, which is why Tohe uses both languages, Navajo and English, to teach the readers, both the Diné and the non-Diné. Through code switching, Tohe is not only giving visibility to past and contemporary Diné, but she also shows that the Diné have, and will continue to, resist erasure attempts.

To resist these erasure attempts and to assert the survival of the Diné, Tohe displays the Diné's past and present visibility and voice through her use of code switching and translation in her poetry to assert survival plus resistance, and to teach the reader about the Diné culture and language to promote alliance. Tohe "recovers... [losses] from the ravages of colonization" for 
her "land," her "languages," her "culture," and her "self-respect" (Lyons 449), while also promoting a dialogue between American Indians and non-American Indians. She is not only sharing a story, or the Diné language and culture, but rather an extended invitation to understand the Navajo Nation.

Oglala Lakota scholar Kimberli Lee, in her article "Heartspeak from the Spirit Songs of John Trudell, Keith Secola, and Robbie Robertson," makes the prudent assertion that: "For centuries Indigenous peoples in this hemisphere have raised powerful voices of resistance to the unjust treatment and outright genocide they have received at the hands of colonizers. This resistance has been, and continues to be, manifested through a variety of rhetorical venues: speeches, stories, poems, songs" (89). Tohe exemplifies this resistance, as well as survival, through her writing. Vizenor defines survivance as the active survival stories that subvert misnomers and misrepresentations about Indigenous people. Tohe uses her writing to divulge specific intricate details of Diné life and the land, which disrupts these misrepresentations. The details about Diné life, in all, reveal the survival of the Diné people, as well as their culture and language. Moreover, these details about Diné life unsettle common stereotypes about American Indians writ large. Through rhetorics of survivance, she brings to life a Diné identity, and not the identity supplanted by Westernized versions of the Diné people. This identity is visible from her giving voice to both past and present Diné, specifically past Diné from the Navajo Long Walk. American Indian scholar Grace Roybal explains that during the Navajo Long Walk, there were no records of the Diné, "the internees." There were no names, "only tallies" (Yurth "Hwéeldi at 150"). In other words, the Diné were voiceless, nameless, and faceless. In the eyes of the US government, they were not people. They were objects. 
Through her poetry, her storytelling, Tohe gives these "tallies" names, faces, and stories. She gives them a voice. They are surviving in her stories and through present-day Diné peoples. Denetdale argues that "Navajos will continue to be understood within Western categories of meaning that sustain colonialist discourses and serve to perpetuate ideas of dominance, hierarchy, and asymmetry" ("Reclaiming" 6). However, Tohe breaks apart these categories through her poetry, and disrupts the colonialist discourse. It is through her code switching and translation that she shows the survivance of the Diné, as she attempts to (re)claim and (re)tell Diné historical and present-day representations, disrupt misconceptions of the Diné way of life, and give voice to both past and present Diné whose stories need to be heard. Her writing intertwines narratives and languages from ancestral memories, histories and stories, as well as her own experiences, to produce new stories that also promote alliance, as she teaches the reader about past Diné, about present Diné, and about the Diné language and culture. Powell posits that "maybe, as allies, we can spur one another on to even more disruptive tactics. Maybe we can learn to take hold of one another and emerge at the beginning of a new story about ourselves, not a 'prime' narrative held together by the sameness of our beliefs, but a gathering of narratives designed to help us adapt and change as is necessary for our survival" ("Down" 57). It is not just the Diné's survival of which Tohe is concerned; she is also concerned about the reader's survival, a survival that will encourage allies through awareness, acceptance, and understanding. 


\section{CHAPTER IV: SUBVERTING ERASURE ATTEMPTS AND TRANSCENDING LIMITATIONS THROUGH TRICKSTER: (RE)WRITING HISTORY AND ATTAINING VOICE THROUGH TRICKSTER DISCOURSE AND THE COYOTESSE IN LAURA}

\section{TOHE'S NO PAROLE TODAY}

"You put me in your boarding school, made me learn your white man rule, be a fool." - Late Dakota performer and Indian activist Floyd Red Crow Westerman

Through her poetry and stories, Tohe gives voice and visibility to both historical and contemporary Diné people. This visibility is enacted through her use of the Diné language, as it is code switching that provides Tohe with a tool to re-tell history through rhetorics of survivance, as she teaches the reader (both Native and non-Native) about the Diné's surviving history, land, culture, beliefs and values. It is also through rhetorics of alliance that Tohe invites the reader to learn the Navajo language in order to promote awareness of the Diné's continued existence and language. In this chapter, I argue that Tohe, through her use of trickster discourse (code switching) and her engagement as a Coyotesse, brings visibility and voice to those who were

silenced, literally, by the dominant US government culture during the American Indian boarding school era. Tohe uses trickster discourse to tell the stories of those who were silenced, and to demonstrate that the American Indian boarding schools were unsuccessful erasure attempts, as she (re)writes, (re)rights and redefines the Diné history through her narratives and poetics.

\section{History of Boarding Schools}

In the early 1870 s, the US government began sending American Indian children to offreservation boarding schools. Following the removal and relocation of numerous American Indian Nations, a formalized American education system was used as the vehicle through which the American Indian peoples of North America could be assimilated. American political leaders 
created the boarding schools as a means to "civilize" the American Indian children. Army officer Richard Henry Pratt was at the forefront of this movement with his motto of "Kill the Indian, save the man." He based his views on an education program he had developed in an Indian prison, and described his philosophy in a speech he gave in 1892: "A great general has said that the only good Indian is a dead one...In a sense, I agree with the sentiment, but only in this: that all the Indian there is in the race should be dead. Kill the Indian in him, and save the man" (Bear). Pratt's goal was to change American Indian children into "white" members of society. In 1879, he established the most well-known off-reservation boarding school, the Carlisle Indian School in Carlisle, Pennsylvania. As Headmaster of the school for 25 years, he was the single most influential figure in American Indian education during his time. American Indian biographer, Barbara Landis explains that "Richard Henry Pratt, the architect of the offreservation boarding school movement, designed his school for utmost efficiency in order to transform Indian children from their perceived savagery into useful citizens- 'civilized' Indians who would champion European-American values such as progress, materialism, and Christianity" (124). The most well-known and pivotal boarding school for "civilizing" the American Indians, including the Diné, was the Carlisle Indian Industrial School in Pennsylvania. In the Report of the United States Bureau of Indian Affairs, the prominence of the Carlisle school is explained in the following excerpt: "Under the able management of Capt. R.H. Pratt this school has attracted wide attention, and has demonstrated to all who have examined it the practicability of Indian civilization. The arrangements for giving instruction in the various trades are more complete at Carlisle than at any other Government school" ("Report" LX111). Part of the "success" of this school was spurred from the curriculum, which privileged Western 
ideas and policies, and excluded and mocked Indigenous knowledge through reprimand, which included physical and emotional abuse.

The goal of American Indian boarding school education was to replace the indigenous identity with Western ideologies and Christian principles. However, some of the Diné families, including Diné leader Chief Manuelito, did not see the boarding school through this lens; instead, they viewed it as an opportunity to educate their children and "speak" the same language as the "whites." Manuelito is said to have told Diné Tribal Chairman Chee Dodge: "[The] Whites have many things which we Navajos need. But we cannot get them. It is as though the whites were in a grassy canyon and there they have wagons, plows, and plenty of food. We Navajos are up on a dry mesa. We can hear them talking but we cannot get to them. My grandchildren, education is the ladder. Tell our people to take it" (Denetdale "Reclaiming" 80). Many Diné followed Manuelito's advice and sent their children to Carlisle. Some went willingly, while others were forced to attend.

The educational policies at Carlisle were to "Americanize" the children. In Boarding School Blues: Revisiting American Indian Educational Experiences, Trafzer explains that "[Captain Richard Henry] Pratt convinced the federal government to fund the first school at the old army barracks at Carlisle, Pennsylvania. Drawing on the beliefs of past reformers, including Eaton, Pratt developed his own theory about Indian education while he directed the lives of American Indian prisoners of war at Fort Marion, Florida" (13). He was in charge of 72 Indian prisoners who had been fighting the US Army in the southern plains. Pratt transported these Cheyenne, Arapaho, Kiowa, Comanche and Caddo prisoners halfway across the continent to St. Augustine, Florida. Like the prisoners at Fort Marion, many American Indian children were 
taken from their families to attend boarding schools in order to learn to speak English and to practice Christianity.

In a paper given at the Nineteenth Annual Conference of Charities and Correction in 1892, Pratt wrote the following: "It is a great mistake to think the Indian is born an inevitable savage. He is born a blank, like all the rest of us. Left in the surroundings of savagery, he grows to possess a savage language, superstition and life. . Transfer the savage-born infant to the surroundings of civilization, and he will grow to possess a civilized language and habit ... The school at Carlisle is an attempt to do this" (qtd. in Prucha 268-9). To accomplish this shift into a "civilized language and habit," Pratt "established an educational system to isolate children from their families, cultures, and languages where white teachers could indoctrinate them into the nineteenth century American society and the English language" (Trafzer et al 13). Pratt was sure to separate the children from their "savage" environment on their reservations, away from their families, and place them in a controlled environment in an isolated institutional setting at which he could gradually integrate them "into the white world in a controlled fashion" (13). This controlled environment consisted of the children being treated like soldiers with extensive "discipline" and rules. Further, he not only changed their traditions, languages, food, and surroundings, but he also made them change their names from their American Indian-born name to Judeo-Christian names, such as "Mary" or "Esther" for girls and "David" or "Joseph" for boys (15). These changes were supposed to help the children to shift from their American Indian identities and into "white" identities that would be created through Pratt's civilizing process. Pratt even took "before and after" images of the students in order to sensationalize the kind of “civilizing" effect the institution had upon its students (Iverson 83). While some students embraced their newfound location and identity, most of the students at Carlisle missed their 
families, and fought against losing their traditions and language. However, the outward appearance of the students was inevitable, as the children were stripped of their clothes, blankets, and jewelry. Their hair was cut and they were bathed in pesticides to "kill the lice" (Trafzer et al 17). While the physical transformation of the children was swift, the inner deconstruction of the "American Indian" identity proved impossible (18); for, even though the children would be beaten if they spoke their parent-language, they would continue to hold on to their identity through their language. Because the children tried to desperately hold onto their cultures and languages, Pratt created the "outing system." By immersing American Indians into the mainstream of American life, the "outing" system had students living among white families during the summer, as he hoped the children would not return to the reservations but rather become part of the white community. This, in turn, would help with the "Indian problem."

While there were numerous boarding schools, some were on-reservation, meaning the US government created a "school” on an American Indian Nation's reservation, and some were offreservation, including Fort Defiance, Fort Wingate, Fort Apache and Chinle, as well as the Haskell Institute, a government-funded institution to help with conformity and assimilation. Between 1880 and 1902, 25 off-reservation boarding schools were built and 20,000 to 30,000 Native American children went through the system. That was roughly 10 percent of the total Indian population in 1900. By this time, 460 boarding and day schools had been built near the reservations, most run by religious organizations with government funds. All told, more than 100,000 American Indian children were forced by the US government to attend Christian schools where tribal languages and cultures were replaced by English and Christianity (“Indian"). In the Report of the United States Bureau of Indian Affairs, of 1886, John B. Riley stated: 
If it be admitted that education affords the true solution to the Indian problem, then it must be admitted that the boarding school is the very key to the situation. However excellent the day school may be, whatever the qualifications of the teacher, or however superior the facilities for instruction of the few short hours spent in the day school is, to a great extent, offset by the habits, scenes and surroundings at home - if a mere place to eat and live in can be called a home. Only by complete isolation of the Indian child from his savage antecedents can he be satisfactorily educated, and the extra expense attendant thereon is more than compensated by the thoroughness of the work. ("Report")

Part of the isolation the children experienced came in a form of assault on the American Indians' identities and included cutting the boys' braided hair, requiring the children to wear uniforms, abandoning traditional Native food practices and gender role expectations, and forbidding the children from speaking their Native languages. Before the children even entered the boarding schools, however, the isolation already began as they were torn from their homes and families. While the government viewed it as a solution to the "Indian problem," for tens of thousands of American Indian children and their families, it was a time of abuse and a desecration of their cultures. Some children were even forcibly taken through the use of armed police (Bear).

One of the American Indian Nations that were flagged to be "conquered" were the Diné, which were branded as subordinates by the US government and expected to integrate and adapt to the dominant American culture. Cultural assimilation, or rather a full cultural transformation, was the goal sought by federal government leaders who wrote and supported treaties that included compulsory education. These policies were implemented as part of American education by teachers and Christian groups. Teresa McCarty, a cultural ethnographer, explains that "in one of the first (unsuccessful) attempts to live up to the 1868 Navajo Treaty provisions for education, 
the Indian Bureau in 1882 opened a boarding school run by missionaries at Fort Defiance, the place where Navajo people had been incarcerated prior to the Long Walk... Disciplinary methods at Fort Defiance resembled those at other Federal Indian schools, and included solitary confinement and chaining students to their beds"(40). Many Diné parents documented the reports of abuse, and in turn, many Diné families refused to send their children to the boarding school in Fort Defiance. However, Indian agent Dana Shipley, the head of the Fort Defiance boarding school, was "determined to boost the meager totals of Navajos enrolled in school. He took Diné policemen with him on his recruitment outings, showing that he meant business" (Iverson 88). In response to these actions, in 1892 in Round Rock, the Diné fought against the boarding school, which resulted in violence against Shipley as he attempted to kidnap Diné children and haul them off to Fort Defiance in order to assimilate and "educate" them.

From the 1870 s to the 1950 s, Pratt's motto of "Kill the Indian, save the man" continued to embolden the use of boarding schools to assimilate American Indian peoples. Though the guise of the boarding schools was to "educate" the American Indian children to become "American," teaching them the language, the traditions, as well as the trades, such as carpentry for the men and housekeeping for the women, some argue that education was not at the forefront. Diné Lucy Toledo, who went to Sherman Institute in the 1950s, states that "It wasn't really about education," because students didn't learn basic concepts in math or English, such as parts of speech or grammar. She also remembers some disturbing free-time activities that the children were exposed to, as she explains that "Saturday night we had a movie... Do you know what the movie was about? Cowboys and Indians. Cowboys and Indians. Here we're getting all our people killed, and that's the kind of stuff they showed us" (Bear). From the upsetting movies depicting the American Indians being slaughtered for being "savage," to being stripped of their culture, 
language, food, clothing, hair, and traditions, the end goal was total transformation. Tsianina Lomawaima, head of the American Indian Studies program at the University of Arizona, argues that the intent was to completely transform the American Indian peoples, inside and out, from "language, religion, family structure, economics, the way you make a living, the way you express emotion, everything" (Bear). Lomawaima explains that the US government attempted to "erase and replace" the American Indian culture with the "American" culture, which was part of the larger strategy to "conquer" the American Indians.

At the beginning of this chapter, I emphasize the Carlisle Indian Industrial School because Tohe, in her No Parole Today (1999), speaks directly to Pratt through her letter in the introduction to her narrative. However, a majority of her emphases is on the government Day School on the Navajo Nation reservation and the Albuquerque Indian School in Albuquerque, New Mexico. The Albuquerque Indian School existed from 1886 until 1981. Near North Valley Neighborhood Association historian, Joe Sabatini, explains that "the Indian school was a boarding school where students lived in dormitories ... The primary occupational mission of the school was vocational agriculture" (Montoya). The school was under strict Catholic rule; however, there were various churches on the property. According to Sabatini, "Churches were built all around the school, of various denominations, for students and faculty. The Queen of Angels was Catholic (on Indian School Street on Pueblo property), Assemblies of God, Mormon, Baptist - all are churches that still exist!" (Montoya). Catholic rule was pervasive, however, and they employed a four-point educational plan for the American Indians. This plan included the following: remove from land, remove and ban culture, merge with the Anglo culture, and use a military regime to enforce assimilation (Montoya). The military-type requirements emphasized certain work clothes, blue and white uniforms, and marching from building to building. There 
were 40 different buildings on the campus including a childcare center, gymnasium and auditorium, arts and silversmith building, offices, dormitories, library, media center, and kitchen and dining hall. The different buildings also housed different American Indian peoples from varying nations, including mostly Pueblo, Diné, and Apache. Though the school's emphasis was on assimilating the American Indian students into the white, Euro-American society, the school "allowed tribal meetings" (Montoya). Some American Indian boarding schools allowed the students to maintain some connection to their culture; however, the boarding schools that mostly followed this sentiment were those considered to be on-reservation boarding schools.

The Day School in the Navajo Nation was considered an on-reservation boarding school, due to its close proximity to the Navajo Nation. The idea of day schools was derived from Commissioner of Indian Affairs (1933-1945) John Collier's “conviction that Indian education should be rooted in the community and should, in turn, stress the values of native culture" (McCarty 48). The Rough Rock School seemed to promote this ideal, as the school was "supposed to be a 'native,' barefoot setting. There was no furniture; the children brought sheepskins to sit upon" (48). While the idea of the on-reservation boarding school was to educate children while also allowing them to maintain a connection to their culture, the treatment of the students was poor, as there was inadequate food, and the children were occupied with doing manual labor, like scrubbing floors and doing laundry, as opposed to learning. Diné Ernest Dick recalls that in the 1960 s, when he was a young student at the school, he was allowed to go to his family only twice a year, and after this visit, he was "stripped" of his identity: "After we came back from home, they would shave your head, shave your hair off again and make sure you take a shower, all of that, you know. But these attendants were all Navajo. They were trained by BIA [Bureau of Indian Affairs] to have this type of a treatment. And we weren't allowed to talk 
Navajo" (49). Despite the location of the boarding schools, on-reservation or off-reservation, the overall goal was to limit connectedness to the students' many Native cultures, traditions, and languages, and to encourage a total transformation into the dominantly white, Euro-American society. While the various American Indian boarding schools attempted to eradicate many American Indian Nations, however, their efforts were not successful, and Tohe proclaims this in her work, No Parole Today.

\section{Tohe's No Parole Today}

In No Parole Today, Tohe speaks on the boarding school era as experienced by different generations of Diné peoples, including her grandmother and her own recollection of the boarding school experience in the 1950s and 1960s. She discloses how forced education at boarding schools shaped the Diné, as she includes poetry about the oppression in the Diné community because of the forced assimilation attempts, such as loss of language and loss of culture. Tohe shares stories about the boarding school experience by giving autonomy to the Diné boarding school survivors. Through these stories, in both her narratives and poetry, she reveals how the students struggle with learning the English language and with the forfeiture of the Diné culture and language. Tohe also demonstrates the (mis)representation of boarding schools as legitimate educational facilities and subverts the Westernized version of the Diné history; she (re)writes and "(re)rights" the Diné history by showing that the boarding schools were not successful attempts at erasure, as the Diné are still here, they never left.

Tohe uses the English language to tell important survival stories to educate both Diné and non-Diné readers. Tohe's writing demonstrates that the assimilation practices were futile, and to spread her message, she first targets Richard H. Pratt, the creator of the first American Indian boarding school, Carlisle. She chooses Pratt as her first target, as his goal was to "Kill the Indian, 
save the man." In Tohe's case, it was "Kill the Indian, save the woman," but she did not / does not succumb to Pratt's expectations of erasing her Diné identity. Boldly, she writes to Pratt at the beginning of her book, which sets the tone of ownership, the ownership of her own body, her own language, her own voice. She writes: "I voice this letter to you now because I speak for me, no longer invisible, and no longer relegated to the quiet margins of American culture, my tongue silenced. The land, the Diné, the Diné culture is how I define myself and my writing” (xii). By sharing the stories of the Diné survivors, including herself, Tohe uses trickster discourse to rewrite and (re)right the Diné history to emphasize that the Diné not only survived the experience, but also continue to thrive. She successfully (re)tells history through the experiences of boarding school survivors. She is able to do this through trickster discourse and her role as Coyotesse.

\section{Transcending Limitations Through the Many Embodiments of Trickster}

Before I argue that Tohe uses trickster discourse in her writing to (re)write and (re)right history and demonstrate survival of the Diné culture, it is first important to establish the complexities surrounding trickster's representations and purposes, especially in American Indian studies. Below, I will discuss a handful of American Indian trickster scholars' views on trickster in order to provide a well-rounded view and understanding of the complicated origins surrounding trickster. In his essay "Trickster: The Sacred Fool," Cherokee Jace Weaver explicates that trickster is an anthropological categorization,

an abstraction from particular embodiments in different cultures. In West Africa, it is Anansi the spider. For the Greeks and Romans, he was Hermes or Mercury. In northern Europe, numerous stories are told about the trickster Loki. Native Hawaiians know him as Maui. It is among the Native nations of the Americas, however, that Trickster plays his 
most important role, taking on many guises - Raven, Iktomi the spider, Wolverine, Rabbit, and the most familiar trickster of all, Coyote, among many others. (247)

As can be seen, trickster, in its ambiguity, has many definitions and many representations for each culture. Some cultures define trickster as male, others as female. ${ }^{40}$ Because of trickster's ambiguous attributes, there is ample scholarship investigating trickster's role in various cultures. In his work, The Trickster: A Study in American Indian Mythology (1956), Paul Radin, cultural anthropologist and folklorist specializing in Native American languages and cultures, studied particular Winnebago trickster myths. Radin preliminarily defines the North American Indian trickster as follows:

Trickster is at one and the same time creator and destroyer, giver and negator, he who dupes others and who is always duped himself. He wills nothing consciously. At all times he is constrained to behave as he does from impulses over which he has no control. He knows neither good nor evil yet he is responsible for both. He possesses no values, moral or social, is at the mercy of his passions and appetites, yet through his actions all values come into being. (xxiii)

While a pivotal work in trickster studies, Radin's work narrowly focuses on the Winnebago trickster in the context of the Winnebago culture; however, his discussion of trickster as one who "dupes others" is one that is applicable to tricksters writ large. In her 1975 article "“A Tolerated Margin of Mess': The Trickster and His Tales Reconsidered," American Indian trickster scholar Barbara Babcock-Abrahams, for example, examines theories of order and disorder, as she explores and analyzes trickster's cross-dressing, social and sexual transgression, sex change, and movement between isolation and community, low to high social status and back again. She labels 
trickster a "negation offering possibility" (182). She also asserts that a trickster "embodies the fundamental contradiction of our existence: the contradiction between individual and society, between freedom and constraint" (161). This is significant because American Indian authors are often writing on the border, ${ }^{41}$ between the dominant, white society and their Native nation; therefore, they are constantly confronted with contradictions from their environments. Because of this, tricksters in American Indian writing typically, according to Babcock-Abrahams, "tend to inhabit crossroads, open public places, doorways, and thresholds. [They] are usually situated between the social cosmos and the other world or chaos" (159). Within and throughout the chaos, the persistence of trickster helps us make sense of the world and its disorder. Ojibwe scholar Kimberly Blaeser argues that "trickster stories still have power: the power to bring us to laughter, the power to baffle us, the power to make us wonder and think and, like Trickster, just keep going on" (48). In line with the idea of confusion and chaos, in Trickster Makes This World: Mischief, Myth and Art (1998), Lewis Hyde calls trickster a "mischief maker" and a "boundary-crosser" (6-7). He also considers trickster to be the "mythic embodiment" of uncertainty, "doubleness," and inconsistency (7).

Unlike some of the aforementioned authors who focus on trickster's representations in one culture, American Indian scholar Franchot Ballinger provides several views of American Indian trickster in the nations of Cree, Cherokee, Nez Perce, Apache and Diné peoples. Since my dissertation chapter focuses specifically on trickster represented in Tohe's writing, my interest is strictly on Ballinger's discussion of the Diné trickster. Ballinger explains that in the Diné culture, telling trickster stories "can become an occasion for parodying behavior threatening to tribal values" (62). These parodies help to foreground and remind the youth of the Navajo Nation the values that the Diné privilege. Further, because trickster stories are grounded "solidly in tribal 
norms," the stories provide a space to reinforce cultural values and serve as a reminder of social responsibility (60). Professor Emeritus and Diné folklorist Barre Toelken explains that, within the Diné culture, telling a trickster tale can lead to an emphatic conversation about Diné values, language, and cultural history (Toelken and Scott 90). In the Diné culture, trickster tales are also considered to be "educative tools" (Toelken and Scott). Trickster, then, reflects culture, embodies the values of a particular culture, pushes these values to the extreme and as such, offers a way to view the structures of society.

\section{Trickster Discourse and Rhetorics}

As many American Indian authors have argued, some American Indians use the tactic of trickster in their writing, such as in their narratives and poetry. The various "roles" of trickster used to get lost in the lenses through which authors were approaching the trope of trickster in literary works. Kristina Fagan, for example, explains that "the trouble with the trickster archetype was assumed to be an inevitable part of Indigenous cultures, and so the criticism paid little attention to the historical and cultural specifics of why and how particular Indigenous writers were drawing on particular mythical figures" (3). In turn, the "“trickster' became the adjective, a label to put on Native humour, art, theatre and literature" (Fagan 7). As a result of this use, almost all rhetorical strategies used by American Indian writers were credited to the trickster, and so Indigenous writers are deprived of their agency because it appeared as if it is the "trickster [was] doing all work," and thus the trickster as a trope "[lost] its usefulness as a term of analysis" (9). However, American Indian scholars such as Oklahoma Creek-Cherokee Craig Womack argue, "we are trying to avoid the kind of literary work that has been so popular in our field in which people avoid historical research and base their criticism exclusively on tropes and symbols [such as the trickster]" ("A Single Decade" 7). As such, my focus of the trickster, in 
Tohe's writing is in the realm of trickster discourse and, more specifically, trickster rhetorics as based on the work of Gerald Vizenor and Malea Powell, wherein trickster discourse is a decolonizing approach that works subversively.

Vizenor explains that trickster is rooted in words. In rhetoric and literature, trickster can be used as a means of establishing voice and being heard in, and disrupting, the conventional discourse. For Vizenor, one way that American Indian writers can enter public discourse is the practice of trickster hermeneutics. Vizenor explains that "trickster hermeneutics is the interpretation of simulations in the literature of survivance, the ironies of descent and racialism, transmutation, third gender, and themes of transformation in oral tribal stories and written narratives" ("Manifest Manners" 15). Furthermore, "survivance stories are renunciations of dominance, detractions, obtrusions, the unbearable sentiments of tragedy, and the legacy of victimry" (Vizenor "Aesthetics" 1). This idea of trickster enabling survivance extends into the idea of disrupting certain expectations placed on the numerous American Indian Nations. Weaver explains that "trickster is a transgressor of boundaries and limits. He subverts expectations and disrupts social norms" (Vizenor "Manifest Manners" 257). As such, trickster rhetorics is the means by which to undo and destabilize a dominant discourse within which American Indian peoples exist as the hyperreal (Vizenor "Narrative Chance" 5). The "hyperreal Indian" is the result of white Americans fabricating what they envisage and expect an American Indian person to consist of. Such simulations of the hyperreal Indian are objectified and illusory representations, through such images as headdresses, feathers, or being placed in the past and/or absent. The mere existence of American Indian peoples, however, defies these constructions, as the trickster rejects such simulations and the hyperreal Indian. 
Malea Powell explains that for Vizenor to play trickster is "to use our knowledge of the language and structure that compose the narratives that bind us as instruments to cut away those same oppressive stories" ("Blood and Scholarship" 9). Essentially, trickster rhetorics break language down to see how it is creating meaning. Powell explains that

[t]he trickster is many things, and is no thing as well. Ambivalent, androgynous, antidefinitional, the trickster is slippery and constantly mutable...Trickster discourse is deflative; it exposes the lies we tell ourselves and, at the same time, exposes the necessity of those lies to our daily material existence... The trickster asks us to be fully conscious to the simple inconsistencies that inhabit our reality. ("Blood and Scholarship" 9)

Trickster rhetorics, then, examines the "reality" that has been created by Western narratives and has potential to "open space for counter-stories and resistance" (8). Powell defines trickster through the lens of rhetorics of survivance to mean that American Indians not only have their stories heard, are the central focus of their stories, but also denounce the crimes committed against them, their bodies, their children, and their lands. Also, in "Rhetorics of Survivance," Powell explains: "For Vizenor, and for myself, this means not only reimagining the possibilities for existence and ironic identity within Native communities, but also reimagining a scholarly relationship to writings by Indian peoples, one that hears the multiplicities in those writings and in the stories told about them" (401). As Vizenor and Powell assert, a significant tenet of survivance is the telling and retelling of stories. Stories allow American Indians to heal, as trickster rhetoric provides American Indian authors with a tool to counter the colonial impositions on the ways they use language and tell stories. 


\section{Another Layer of Trickster: Understanding the Power of Coyotesse}

It is not only through rhetoric that trickster can help to disrupt or (re)tell a story and demonstrative survivance; the author can also take on the role of trickster. This role of the female author is through the form of Coyotesse. Interestingly trickster scholars, as can be seen above, mostly define or identify trickster as male or without gender. Dunn, however, argues that women authors can be trickster, they are trickster and trickster gives them power. American Indian “women's power comes from and through home and hearth, our place in the natural world - its ritual center; its continuance of existence, rebirth and survival - not in reaction to any presumed powerlessness" (195). American Indian women then retain power through trickster tales and storytelling. Dunn explains: "We affirm our ancient place with our words and provide them in our continued existence, simply by telling the traditional stories. We therefore become tricksters at the crossroads. . . We become Coyotesse ... simply by re-telling the stories, we resist" (195). As Vizenor explains, trickster discourse provides a means to convey survivance; in this case, according to Dunn, trickster also allows for resistance. This resistance is against assimilation, appropriation, and erasure. In the face of adversity, according to Dunn, it is not a strong, virile male trickster, it is the Coyotesse, that "bushy tailed, non-conformist Indian feminist ... [who] pieces the tribe together again, given her power" (197). It is Coyotesse who must "venture into the darkness to bring back the knowledge to the tribe" (200). Coyotesse protects her tribe; she educates and saves her tribe.

Diné women, ${ }^{42}$ including Tohe, bring to life the Coyote trickster and other spiritual deities of the Diné in written form. Like cunning tricksters, these women use the English language as a mode of representing their traditional way of life, and they use the colonizer's language to subvert westernized representations of history. Dunn states, "Coyotesse is a feminist 
whether she accepts that label or not: by writing about women's experiences she takes on the cause. Her reworking of language makes her the trickster. She steals the fire, the fire being language, and makes it her-the tribe's — own. Because she walks tenuously between the spirit world and the ordinary world, she transcends both sacred and secular, becoming both sacred and secular" (Dunn 201). Tohe demonstrates her power as Coyotesse through her writing, as she speaks back against Pratt, demonstrating the survival of the Diné, despite the erasure attempts of the American Indian boarding school system.

\section{Speaking Back to Pratt, Reclaiming Voice and Language}

Tohe begins her book No Parole Today with a letter addressing Pratt's attempts to eradicate the many cultural practices and languages of American Indians. Tohe acknowledges that Pratt's army did effect the Diné, as she writes: "the assimilation policies you put in place to turn Indian people into civilized white American citizens, who would dress, worship, think, and hold the values of the dominant culture, still affect us today" (ix). She continues: "The most crippling legacy of boarding schools is the devastation of our native languages and culture. We are still trying to recover from that loss" (x). However, she strongly supports her previous statement with an assertion that he (Pratt) did not eradicate them or affect their loyalty to the Diné culture. She tells him, “I am a survivor, as my parents' and grandparents' generations were, of the legacy you established" (ix). She explains that she is a survivor because her greatgrandfather, Hoskie Thompson, made it, despite his "serving a sentence" in the boarding school. Tohe also gives homage to both survivors and non-survivors who endured boarding schools. She tells Pratt: "We are veterans of these institutions. While some of us survived these schools, others ran away or died trying. Some died from loneliness or from a broken heart" (ix). Her use of the phrase "veterans" depicts the survival of the Diné, and provides a tone of going to war or 
surviving a war, which is relative to the "war against Indians" during the 1800 s, as this led to the use of boarding schools. According to Tohe, some did survive the war and are still present. She also states that some "died trying” to escape, which demonstrates resistance against Pratt's ideology. This idea of escape is also extended in her description of the military-type regimen expected of the students:

At the Indian school, my life was measured and accounted for on a daily basis: roll call, nine-week work details, lights out at ten p.m., lights on at five a.m. Fences surrounded my life. Cement covered the earth beneath my feet. In first through third grade, I marched to my classroom with a John Philip Sousa march playing over the intercom, which was, of course apropos because you [Pratt] modeled Indian schools after the rigid military life in which you [Pratt] made a career. (ix)

Boarding schools were viewed by some as an assimilation attempt, a method to help the American Indians "fit" into society; however, Tohe disrupts this notion that the boarding school was an innocent "school"; she provides the reader with the reality that it was like a prison, the Diné were "prisoners of war." She provides this tone through her use of words "measured" and "accounted for" to describe her time at the school. She also paints a picture of a prison as she explains that she felt "cement" under her feet, "fences surrounded" her, and she "marched" to her classroom ("marched" is a term that is also relevant to the history and happenings of the Navajo Long Walk"). She also identifies the idea of "fences" or borders that prevented the students from physically leaving the school, while also being psychologically separated from their culture, as she explains that "assimilation made us feel ashamed for what we were, where we came from, how we spoke, our stories, our families, how we dressed, and for speaking our language" (x). It 
is through this narration that Tohe, as Coyotesse, identifies as a survivor, a person who has persevered through the legacy of assimilation or "Kill the Indian, Save the Man," and also gives voice to those who survived or perished while trying to survive.

Still speaking to Pratt, but also speaking to the reader, Tohe continues to explain how she is a survivor, beginning with her own experiences in boarding school during the 1950s. She explains that "outsiders" gave the Diné the name "Navajo." However, she rejects the colonized name and further states: "I prefer to call myself the name my ancestor gave us because I am trying to de-colonize myself' (x). This reflection on how she identifies seems to have begun during her boarding school years. This can be deduced because she tells the reader that she skipped the "Beginner class" and went straight to "First grade" because she was "one of the few students who could speak English, though Diné bizaad was [her] mother tongue" (x). While she identified with her Diné culture and language, she was able to speak English well enough to adapt to the boarding school's expectations to move her from "beginner" to "first grade," and with her ability to speak English came her ability to help her classmates. Tohe clarifies that she would "translate" language for her classmates. Her grandmother called her "hwiní'yu, being useful, because [she] translated for [her] classmates" (x). Even though Tohe is reflecting on her time in boarding school in the Introduction to her book, she is also showcasing her role as Coyotesse while in the boarding school. The school's goal was to eradicate anything related to the Diné's language and culture, yet Tohe maintained her connection to her Diné language, while using the English language to help her classmates because she wanted to help save them. She claims: "If I didn't help them, I felt I would be a participant in their punishment" (xi). Tohe, as trickster, was secretly disrupting the environment at the boarding school because she would continue to speak the Diné language "in private, far from the ears of the teachers" (xi). Tohe also 
asserts that "because [she] spoke two languages," reading "came easy" for her (xi). She makes it a point to "tell" Pratt that she spoke both languages, which goes against the goals of the boarding school, as well as the expectations of Western society. As Chicana scholar Gloria Anzaldúa asserts, "I will no longer be made to feel ashamed of existing. I will have my voice...I will overcome the tradition of silence" (59). Tohe was supposed to abandon the Diné language and adopt the English language; however, she uses both and as Coyotesse, or rather trickster, she is not silenced. Standing Rock Sioux Vine Deloria identifies trickster as a "transformer" by forming "order out of chaos" (25-26). Tohe's acting as a translator for her peers, continuing to speak the Diné language in private, and her efforts to speak both languages constituted her attempts at making order out of the chaos of boarding school life, as the assimilation attempts stripped identity and handed out harsh punishments. Her boldness, paired with her education and fluency with English, provide her with a tool to speak back to Pratt over 50 years after her boarding school experience, and with her ability to speak and write in English, as she tells Pratt: "we are still here. We have not vanished, gone away quietly into the sunset, or assimilated into mainstream culture the way you envisioned. At least some of us haven't. Those who chose assimilation we call apples - red on the outside, white on the inside" (xi). Her references to vanishing "quietly into the sunset" is in reference to American Indians being placed into the past via fugitive poses, ${ }^{43}$ a product of assimilation attempts. She also argues that assimilation was a choice as she declares that some "chose" assimilation. She, however, did not, and she lets Pratt and the reader know this: "Western culture has always been destructive to indigenous peoples," but "our grandmothers and grandfathers taught us to hold to our beliefs, religions, and languages. That is the way of survival for us" (xi). Her holding onto her beliefs and language not only 
helped her peers survive in the boarding school, but also helped her in her attempt to decolonize herself.

Most importantly, by using pronouns such as "I," "us," and "we," she is situating this narrative as first-person, her own narrative. Her decision to tell her story is poignant because women's narratives, including America Indian women's stories, are historically the first to be subjugated. ${ }^{44}$ Tohe transgresses these rules and unashamedly declares that the reader will only be provided with her point of view in this story; she is privileging the Indigenous woman, as she uses pronouns such as "I," "me," and "my," which tells the reader that this narrative is hers, not another's story. Tohe's rejection of the other perspective, or rather the colonial perspective, marks her defiance against the colonial imposition on her words and on her stories. She is controlling the story that is being told, the way that it is being told, and even who gets to speak in this story (notice, Pratt is "silenced" in her story). She is acting as Coyotesse, as the trickster exists in the spaces "between the real and the imagined, breaking down paradigms and binaries, and trickster discourse is the means by which to undo or rather subvert a dominant discourse" (Vizenor "Narrative Chance" 5). The dominant discourse is being silenced and her story is being told, and in turn, she tells the stories of both those that did and did not survive boarding schools. She is a survivor, and she tells Pratt that he was unsuccessful in his attempts to eradicate her, her people, and her culture:

I voice this letter to you now because I speak for me, no longer invisible and no longer relegated to the quiet margins of American culture, my tongue silenced. The land, the Diné, the Diné culture is how I define myself and my writing. That part of my identity was never drowned; it was never a hindrance but a strength. To write is powerful and 
even dangerous. To have no stories is to be an empty person. Writing is a way for me to claim my voice, my heritage, my stories, my culture, my people, and my history. (xii)

Tohe, as Coyotesse, attempted to make order out of chaos at the boarding school, and her above declaration also portrays her survival, physically, psychologically, and culturally. As Coyotesse, Tohe is able to avoid the expected role of the perpetual victim. Vizenor argues that American Indian stories, trickster stories of resistance and survivance, are eversions of tragic victimry (Vizenor "Fugitive" 29). Rebelling in the boarding school and writing back to Pratt is Tohe's aversion to victimry. She is not silenced. She is not a victim. She is a survivor, and she is telling her own stories.

\section{Trickster Fills the Silence}

Trickster allows for counter-stories; stories that challenge the Westernized version of history that misrepresents and/or silences American Indians. According to Tuhiwai Smith, "Indigenous people want to tell our own stories, write our own versions, in our own ways, for our own purposes. It is not simply about giving an oral account or a genealogical naming of the land and the events which raged over it, a very powerful need to give testimony to and restore a spirit, to bring back into existence a world fragmented and dying" (28). Further, in Ernest Stromberg's edited collection, American Indian Rhetorics of Survivance, Robin Derosa argues that the "use of the colonizer's tools by the colonized not only suggests a kind of resistance," but also suggests that the "position of power is itself dramatically unstable, able to be inhabited by those who supposedly, by definition, are excluded from its space" (192). This idea of using the colonizer's tools as resistance can be seen in Tohe's narrative, beginning with the title, as she demonstrates her focus on being silenced; however, simply by writing this narrative and the poems within it, she is not silent. Tohe explains that the students were silenced; they were not 
allowed to speak "the language of their ancestors," as the government's "policy meant to assimilate [them] into the white way of life...the taking of [their] language was a priority" (2). Tohe also reflects on how students were taught the English language by using Dick and Jane books, reading and phonic practice books created by Zerna A. Sharp and William S. Gray in the 1930s. She writes, "In the first grade we received the first of our Dick and Jane books that introduced us to the white man's world through Father, Mother, Dick, Jane, Puff and Spot. These and other characters said and did what we thought all white people did: drive cars to the farm, drain maple juice from trees, and say oh, oh, oh, a lot" (3). By recounting the characters in the Dick and Jane books, Tohe provides the reader with an idea of what the Euro-American stereotypes were during that time period; however, the reality is that the Euro-Americans the students in the boarding school saw were not like this. They promoted assimilation.

While these Dick and Jane readers were meant to help assimilate the American Indian students, through both character representations (how they "should" act) and language (using the English language), Tohe subverts the narrative of Dick and Jane. She creates her own version, using the colonizer's tool of Dick and Jane. She titles her parody, "Dick and Jane Subdue the Diné" (2). She begins her poem with a similar format as the Dick and Jane books: "See father. / See mother. / See Dick run." However, she then shifts into her own version: "See Eugene speak Diné. / See Juanita answer him. / oh, oh, oh/ See teacher frown. / uh oh, uh oh" (2). Tohe uses the format from the Dick and Jane readers to develop the story of Eugene, Juanita and the teacher. Then, instead of having characters that receive rewards for their actions, Juanita and Eugene are punished for their actions, for speaking Diné: "See Eugene with red hands, shape of ruler... / See Eugene cry. / oh, oh, oh/ see Juanita stand in corner, see tears fall down face" (3). The teacher "frowns," Eugene "cries," and Juanita stands "in the corner" as "tears fall down 
[her] face." What is also significant in this version of Tohe's Dick and Jane is that she uses the same cadence as a person would "expect" an American Indian to speak with missing words, such as broken English: "Juanita stand in corner" (instead of Juanita "stands" in "the" corner) and "tears fall down face" (instead of tears fall down "her" face). She not only disrupts a colonial narrative with her own "Indianized" version, while making fun of the expectations placed on how American Indians speak, but she also takes a snapshot of the time period for the reader, in terms of the punishment the students faced for speaking their native language. While she is doing this, however, the students' resistance shines through as Juanita and Eugene had to have "disobeyed," or rather resisted, the rules against speaking their Native language in order to have received this punishment.

Coming back to the idea of being silenced, Tohe's version of the Dick and Jane readers provides the reader with a more precise representation of the assimilation practices and intentions of the majority of the Euro-American communities during that time period, specifically at the boarding school. The students were not just "taught" the English language; they were punished if they spoke anything other than the English language. So, if they did not speak the English language, they were forced into silence for fear of punishment. Further, these experiences of many American Indian people, which Tohe portrays in her narrative and versions of the Dick and Jane readers, were silenced because the American Indian versions of history were not presented to the American public. ${ }^{45}$ Tohe, however, shares their stories, her stories, through her version of the Dick and Jane reader. One of the rhetorical tactics often credited for the success of American Indian rhetorics of survivance to intervene in dominant discourses is trickster discourse. Vizenor explains that "the trick, in seven words, is to elude historicism, racial representations, and remain historical" ("Trickster of Liberty" xi). She tells of Eugene's and 
Juanita's experiences and instead of being silenced, she reveals their stories using the rhetorical tools given to her by the colonizer. To elaborate, American Indian scholar Ernest Stromberg argues that trickster narratives interrupt discourses of power by "discovering and applying" the dominant culture's "available means of persuasion" and "establishing a measure of identification with their white audience... [and assuming their] language, styles, and beliefs...in order to establish a degree of consubstantiality" (5-6). The goal of her version of the Dick and Jane readers, in her poem, is to provide a counter-narrative that rejects the imposed representations of both the Euro-Americans and the Diné, reclaims the Diné students' stories, and eludes the Westernized version of colonial history. Tohe demonstrates this elusion by continuing her version of the Dick and Jane reader with the following: "Oh see us draw pictures / of brown horses under blue clouds / We color eyes black, hair black. / We draw ears and leave out mouth" (3). Not only is Tohe writing a counter-narrative to the Western training tool of Dick and Jane, she also demonstrates that the students were resisting by using writing to "speak." By writing "we draw ears and leave out mouth," Tohe shows that the students were aware of this silence. She, however, again speaks back by disrupting the Dick and Jane narrative, while explaining to the reader: "Utter one word of Diné and the government made sure our tongues were drowned in the murky water of assimilation" (3). She, however, does not drown and is not silenced, as her counter-narrative depicts her survival, the Diné's survival.

\section{Trickster Breaks the Silence}

While Tohe, as Coyotesse, filled the silence that was impinged upon the Diné students with her counter-narrative of the Dick and Jane reader, she also breaks the silence that the teachers imposed on the students when intentionally misnaming them. She does this through her poem "The Names." In this poem, she focuses on the place of the classroom as a colonized space 
that literally silences the students through the teacher's actions. In her poem, Tohe paints a picture of a classroom during the boarding school era, as the teacher is taking roll call. The teacher mispronounces the students' names, specifically the names that are associated with the Diné culture and language. The teacher's mispronunciations cause the students anguish, as Tohe uses words like "winces," "puzzled expression," "tense up," "start to sink," and "dread" to show the students' reactions to hearing their names being westernized and bungled (4). Tohe asserts that one student, Virginia, "never corrects the teachers," which shows that most of the teachers mispronounce her name, yet she stays silent. Further, Leonard too is silent as he "never asks questions" when his name is misread. He also never answers during roll call, he has "no voice"; so, he only raises his hand (4). Tohe, herself, explains that she "tensed up" when waiting to hear the teacher call her name. While she depicts the students' reactions to hearing their names being distorted, she also demonstrates the teacher's lack of knowledge in terms of the Diné names and her lack of care about the Diné language and culture. The teacher's intentional ignorance (I say "intentional" because it is obvious the teacher did not learn about the Diné culture before working with Diné students, nor did she take the time to ask how to pronounce the students' names) causes the students to feel powerless, to be literally silenced out of shame. The students are not only silenced from shame, as can be seen through their reactions to the teacher's mispronunciations, but they are also muted because the teacher does not allow for dialogue, only the teacher is speaking.

To break this silence, Tohe, as Coyotesse, educates the teacher through her poem. When the teacher calls Virginia by the wrong name, "Virginia Spears," Tohe interjects with a response to the teacher, as she writes the following: "Her name is Speans" (4). She gives Virginia her name back. She then gives an example of a name that the teacher botches, as she writes "Leonard 
T-sosie." Again, Tohe corrects the teacher (and the reader) by writing, "(His name is Tsosie). Silent first letter as in ptomaine, / Ptolemy" (4). For this example, Tohe not only gives the student his name back, but she also showcases her knowledge of western science through her mention of "ptomaine" and her awareness of the Greco author, "Ptolemy." Further, when the teacher asks Mary Lou Yazzy if she is related to Thomas Yazzy, Tohe rejects this assumption by explaining that "Yazzie is a common Navajo name, like Smith or Jones" (4). She also notes that the teacher begins to rhyme Mary Lou's name with "jazzy and snazzy" (4). This rhyming undermines Mary Lou's name to a sing-songey “thing," not a name of a person. With her rhyming, the teacher objectifies Mary Lou by reducing her name to words that rhyme with it, and she subjugates her by having control of her name and yet choosing to toy with it and play with its meaning. Diné naming, such as personal name and placenames, are derived from meanings within the Diné culture; they are significant. ${ }^{46}$ The teacher's intentional mispronunciation and mockery of the students' names undermines the sacredness of this naming and these placenames. Tohe, however, takes back ownership of their names by giving an explanation for each name: “Tohe, from T'óhii, means Towards Water. / Tsosie. Ts'ósí means Slender. / And Yazzie, from Yázhí, means Beloved Little One/Son" (5). With these explanations, Tohe not only gives the derivative for each Diné name, but also their meanings. By the teacher westernizing their names, the original meanings of the Diné words are ignored. Also, when the teacher misrepresents the names, through her uttering, shorthand, and rhyming, the students' names become incomprehensible, they are simply sounds, not names. Tohe, with her interjections, turns those inaudible sounds into the students' names, she gives them back the ownership of their namesake. Further, at the beginning of her poem, she demonstrates how the boarding school system gave the students" Euro-American names ${ }^{47}$ such as "Jackie" and "Grace"; she also depicts the 
students' English nicknames, such as "Cherry" and "Doughnut." ${ }^{48}$ These names, however, are also the first names of the students. Tohe then ends her poem with the students' last names, their Diné names and identifiers, with the correct spelling and punctuation for correct articulation: "Roanhorse, Fasthorse, Bluehorse, Yellowhorse, Begay, Deswood, Niilwod, Chee, 'Átsidí, Tapahonso, Háábaah, Hastiin Nééz” (5). By beginning the poem with the Euro-American-given names and then ending her poem with their Diné names, Tohe is showing not only resistance, but also survivance. Regardless of where the students "began" in the beginning of the poem, and after enduring lack of respect and ignorance from the teacher, their names remain rooted in the Diné culture. Though the teacher debases them to being mere check marks - as Tohe explains "we are little check marks besides our names" - Tohe's ending with their Diné last names gives her and the students the last word (5). She gives them their identity back.

In Mixedblood Messages: Literature, Film, Family, Place, Choctaw, Cherokee, IrishAmerican Louis Owens states that trickster rhetoric liberates "Indianness" in all its manifestations, as "the role of trickster is to dismember all constructions that impose definitions and limit possibilities" (86). The classroom, in the sense of the teacher's power, is a colonized space and the students are on the border between their identity and the identity that the teacher imposes on them. In Borderlands/La Frontera: The New Mestiza, Anzaldúa describes the borderlands as rupturing spaces where time, history, and peoples collide. To live in the borderlands is recognizing that in this space you are "at home, a stranger" (216). To live in the borderlands means that our bodies are the battlefields, and we are always fighting back (216). Tohe, as Coyotesse, brings back the identity of the students by interjecting corrections throughout the poem, redirecting the teacher's power over the students by controlling and distorting their names. She fights back. 


\section{Physical, "Real," Tricksters}

In addition to Tohe acting as Coyotesse, she also mentions the nickname "wabbit" in the beginning of her poem. Since Tohe is Coyotesse, fighting back against the colonial powers in the classroom, the use of the nickname "wabbit" adds an interesting dimension to her trickery, as "Wabbit" may be a reference to the trickster rabbit. Rabbit is a known trickster in Cherokee and Creek folklore, ${ }^{49}$ and is sometimes used in Diné cultural stories. Tohe writes "Wabbit" which can be a play on a more contemporary rabbit, Bugs Bunny (as the loveable "wascally-wabbit"), or a reference to African American trickster Brer Rabbit. ${ }^{50}$ According to the Director of Syracuse University's pop-culture program, Robert Thompson, "If you want to teach Folklore 101, and you need an example of a Trickster, Bugs Bunny is it ... He defies authority. He goes against the rules. But he does it in a way that's often lovable, and that often results in good things for the culture at large" (Sutherland). ${ }^{51}$ Further, Brer Rabbit, similar to Bugs Bunny, possesses great cunning and wit. ${ }^{52}$ Tohe defies the teacher's authority in her poem, as she corrects the teacher's pronunciations of the students' names and her actions help the students to reclaim their power in a colonized space, thus "resulting in good things" for the Diné students. Regardless, trickster rabbit is known to trick an opponent by mimicking her adversary or rather putting words in the adversary's mouth. She may not insert words into the teacher's mouth, but she does interject in the teacher's story in her poem, as well as use parenthesis to act as an aside, while the teacher is "speaking." Since the boarding school classroom acts as a colonizing space, the relationships between colonizer and colonized are clear: Tohe and her peers are the colonized and the teacher is the colonizer; in other words, one dominates the other. In regards to trickster, while rabbit is small (like the students, such as younger and powerless), rabbit is always able to out-trick the predator of trickster coyote ${ }^{53}$ (coyote, in this instance, would be represented by the teacher). Also 
important to consider is that rabbit, as trickster, is known as the defender of truth and justice, as well as acts as a nostalgic reminder for tradition (Ballinger 44, 81). Tohe, in this case, is acting as both. She defends the truth by defending the significance of the Diné names amidst the teacher's jests, and she reminds the reader of the placement of names within traditional Diné culture. ${ }^{54}$ So, while Tohe is Coyotesse, she also places a known trickster, rabbit, in her poem to add to the understanding that she is attempting to disrupt the colonial space that the teacher created and shift the power dimensions in the classroom; she does not do this to overtake the classroom space. The power of her writings resides in her insistence that readers understand the historical record that she is trying to correct, and that readers see how dominant discourses tried to erase the significance of Diné culture, its naming practices, and so on. In a sense, she is rewriting history through her poems.

The continuation of the separation between languages (seen from the rift between the teacher and the students in the above example), continues into Tohe's poem "Sometimes Those Pueblo Men Can Sure Be Coyotes." While Tohe used "wabbit" (trickster rabbit) to show the distance between the students' and the teacher in naming, as discussed above, she uses coyote in "Sometimes Those Pueblo Men Can Sure be Coyotes," to serve as a tool with which she gives a message about the boarding school experience and the emphasis on language. As discussed in the beginning of this chapter, the goal of American Indian boarding schools was to push assimilation practices, and one goal was to eradicate the usage of American Indian languages, including the Diné's Navajo language. In her poem, however, the use of the Navajo language is used as a tool for trickery. The poem sets the scene of two, young Diné women who need a ride back to their dorms after staying late at school. They call for a ride, and are picked up by a "Pueblo man," named Mister Kayate, in the “'G-car,' government car." During the ride, the girls 
engage in girl talk, discussing how they had the "best looking Pueblo man" driving them. They use the Navajo language in order to speak in code, a secret way of talking about the man's attractiveness without his knowledge. Tohe provides the reader with both the girls' conversation and the English translations for the dialogue: “Éí hastiin ayóo baa dzólní' this man is very handsome / Éí laa' I agree" (16). They also discuss his marital status, if he has children, and so on, all the while assuming that the man could not understand the Navajo language.$^{55}$ However, when they get back to the Indian School, they realize otherwise. The man says, "A'héhee' at'éke...thank you, girls" (17). The girls "stumbled" out of the car in embarrassment. It is then that the girls view him as "Pueblo coyote," as opposed to his previous descriptor of a "Pueblo man." He shifted from being viewed as a man to being seen as a trickster. While his secretive knowledge of the Navajo language could earn him that title, as the girls were not aware of his knowledge and he stayed quiet until their departure, the fact that he does speak the Navajo language is even more significant, and his being trickster, or rather Coyote, makes the reader aware of this significance.

Coyote, also known as Ma'ii in Diné stories ${ }^{56}$ is a significant trickster in the Diné culture. Diné scholar and folklorist Barre Toelken explains that coyote provides comic relief for the Diné; however, the humor also has undertones of critical views of society. He states that in laughing at Coyote, the Diné are able to enjoy "vicarious experiences with taboos, disorder, or defective morality" (389). Coyote is also known to be contradictory, ambiguous, and complex, as the coyote trickster engages in "enlargement of social boundaries in expanding the limits to what is possible and allowable as well as defying (as in limiting) the boundaries of the acceptable... [and] defying and confusing social rules and expectations such as the rules of hospitality or socially determined expectations" (Ballinger 68). In other words, Coyote attempts to bring 
awareness of society's inconsistencies and arbitrary expectations. Because of Coyote's ability to defy "socially determined expectations," he/she is then able to allow the reader to see particular problematic aspects of society; for example, "on the North American continent, especially in the West, Wolf (or some other elder brother of Coyote) creates a utopian world, but Coyote transforms it into a human world; that is, he 'transforms the natural order into a cultural one"” (Ballinger 68). So, not only could the Pueblo man (now, the Pueblo trickster) understand the girls as they were speaking, but he could understand the language that they were using; according to social expectations, however, during the boarding school era, he should not have understood the Navajo language, and that is what the girls made sense of in the colonized space of the boarding school environment. Further significant is that he understood the Navajo language, and likely his own, despite the federal government's attempts at eradicating all American Indian languages. This is also poignant because Mr. Kayate worked for the boarding school, the very system that was constructed to decisively eliminate American Indian cultures and languages. Not only was trickster in the space of the car with the girls, but also in the colonized space of the boarding school, as he was not expected to acknowledge his language, let alone another Nation's language. Weaver posits that it is necessary for trickster to "cross the line" in order to subvert expectations and disrupt social norms (257). Trickster's disruption of society's norms is not to cause undue emotion or strife, but to encourage acknowledgement of a society's oppressive nature. Mr. Kayate's surprise for the girls (understanding their language), as well as his retention of an American Indian language (maybe even languages, as he may still have his Pueblo language retained) is his disruption, or rather his quiet resistance as trickster. Moreover, his language abilities "encourage acknowledgement" of society's oppressive nature; in this case, it is the oppressive nature of the colonized space of the boarding school. 


\section{Tohe as Coyotesse, Again}

Above, I focused on Mr. Kayate as trickster in the narrative, as Tohe titles him as such in the beginning of her poem, "Sometimes those Pueblo men can sure be coyotes" (Tohe 16). However, Tohe too is trickster, as she keeps the focus on the Pueblo man as trickster, but she also focuses on the Diné girls. Tohe assumes her role as Coyotesse and uses her poem to speak directly to the reader through the characters of the girls who also represent trickster, or rather coyote. Through the characters of the girls, Tohe demonstrates how they struggle for humanity during the boarding school era. The girls were in an environment that attempted to shape them into a particular model of assimilation, such as promoting the abandonment of their cultures and languages; however, the girls still find a way to not only withhold their Navajo language, but they have also learned to acclimate into an environment that is both hostile in its punishments for speaking an American Indian language, and an environment that is modeled after a military camp. The girls are stuck between two worlds: the environment of the boarding school and their desire to be "normal" teenagers, not the oppressed "Diné" teenagers. Trickster lives between binaries, pushes certainty toward absurdity, and act as a "mediator who breaks down any hard and fast distinctions" (Blaeser 51). Despite the obstacles the girls face, they break these distinctions. They maintain their innocence, as they were "secretly pleased" with Mr. Kayate's handsomeness, and their "enthusiasm" was "running away with [them]" (Tohe 16). They were also "saying those things adolescent girls say" (16). Not only were the girls acting like "normal" teenage girls, but they were also acting as trickster through the use of their Navajo language. They spoke the Navajo language despite the colonized environment and despite the man's connections to the boarding school. Through their dialogue, there are resisting the colonized space of the boarding school. The girls also assumed Mr. Kayate could not speak the language of 
the Diné, as they "were making all kinds of comments about him in Diné...not even thinking he might understand [them]" (16-17). This could be social commentary that he would not understand them not because he is Pueblo, but because he worked for the boarding school, and the goal of the boarding school was to promote the English language.

With this example, Tohe is "teaching" the reader about the assumptions surrounding American Indians, and how they are usually false. The lessons trickster encourages the reader to learn are often moral ones, where the trickster teaches by doing what is not acceptable and displays the taboos of the culture (Smith, J. 60). Further, Kimberly Blaeser asserts, "Perhaps the most frequently noted purpose of trickster tales is their teaching dynamic. Obviously lessons are conveyed through the stories by example: Trickster learns lessons the hard way, we work to learn them the easy way, vicariously" (55). Thus, the teaching dynamic works both to explain a specific cultural outlook while also defining how the community should act within this outlook. This can be seen as the girls assumed the driver could not understand them, and also how the boarding school assumed he would not use or acknowledge his language. Tohe challenges expectations by making Mr. Kayate a competent Navajo-language speaker, and so she challenges any naive view of the Navajo language as only being spoken by the Diné. Tohe, as Coyotesse, teaches the reader that any person can learn any language; for example, the man was Pueblo, but he understood the language of the Diné, and likely English, as he worked at the boarding school. His ability to understand multiple languages is part of his resistance as trickster; for, when a person has access to more than one language, it allows him/her to cross boundaries, like the Coyote trickster. ${ }^{57}$ Tohe not only shows the reader this through her narrative surrounding Mr. Kayate, but also through her use of both the English language and the Navajo language in her writing. Tohe includes the Navajo language in this poem to deliver the girls' specific discourse. 
Tohe does not permit the dialogue to be silenced by only telling the story in the English language. Unlike the students' silence in her poem "The Names," Tohe gives voice to the narrator, Rena, and to the Pueblo driver by including their dialogue in their Navajo language. They are not muted, and it is through trickster discourse, or rather the insertion of the Navajo language into the narrative, that they are heard.

\section{Trickster Discourse: Speaking Back, Literally}

Code switching, or shifting between two languages, is considered to be a part of trickster discourse, as Owens explains that code switching is a trickster sign (109). Powell defines trickster rhetorics as a part of survivance in which American Indians not only have their stories heard, are the central focus of their stories, but also denounce the crimes committed against them, their bodies, their children, and their lands. Trickster discourse, then, is a decolonizing strategy that can be used to "open space for counter-stories and resistance" (Powell "Blood and Scholarship" 8). Just as Mr. Kayate and the girls used the Navajo language as means of resistance in the above-discussed poem, Tohe, as Coyotesse, too uses the Navajo language as a trickster strategy through her code switching. Interestingly, Tohe engages in code switching mostly when using dialogue in her writing and when her grandmother is speaking / telling stories. This is significant as Tohe's code switching, or rather, her engagement in trickster rhetorics demonstrates a refusal to be silenced and a refusal to be bound by rules on how to tell one's story, both of which connect to dialogue and storytelling.

In the story "So I Blow Smoke in Her Face," a girl named Vida tells the reader that her family owns horses and that she likes to ride them as much as possible. She often goes riding with her cousin, Viv, who is like her sister because "according to Diné kinship beliefs, [they’re] sisters because [their] mothers are sisters" (26). When Vida and her cousin, Viv, go riding one 
afternoon, Vida's uncle warns her that she will tire out her horse, and he claims, "Your mother won't like it" (26). Vida then tells the reader that her mother, "the matriarch, is his older sister who inherited the homesite and most of the cattle and horses from her mother, as it is in the Diné tradition for daughters to inherit the family's land and property" (26). The narrative then switches to the environment of the boarding school, as Vida tells the reader that the nickname Wishbone, which some of the girls at school call her, is not as bad as some of the names given to her by the boarding school: "troublemaker, incorrigible, dumb Indian" (26). The girls want the company of "the wilderness," and so they have a driver drive them "up and down Central," and when they "drive down Fourth," the narrator tells the driver to let them out of the car. The driver does not want to, but the narrator tells the driver that they are "government property," and the car door opens (27). Vida has a crush on a boy named Edgar and so the girls go to Edgar's dorm. Vida gets caught and when the head matron, Mrs. Harry, who is American Indian, is "ready to tell her off," Vida blows smoke in her face from her cigarette. The narrative ends with Vida being back on her mother's farm, riding her favorite horse. Overall, the tone of the narrative is resistance; the narrator, Vida, is resisting the boarding school, as she fights against the school's assimilation practices: she smokes, she does not follow the "military rules," and she yearns for her home, as she thinks about her horses, "the smell of sage after a summer rain," and her mom's "warm, round tortillas" (29). However, it is not just Vida's actions that depict resistance; the students speaking the language of the Diné is also resistance.

Since the Diné students are in the boarding school, they are expected to speak English and abandon the Navajo language. However, like trickster, they wear a mask, one that they show in front of the Euro-American workers. That mask speaks English, using words like "Okay" (28). However, when they are alone, with no boarding school workers around them, they speak the 
language of the Diné. Tohe only code switches in the story when using dialogue between the Diné students. This can first be seen when Vida greets Edgar and his cousin: "Oh, hi Jasper. Edgar hágo bidini" (27). ${ }^{58}$ Then, when Vida, Edgar and Viv are discussing the duties assigned to them at the boarding school, Edgar mentions that he had "kitchen detail," to which Viv asks, “Hát'ílánaaddeidaq? Was it bear meat again?" (27). Both of these instances of speaking the Navajo language are during time of rebellion or resistance. Vida and her cousin were not supposed to be in the boys' dorm, and when discussing the food, they are making fun of the "white people's food," as they say that it is either "salisbury steak or roast beef...known as bear meat and rubber meat, respectively" (27). Vida wants her mother's "warm tortillas."

The next examples of dialogue are also during a time of resistance, as Vida gets into trouble for visiting Edgar. When the girls reach his dorm, he teases that Mrs. Harry will catch the girls. He says, "Nihíma nicháa 'ha'dooshkeel” (28). Vida then tells Edgar, “'Éi laa'. She's had it in for me ever since I got back late from Christmas vacation" (28). Vida was not supposed to stay "late" while at home, she was supposed to get back to the boarding school, but she was late coming back. She did not want to return. It is poignant to consider that not only was the dialogue used when the Euro-American workers were not around, and that the dialogue was used during times of rebellion and resistance against the government's assimilation practices in the boarding school, but also that Vida does not speak to those in authority over her, namely Mrs. Harry; instead, she blows smoke in her face. She silences Mrs. Harry; she stops her from speaking. So, not only were the students speaking the Navajo language in the colonial space of the government boarding school, but Vida stops Mrs. Harry from speaking English. This is different from the students' reaction in her poem "The Names," as the Diné students were muted by the white, Euro-American teacher. This time, however, the white, Euro-American teacher is silenced by the 
Diné student. Through trickster rhetorics, the power has shifted. Not only has the power shifted, but by code switching, Tohe is giving the students' story and not the teacher's, or rather, not the privileged story and language of the oppressor. Her storytelling ensures her survival, or rather the Diné's survival, through their stories, as their survival is co-dependent on their language; thus, her use of trickster rhetorics to protect and ensure her story is heard is an act of survivance: a survivance of stories, Diné peoples, and lands.

The survivance of the Diné is important to note because of the immense amount of effort that the boarding school exacted in order to assimilate them. For instance, in the narrative "Christianity Hopping," the narrator explains that the Diné students were exposed to various religions at the boarding school. Each day was a different experience with religion: Catholic, Presbyterian, Mormon, and so on. All of which the students made fun of and mocked. One example of this is as follows: "On Sunday mornings we were Presbyterian so we could drink coffee and eat Oreo cookies. Sunday evenings we were Christian Reformed because it was the farthest away from the dorm...Mormons don't drink coffee so we reserved Wednesday afternoons to be Gáamalíi, Mormon" (11). What is interesting about this example is that the students were the ones being forced to assimilate into the Euro-American-fueled customs and take on fake personas, forcibly abandoning their cultures and languages, however, the students were the ones playing the roles of the assimilators by mocking the religions. This can be seen through their roleplaying signifiers, such as "we were Presbyterian," and "we were Christian Reformed," and "we reserved Wednesday to be...Mormon." Further, they gave the religions names in Diné. "Gáamalíí" was used for Mormon, and "Ééneíshoodíi" or "sweeping robes," as they called them, for Catholics. This is significant as the Diné, and other American Indian nations were given names by the boarding school, as can be seen in Tohe's poem "The Names"; 
yet, in this instance, the students are naming the assimilators' religions. The students are not only engaging in trickster rhetoric by speaking the Navajo language, but also acting as trickster, as tricksters "challenge the status quo and disrupt perceived boundaries ... tricksters face the monstrous, transforming the chaotic to create new worlds and new cultures" (Smith, J. 2). The religions can be seen as monstrous because the students are being forced to learn a religion that is different from their own; so, out of resistance, they "transform" the society, in which they are being held in order to assimilate, through their mocking and naming.

While the trickster discourse used throughout the use of dialogue and during the discussions of religion displays Tohe's engagement in trickster rhetorics and depictions of resistance, the emphasis on the past, more specifically, on the idea of the maternal "grandmother" is also evident in her narratives. The emphasis on the past, and more specifically, on "grandmother," can too be seen in "Christianity Hopping." One day when the students leave the boarding school for the day, they leave on a yellow school bus that "chugged at fifty miles per hour top speed" (11). The students are joking about how old the school bus is when one student says, "our grandmother sat in the back of the bus while her tsilyéél, hair bun, bobbed up and down" (11). Tohe, as Coyotesse, engages in trickster rhetoric through her code switch from the Navajo language to the English language, specifically for the term "tsiíyéel," which is translated as "hair bun" in English. Tohe provides the reader with the English translation, but most noteworthy is her code switch when discussing the idea of grandmother. This is, again, seen when the students are laughing about imagining their grandmothers running alongside the old bus: "We laughed imagining our old grandpa driving into a big city with grandma running in her long skirts and moccasins" (11). What is interesting about this dialogue, however, is that the narrator adds, "Our grandpas and grandmas who might read and write only a little English, if 
any" (11). The narrator adds this before stating, "Then one of the girls had the final word, “"Éí shíi nichai dóó nimásání t’ééya' ákódzaa.' 'That's probably what your grandma and grandpa did.' Yes, that's what we did, always running to stay caught up for the handouts" (11). Within this trickster discourse, the reader can see the emphasis on the past, more specifically the grandparents in particular. Interestingly, the grandparents too endured the boarding schools, even the tragic event of the Navajo Long Walk, and yet the Navajo language continues. The emphasis on the past and the connection to the Navajo language, in relation to trickster rhetorics and survivance, are ways by which to counter the colonial impositions on American Indians; more specifically, Tohe uses language and storytelling to defy rhetorical colonization. Though the students are speaking, the grandparents too become visible, which demonstrates the survivance of the Diné, as the voices of the Diné continue, despite such colonial attempts to silence them. Tricksters' polyvalence and multivocality make them emblematic of the intersection of voices, and they play a central role in the connection of self and culture (Smith, J. 4). The Navajo language connects the Diné to their culture, especially in such a colonized space such as the boarding school. Moreover, the connection to the past voices, grandparents, displays the Diné survivance, as their voices are still heard and revered. Further, the stories of the grandparents give voice to past Diné, and so the Diné's history is being shared by Diné, not the Westernized versions which silence American Indian history.

The idea of giving voice to the past Diné is also seen in the Prologue to Tohe's narrative. Tohe's grandmother, Julia Barton, narrated a story about her experiences in the boarding school, and Tohe shares her grandmother's story in her prologue “Once You Were Signed Up.” Before I explain the use of trickster rhetoric in her grandmother's narrative, it is important to point out Tohe's inclusion of her grandmother's story. She gives her grandmother voice by letting her 
grandmother share her own story about the boarding school experience. Further, the story also depicts the reverence of women in the Diné culture. In the above examples, the students make mention of "grandmother," and Tohe too includes her own grandmother's voice. This is significant as the Navajo Nation is a matriarchal society. ${ }^{59}$ Denetdale explains that the Diné women's roles, as the carriers of tradition and culture, as well as storytelling, is evidenced even in the Diné creation stories, which act as templates that shaped the Diné perspectives on women's role in the Navajo Nation. Diné women used to "wield a significant amount of autonomy and authority in their society" before Westernization ("Reclaiming" 8). Further, in "Facing the Legacy of Boarding Schools," Eulynda Toledo-Benalli posits: "Our Diné cultural behaviors are embodied in our language, thought, and prayers, which have always been passed down by our grandmothers and mothers. But these women have been suppressed $—$ our minds have been colonized. Indigenous women's knowledge needs to be documented. This knowledge is uniquely ours and does not have Western categories, but it is just as valid as Western knowledge" (1).

The validation of this knowledge is evidenced through Tohe's inclusion of her grandmother's narrative; however, her grandmother's story also contains trickster discourse, which further demonstrates the strength of Diné women. In the beginning of Barton's boarding school narrative, she explains that she was told "Don't speak Indian" when she was in boarding school at both Fort Defiance and the Sherman Institute (Tohe xiii). If a student disobeyed, they were given extra chores and much "work, work, work" (xiv). She further explains that the schools were structured after military rules and commands, and some students attempted to run, while others stayed because they could not go anywhere. She also remembers that there was a sickness outbreak from the German measles. Her fondest memories, however, were their making 
"sock balls" and having bumble bees as pets (xv). Lastly, she tells the reader that they enjoyed going to the graveyard because it was the one place they did not get "scolded" (xvi). Ultimately, however, she was happiest when she got to go home and see her mother, as she states, "it was good to be home" (xvi).

While Barton's narrative, itself, speaks back against Pratt (which is the goal of Tohe's narrative in its entirety), as it shows that the boarding school was not successful in eliminating the Diné's culture, it further depicts the survival of the Navajo language. Barton has two instances of code switches in her narrative. The first is when she describes the boys' jail and how the boys were placed there if they attempted to run away. She explains that they did not have a toilet, had barely enough light to see, and they would yell and cry for help. When she explains the jail, she calls it a dungeon: "The back part was okay but the front part it had ha'a't'ílda, whatchamacallit bars. $A k o$, so that we used to see who was in the jail there as we went into the classroom. Hágoshii aadęé naaztlle áshiiké, the boys used to stand in there. They had their own jail. Nihi éi, we had those dungeons down there" (xiv). Barton, interestingly in her storytelling, included the English version of the Navajo language. I say this is interesting because this was a story that she told to Tohe; so, in her story, she spoke both languages at particular times. The first time is seen in the above-example, which depicts the hellish experiences of the Diné boys who struggled to escape the assimilation attempts of the boarding school. Barton uses the Navajo language, and translates for the reader, in the part of her narrative that discusses punishment for running from assimilation as a jab at Pratt, whose assimilation attempts were not successful.

She continues to speak back at Pratt in her second code switch, as she uses the Navajo language when she discusses the students' desire to go to the graveyard when they went for their walks on Sundays; she explains that they "weren't even afraid of the ch'ídiis, ghosts" (xvi). 
Similarly to the example above, she provides the English translation for the Navajo language when using the term "ghosts" in reference to the graveyard, however, the "ghosts" could also be those who worked at the boarding school, including the creator, Pratt, as she explains that the graveyard was one of their favorite places because they did not "get scolded" there. At the graveyard, they were not afraid of the metaphorical ghosts (souls of the deceased), yet, while at the graveyard, they were also not afraid of those they were most afraid of: the assimilators. This lack of fear is also demonstrated in her narrative through her use of the Navajo language. Vizenor explains that "because of their ability to shapeshift, tricksters are as arbitrary and changeable as language" ("Anishinabe" 170). The idea of "shapeshifting" happens through the trickster rhetoric, as Tohe is able to speak back to Pratt through the Navajo language, and in doing so, she reclaims a part of the Diné history because she tells her own story.

While Barton was at the boarding school, she silently rebelled, which can be seen through her retention of the Navajo language; however, while at the boarding school, she was forced to adapt in order to avoid punishment. She did not necessarily have to adapt in the sense that she abandoned her Diné beliefs, yet, she had to acclimatize to make her life easier, to "tough it out" (xiii). A similar idea of acclimating in order to survive can also be seen in Tohe's poem "Joe Babes.”

\section{Students or Tricksters: Shapeshifting and Survival}

The poem "Joe Babes" depicts the identity or persona that young students imitated from the colonizer. The poem also explains how and why the young, female, Diné students chose to emulate certain Westernized behaviors, and how they transformed to survive. One example of this can be seen in the following example: "Some teased their hair / into bouffant hairdos and / wore too much makeup. / Others wore outdated dresses and shoes, / and washed their hair with 
detergent soap" (8). The "teased hair," "bouffant hairdos," "makeup," and detergent soap" are all identifiers of the Westernized society, specifically women, during the 1950s and 1960s. The bouffant style, or rather the teased, "big-hair fad" was made popular in the 1960s by North American women. The "big hair" was used to gain attention, be noticed, and display a sense of "wealth and indulgence" (Powell and Roach 83). The style was considered to be sophisticated and trendy by mainstream, Westernized standards. ${ }^{60}$ The young, Diné women's adoption of this Westernized hair style shows how the young students began to transform their cultural teachings about beauty in the Diné culture. ${ }^{61}$ Their long, flowing hair ${ }^{62}$ that would usually be worn down, or in a bun called "tsiyeel," which is a traditional Navajo bun tied with yarn was replaced with the bouffant style (Morales). The women chose to adapt to the Westernized hair style. The question becomes: were they trying to fit in? Alternatively, were they trying to survive? The mimicry of the Westernized makeup and hair were the Joe Babes' attempt to adapt to their surroundings at the boarding school; they had to transform in order to survive. Trickster is "often the little guy using his wit to overcome a large pre-dominant force" (Womack "Red on Red" 152). Womack argues that trickster also provides "Indian people with road maps for survival in the face of oppression" (162). The Joe Babes were the "little girls" using their strength of adaptation to attempt to survive in the face of the oppressive environment of the boarding school

The Joe Babes also "misbehaved" in the classroom. Tohe writes, the "Joe Babes sat quietly/ in the back of classrooms/ even when they knew the answers,/ were described as shy, dumb, angry, or on drugs/ by the teachers" (8). They were viewed to be "misbehaving" because they would not answer; however, more important to note is that they "knew the answers." Like Tohe's poem, "The Names," they too were rendered silenced. Yet, because of the imposed silence, they were deemed to be "shy, dumb, angry" or "on drugs" by their teachers; yet, they 
knew the answers, but were prevented from speaking, from having a voice. So, the teachers accepted their new, Westernized physical appearance, but because they did not conform to expectations surrounding their participation in the classroom, because of their silence, they were considered to be outcasts or rebellious.

Further, like trickster, the girls did not let the teachers know the "real" them. They wore a mask, which was "makeup" and big hair. Also like trickster, they transformed themselves to adapt to their environment. Ballinger asserts that tricksters "transform themselves and the realities around them," which reinforces "their roles as the image of life's many-sidedness" (31). The girls' transformations depict the "many-sidedness," or rather the contradictions of their reality in the boarding school. Because trickster points out contradictions, Vizenor considers trickster narratives to be "ironic survivance" ("A Trickster Discourse" 170). Their mimicry of the Westernized versions of beauty were their attempts to survive in the colonizer's environment.

Their silence in the classroom was also a way to protect themselves from ridicule and misrepresentation. When they did speak, "they spoke in broken Indin-gish" (Tohe 8). Based on this descriptor of the Joe Babes, they did not seem to "fit in" with either culture, as they struggled to adapt to their surroundings, but they also held onto their language and culture, which resulted in their blended language of "Indin-gish." They are also described as "the ones who stood in corners / for speaking Indian / until the government said it was okay" (8). "Standing in a corner" is representational of being punished in the classroom. In this case, they were punished for speaking their language, the Navajo language. Because of the teachers' suspicions, the Joe Babes were "given pernicious looks / by the cashier in the public school cafeteria" (8). Though they wore their hair and makeup in a way that related to the Westernized representations of femininity and beauty, they were still "Indian," who spoke both languages. They did not just 
rebel through language, however, but also through their actions. They "sang in Indian clubs / and danced at pow-wows" (8). They were silenced in the classrooms, but they "sang" at Indian clubs, because of this, they were viewed as rebellious or "on drugs" by the teachers. The Joe Babes' actions are trickster-like in that they decide which role they will play. In other words, they control what they will adopt from the dominant culture (hair, makeup) and what they will resist (language, culture). Further, Tohe's use of identifying the Joe Babes as "the ones who..." demonstrates that they are being described by another's perspective; they are not identifying or describing themselves. This inability to establish and maintain one's own identity was also evidenced through the assimilation attempts by the boarding school, but through their "rebellion" they resist these assimilation attempts or use them on their own terms, as they decide what appearances and actions, and language, are appropriate or inappropriate.

The girls' "rebellion" helped them to "form" their environment to suit their ability to survive. Weaver claims that as cultural-hero, trickster "shapes the world and gives it form" ("Other" 249). The Joe Babes shaped their environment in the boarding school. Their actions of rebellion and selected conformity (hair, makeup) helped them to survive in a world that was not their own, in a world that attempted to change them. Their ability to adapt helped them adapt into the larger, Euro-American culture, as the narrator writes that the "Joe Babes/ were the ones that left the reservations/ for the cities, for the schools, for the jobs/ We were the Joe Babes. / All of us" (Tohe 9). Tohe shows her readers that the Joe Babes left the reservation to live in and acculturate to the Euro-American life. The young women knew that the boarding school was an attempt to change them and that the dominant culture would require them to adapt to their surroundings, and they did. Interestingly, Tohe also writes "All of us," which could mean that "all" Diné women were forced to adapt and transform, like the Joe Babes, in order to survive; 
yet, they were successful as they are still here. Pratt did not triumph, as they were not eradicated or erased. Their stories are being told by a "representation" of a "Joe Babe," a survivor and resistor.

Through her storytelling as a Diné author, Tohe takes on the role of trickster (Coyotesse) to (re)tell, (re)write, and (re)right the Diné history, a history different from those represented by Westernized versions. Denetdale argues that "oral traditions have been examined to illuminate Indigenous peoples' perspectives on the past." She goes on to explain that "if we view oral traditions and history as cultural constructions embedded in social processes, we discover that the meaning of the past differs across cultures and raises questions about the authority we continue to give to documentary evidence" ("Reclaiming" 81). Denetdale explains that the Diné "perceive their own past differently" than the skewed, Westernized versions (7). Because of this, Diné authors work to (re)tell their own history, which Tohe does through her use of trickster rhetoric to tell the stories of the boarding school survivors. Through her storytelling, she teaches the reader about the Diné's historical experiences during the boarding school era. Weaver asserts that trickster stories are "teaching stories" (“Other” 248). Tohe’s narratives and poetry teaches the reader the Diné version of the boarding school era. In other words, Tohe disrupts the Westernized depictions of the Diné history with accurate representations and stories about the Diné boarding school experience. Also significant is that Tohe disrupts the Western dichotomy of colonizer and colonized. Weaver posits that trickster "turns the world upside down ... subverting expectations" (250). Tohe does this by telling Pratt (in the English language) that he did not succeed in eradicating her, in eradicating the Diné. She speaks back to him through the very language he used for assimilating her; further, she interjects some of her narratives and poems with the Navajo language, the very language he was attempting to erase. 
Tohe, as Coyotesse, also gives voice and visibility to the Diné students who were victims of assimilation through the boarding school system. She tells her story, her grandmother's story, and the stories of those who survived the American Indian boarding schools and the assimilation attempts that historically silenced them. Through her storytelling, Tohe retells the Diné history from the perspective of the Diné students, who both resisted and survived the boarding school assimilation process.

While the Diné were changed by Pratt's boarding school system, as they had to learn about a new culture in order to survive, Pratt did not eradicate them, they did not abandon their culture, and they did not disregard their Navajo language. They retained their connection to the Diné culture and language while attempting to resist colonization and the assimilation process. Tohe demonstrates the retention of their language through her trickster discourse of code switching from the English language to the Navajo language. Further, she depicts the students' resistance toward the boarding school. The students were not complacent in their acceptance of the colonization being used against them, instead, they resisted. Tohe depicts this resistance in order to demonstrate the Diné's continued presence over the expected absence, erasure, and denial imposed on them through Western narratives and representations.

In American Indian Rhetorics of Survivance: Word Medicine, Word Magic, Stromberg alludes that trickster stories can rewrite history, as well as aid in a fight for self-determination and self-definition (2). Tohe, through her use of trickster discourse and through her role as Coyotesse, does indeed (re)write and (re)right the Diné history, and in turn disrupts the colonial gaze from the Westernized renditions of history and actually redirects it to the Diné's view of their own history. She also shows Pratt that she is not the perpetual "Indian" victim, and goes on to defy his assimilation attempts by portraying the continued existence of the Diné. She begins 
her narrative by addressing Pratt's failed attempts at eradicating the Diné, and she ends her narrative with the line, “. . and I will live to tell my children these things" (47). She starts her narrative with resistance and ends it with her declaration of survival. So, while Pratt may have started the "war" against the Diné culture and language, it is through her writing that Tohe gets the last word, in English, by choice. 


\section{CHAPTER V: PEDAGOGICAL TOOLS TO BRING AWARENESS OF RHETORICAL}

SOVEREIGNTY IN AMERICAN INDIAN LITERATURE: TEACHING SURVIVANCE AND PROMOTING ALLIANCE THROUGH CODE SWITCHING AND TRANSLATION IN THE INTRODUCTORY LITERATURE CLASSROOM

Analyzing American Indian ${ }^{63}$ literatures and rhetorics in the writing and literary classroom is the first step to gain "acknowledgement, respect, and awareness for the rhetorical sovereignty that is still very much ignored and disregarded in not only our society, but also in various classrooms throughout our school systems," more specifically, our college classrooms (Hoover 170). As Jessica Safran Hoover argues in "Rhetorical Sovereingty in Written Poetry," "simply reading American Indian literature will not encourage students to appreciate the significance of the voices in the texts," the very voices that I emphasized in previous chapters (170). In order for the significance of the rhetoric to be understood, the rhetorical sovereignty of the author and the resistance within the language, and the stories, need to be foregrounded. ${ }^{64}$ Oglala Lakota scholar Kimberli Lee, in her article "Heartspeak from the Spirit Songs of John Trudell, Keith Secola, and Robbie Robertson," makes the prudent assertion that: "For centuries Indigenous peoples in this hemisphere have raised powerful voices of resistance to the unjust treatment and outright genocide they have received at the hands of colonizers. This resistance has been, and continues to be, manifested through a variety of rhetorical venues: speeches, stories, poems, songs" (89). We must inspire our students to participate with these mediums through literary or rhetorical analyses, as well as intellectual alliances, so they may understand and appreciate this resistance (Hoover 170). This resistance can be seen, heard, and understood by determining the "hows" and "whys" of the rhetoric used in the texts (King). 
Leech Lake Ojibwe rhetoric and composition scholar, Scott Richard Lyons, argues that treaties and federal Indian laws should be taught as rhetorical texts themselves (464). Recognizing the rhetorical aspects of treaties and laws may facilitate better understanding of the strategic, rhetorical choices made in response to them, or made in a world that official rhetorics, in part, contributed to shaping. American Indian literature should also be taught as rhetorical texts, because rhetorical analysis "fleshes out concepts that literature portrays through storytelling and images of the American Indian nations," as well as provides a space for their voices to be heard (Hoover 170). By bringing rhetorical sovereignty to the "forefront of our students' literary foci when engaging with American Indian texts, we can disrupt our students' preconceived notions" of who is/who identifies as American Indian, how the "English language is privileged through colonial attempts to silence American Indian nations," encourage recognition of the individuality of each American Indian nation, and bring awareness to the "rhetorical power in the voices of American Indian authors" (171).

The purpose of this chapter is to demonstrate the effectiveness of using Laura Tohe's text, Tséyi' / Deep in the Rock: Reflections on Canyon de Chelly in the classroom when teaching about sovereignty. Tohe is revered for her poetry, as well as her various texts and plays, and she is increasingly the subject of scholarly studies, as her work has been anthologized and is more often cited, as recently as 2015, as Tohe was named the Navajo Nation's Poet Laureate in September 2015. Tohe gained recognition among the Diné, as well as her scholarly counterparts and other Native nations, for her compilation of poetry and short stories, Tséyi' / Deep in the Rock: Reflections on Canyon de Chelly, which emphasizes the connection between land rights, historical trauma, and American Indian identity, specifically in the Navajo Nation. There is also an emphasis in the book on the importance of language and its connectedness to identity as Tohe 
uses code switching (between the Diné language and the English language) throughout her work. In this chapter, I offer a way to further the understanding of rhetorical sovereignty in the literary classroom with a specific focus on texts by and about American Indian peoples, while also establishing alliances between American Indian authors and non-Native students, as well as Native students.

It is important to include Native students in this list of allies, because of the following reasons: 1.) students' identifications are complex, such as unenrolled, urban and mixed-heritage students (for example Mexican-Americans with indigenous heritage or African American students with indigenous heritage), some of whom will not self-identify to the professor or their classmates, and/or may feel they have little understanding of that part of their heritage; and 2.) because there are campuses with demographics that lean heavily toward other groups and little Native presence at all; for example, it is important to note that the examples provided in this chapter, in regards to pedagogy, were used at Illinois State University, which, as of December 2016, had an enrollment of only $0.1 \%$ American Indian or Alaskan Native students ("Illinois"). ${ }^{65}$ Furthermore, while I could find the enrollment percentage for the number of America Indian students at Illinois State University, many college and university websites did not even list America Indian students as part of their enrollment numbers, and many of these colleges and universities were white-dominant institutions. In "Measuring the Influence of Native American College Students' Interactions With Diverse Others on Sense of Belonging," Terrell Strayhorn et al explain that US colleges are broken down into two, specific categories in regards to domain racial composition: predominantly White institutions and minority-serving institutions, one of which is tribal colleges and universities that educate $5.5 \%$ of American Indian students (50). In all, American Indian students make up only $1 \%$ of the total undergraduate student population, 
and according to the US Department of Education, only 39\% of American Indian students complete their degrees in a five-year period, and also have the lowest degree-completion rates among all students ("US Department"). Strayhorn et al argue that some students leave college because of a lack of belonging, as some American Indian students feel marginalized, alienated and unsupported at their institutions (63-4). Strayhorn also states that little research is done to determine American Indian students' feelings, involvement and success in college, as there is little known about these because of the "asterisk," which is a common method used to exclude American Indians from scholarship and data due to their small representation, low numbers, and "statistically nonsignificant" results; the asterisk may be responsible for making American Indian students invisible in higher education research (50). It is because of this invisiblity that we must also include Native students as part of the audience for the pedagogy discussed in this chapter.

I draw specifically on the works of Scott Lyons and Malea Powell, and on their concepts of rhetorical sovereignty, survivance, and rhetorical alliance. I explain how these terms can suggest an approach for using American Indian texts, in such a way that we may speak of both sovereignty and alliance in the classroom, with a focus on language's role in attaining sovereignty and its ability to build alliance. In "Rhetorical Sovereignty: What Do American Indians Want from Writing?" Leech Lake Ojibwe rhetoric and composition scholar Scott Lyons explains that what American Indians want from writing is the ability to pursue rhetorical sovereignty, or the "inherent right and ability of peoples to determine their own communicative needs and desires, to decide for themselves the goals, modes, styles, and languages of public discourse" (449-50). Lyons provides us with a demonstration of how rhetorical sovereignty is part of the decolonization work of American Indians, as writing provides a means for regaining the sovereignty that has been denied for American Indian peoples after years of colonization, 
subjugation, and resistance. Lyons suggests that we move away from using texts about American Indians to texts by American Indians to understand rhetorical practices. Treaties, political documents, and written oral stories all provide the means of constructing how American Indians use(d) writing to make meaning and express their sovereignty through public discourse.

Mixed-blood, Indiana Miami/Eastern Shawnee/EuroAmerican rhetoric scholar Powell extends Gerald Vizenor's theories on rhetorics of survivance as she investigates the rhetorics of resistance + survival among late nineteenth and early twentieth century American Indian rhetors, Sarah Winnemucca (Northern Paiute), Charles Eastman (Santee Dakota), Susan La Flesche (Omaha), and Andrew Blackbird (Harbor Springs Ojibwe/Odawa). Drawing on Lyons's argument, in"Rhetorics of Survivance: How American Indians Use Writing," Powell demonstrates how Winnemucca and Eastman used rhetoric to both resist and survive and how doing so worked to transform themselves from object-status to subject-status, to assert a presence instead of an absence. Powell asserts that American Indian texts must be examined to distinguish the important rhetorical strategies they use, and establish how American Indian authors use specific representations of American Indians in public discourse in order to recast American Indian identity and forge new stories.

An expansion of rhetorics of survivance is rhetorics of alliance. In Powell's article "Down By the River, Or How Susan La Flesche Picotte Can Teach Us About Alliance as a Practice of Survivance," she affords an example of how La Flesche Picotte, an Omaha physician, spokeswoman, and public health activist uses alliance and adaptation tactics in her writing. It is through the example of La Flesche Picotte that Powell argues how rhetorics of alliance can bridge the gap between American Indian and Western traditions. 
Powell's goal is to "make visible the fact that some of us read and listen from a different space, and to suggest that, as a discipline, it is time we all learn to hear that difference" ("Rhetorics" 398). If we pay attention to the rhetoric and listen, as responsible citizens, Powell suggests that "we can begin to reimagine ourselves, our pedagogies, our discipline in relation to a long and sordid history of American imperialism. That we will not shirk from the hard work implied by stories - like the new histories and theories - being offered" by American Indian rhetorics (428). In order to be able to listen and engage in the ways that rhetoric of alliance offers, there must be intellectual engagement from both the colonizer and the colonized, or the insider and outsider to the intellectual community. She explains that:

We need a new language, one that doesn't convince us of our unutterable and ongoing differences, one that doesn't force us to see one another as competitors. We need a language that allows us to imagine respectful and reciprocal relationships that acknowledge the degree to which we need one another (have needed one another) in order to survive and flourish. We need, I would argue, an alliance based on the shared assumption that "surviving genocide and advocating sovereignty and survival" has been a focus for many of the people now on this continent for several centuries and, as such, should also be at the center of our scholarly and pedagogical practices enacted in the United States. (41)

In order to create this "new language" in the literary classroom, we must ensure that our students can "hear" and appreciate those voices that may be different from their own. 


\section{Exigency}

Unfortunately, many non-American Indian students enter general education introductory literature courses without previous knowledge of the array of prominent American Indian authors, the existence of the various Native Nations, and the understanding of the sovereignty that is displayed in the American Indian works. In "Teaching Native American Literature: Inviting Students to See the World Through Indigenous Lenses," Carol Zitzer-Comfort explains that while ample scholarship has been written about teaching American Indian literature, "a majority of students come to postsecondary American Indian literature courses with a dearth of prior knowledge about native worldviews, tribal diversity, and myths and themes that appear in much of the literature" (1). Continuing with this idea, some students also enter the literature classroom with a preconceived notion of the umbrella term of "all American Indians," as the concept of separate Nations and tribes falls to the wayside in much of the teaching surrounding North American history. American Indian texts, therefore, "need to be read and understood as grounded in the communities and exigencies from which they come, not as isolated, and certainly not as a representative example of a 'minority' text” (King 219). The teacher can ground the texts as works from specific authors from particular Nations, and because of this the students will be able to understand the diverse and unique Nations that inhabit the United States, which in turn, will help to rectify any preconceived stereotypes and conflation of the diversity surrounding indigenous peoples' beliefs, cultures, and languages. Further, students may enter the introductory literature classroom with limited experience in reading, writing, and thinking critically. As Andrew Weeks et al argues in "Making Ends Meet: Literature Pedagogy, Faculty Graduate Student Teamwork, and Undergraduate Literacy," this does not mean that they "cannot benefit from a writing- intensive literature course — they can benefit greatly — but the instructor 
has to recognize their needs and develop suitable strategies for meeting them" (230). The need for attention to the individual needs of students is especially true when teaching about areas of literature about which they are not privy, as most of our students come from different backgrounds, experiences, races, and ethnicities. However, it is also important to note that even if a student does self-identify with a particular ethnicity, for example those students with Native heritage, they may themselves never have been introduced to the histories or cultural works of those groups, due to the lack of inclusion in many schools even today in the twenty-first century. In order to bridge any divisions because of these differences, as instructors, we need to show students that differences are inevitable and acceptance is important.

In "Rhetorics of Survivance: How American Indians Use Writing," Powell opens up a discussion about the way different people "read and listen from a different space" (Powell 398). This is applicable to our understanding that our students (those whom do not have any background in American Indian history and/or literature) are reading and listening from a “different space.” Encouraging students to read works like Tohe's, which include code switching, not only promotes awareness of American Indian works and voices, and requires an understanding of sovereignty that is still relevant to American Indian nations today, but also calls for students to rethink and reconsider any preconceived notions and stereotypes that they may have in regards to American Indians, as well as the English language.

Further, providing students with an understanding of why the code switching is significant in an English-dominant text adds to the discussion of sovereignty, as language has a significant role in American Indian cultures and identities. ${ }^{66}$ As discussed in previous chapters of this dissertation, I am using the definition of code switching provided by professor of Native American literary studies Holly E. Martin (2005), as she states that: "Codeswitching 
between...English and a Native American language, creates a multiple perspective and enhances the authors' ability to express their subjects. Also...writers lay claim to the languages of their communities and resist the dominance of English by proposing that these languages can accompany English in the creation of works of US literature" (403-4). This definition allows me to encourage my students to consider the significance of both languages in a single text. In other words, by acknowledging both languages in the text, the goal is to promote students to ask "why", i.e. why are both languages are used? Since most of the students will only understand the English portion, by guiding them to question why the Diné language is included along with the English language, my objective is to enable them to consider the dynamics of the two languages being used together, and not just gloss over the “other" language. In addition, Joy Harjo (Mvskoke/Creek Nation) and Gloria Bird (Spokane) state that many American Indian individuals and nations use "the 'enemy's language'to tell our truths, to sing, to remember ourselves" (21). This is also amidst discussions of language loss by many American Indian nations, ${ }^{67}$ so, by encouraging a discussion of the connections between identity and language, this will allow students to understand and appreciate the code switching on a deeper level. Furthermore, including additional works that do not include code switching, such as excerpts from the scholarly articles of Malea Powell or Scott Lyons, or select poems from Luci Tapahonso, Rex Lee Jim, or authors of different American Indian nations, will also enhance the discussion of the differences between the varying nations that are housed under the umbrella terms of "Native" or “American Indian.”

\section{Contact Zones, and "Unsafe" Spaces}

To understand the diversity and complexities surrounding ethnicity, students must learn how to negotiate "contact zones." Mary Louise Pratt characterizes contact zones as "social 
spaces where cultures meet, clash, and grapple with each other, often in contexts of highly asymmetrical relations of power, such as colonialism, slavery, or their aftermaths as they are lived out in many parts of the world today" (33). In a general education introduction to ethnic literature course at Illinois State University during the fall 2012 semester, I focused on contemporary ethnic American literatures, with a strong emphasis on American Indian texts. Because my students entered the classroom with such a limited understanding of colonialism and oppression, I had them not only read and analyze Pratt's article in order to flesh out the meaning of "contact zone," but I also encouraged them to ponder the questionable division between who is "American" and who is "not," which aided them in their education and understanding of the various definitions of race, ethnicity, and the concept of white privilege. I elaborate on this below in the "Course Context" section of this chapter.

The classroom as a contact zone also influenced my own pedagogy because while I wanted to encourage my students to share their experiences and understandings of American Indian authors, with which they entered the classroom, I also wanted to disrupt their preconceived notions of American Indians, as some students did not realize that "they" (American Indians) "still existed," while other students confessed to associating "feathers and chanting” with "being” American Indian. Because of these stereotypes and misconceptions, I wanted to make the classroom a space of being "not safe," not safe in the sense that differences and diversities are not discussed. Discussion of these concepts is vital. A contact-zone classroom suggests a way to begin working with the diversity and complexity of our classrooms, universities, and home communities; however, some argue that the "clashing" and "grappling" of a classroom in which "no one is excluded, and no one is safe" (Pratt 86) does not prompt dialogue because of fear. Cherokee, Choctaw and Irish author Louis Owens, on the other hand, 
argues that "it is our responsibility, as teachers and writers, to make sure that our texts and our classrooms are not 'safe' spaces from which a reader or student may return unchanged or unthreatened....It is our job ...to make people listen well, to disrupt the discourse of dominance, to challenge and discomfit the reader, to ultimately startle that reader into real knowledge" (4647). This is especially important in the twenty-first century as we face political views that support a divisive rhetoric and a particular view of those of color in a "white" America. Above, when I mentioned disrupting the dominant discourse, this is what I mean; the dominant discourse that English and "white" are the "correct" ways of thinking, speaking, and being, i.e. that English and whiteness are constructs of "American." As instructors, we have to break our students' preconceived notions and work against a dominant society that supports this divisive and homogenous view that anyone not speaking English, and anyone that is not viewed as "white," is a threat and/or is not American. ${ }^{68}$

\section{Course Context}

As mentioned above, in my general education introduction to ethnic literature course in 2012, I attempted to inspire my students to put into dialogue their own worldviews, as I encouraged my students to investigate the concept of ethnicity in order to understand the differences between ethnicity and race, as well as their varying definitions. This approach exposed students to the understanding that we all have ethnicities and are "ethnic" in our own, unique ways, even the most canonical authors. I established this lens by focusing on a wide range of ethnicities and literary genres, as this course investigated the role of race and ethnicity in the American experience, while encouraging the students to question the following:

- How are ethnic peoples construed as alien "others" by American culture and why?

- How do they resist this othering through literature? Through language? 
Students answered these questions throughout the semester by writing various reading responses on the texts and by writing in their journals, in response to prompts that encouraged them to critically think about and analyze society's expectations of ethnicity, past and present stereotypes surrounding people of color, and the varying ideologies of the treatment of various ethnic groups. I also required my students to consider literary elements such as style, tone, theme, and character through the lens of the authors' messages about ethnicity, race, and culture. American Indian rhetorician and composition scholar Lisa King asserts that "the implications for classroom practice involve questioning not only the historical narratives that shape our practices but also how we all (white included) construct ourselves and are constructed by others as instructors and people who are 'raced' and 'cultured,' and then involve our students in doing the same" (211). A majority of my students were not familiar with literature by various ethnic groups, nor what constitutes American ethnic literature, such as American Indian literatures.

Before the students began reading and analyzing the literature for the course and because of the students' lack of experience with ethnic literatures, I focused on defining and problematizing the concepts of race and ethnicity. The first class period was focused on the discussions surrounding race as a socially-constructed concept that is both unstable and informed by political power, and that race is a part of one's ethnicity or ethnic group (Omi and Winant 55). I placed the above-referenced definition of race on the board, along with a few definitions of ethnicity. I also wrote the following on the board in regards to understanding and defining ethnicity: "R.A. Schermerhorn defines an ethnic group as a "collectivity within a larger society having real or putative common ancestry, memories of a shared historical past, and a cultural focus"” (qtd. in Sollors xii). Similarly, Abner Cohen sees ethnicity as part of a power system, and Robert Merton states that ethnicity is a term that constitutes insiders and outsiders, while George 
Devereux and Philip Gleason correlate ethnicity with identity. Ulf Hannerz establishes ethnicity with particular organizational boundaries, and Herbert Gans investigates 'symbolic ethnicity,' in which the third generation attempts to connect with their ethnic roots through identity-making and awareness" (434). I then started the discussion about race by asking students if they have ever had to check a box when filling out a job or college application; all of the students raised their hands. I then asked the students how we know which box to check. Some said: "if you're white, you check Caucasian" and "if you're black, you check African American." Others lamented that they were not sure which box to check because they were "mixed white and black" or "none of the boxes applied to them" because they were not "solely Caucasian, black, Hispanic, or Asian" because they come from mixed backgrounds. One student even noted that he checks the "other" box because he is "a Heinz 57." We first discussed the difference of each definition surrounding ethnicity (as listed above), and then I asked the students to consider what their ethnicities were and how they viewed the above-named definitions in relation to those ethnicities; they wrote their responses in their journals. After writing, I asked them their thoughts on ethnicity, the definition as well as their own. Some of them looked blankly at me, and some noted that they had no idea of their background. Others were excited to share that they were German, Italian, Chicana, and so forth. When one student stated that he was "a mix of Polish and Korean," another student noted "but you don't look Korean."

This concept of "looking" a particular way, a particular identity or ethnicity, brought about a great discussion about expectations and representations of identity. I started this discussion with the following example, which I shared with my students. In his article "Death to the Originary Narrative! Or, Insurgent Multiculturalism and Teaching Multiethnic Literature," Jose L. Torres-Padilla writes: "The taxi driver compliments Takaki ${ }^{69}$ on his English and asks him 
how long he had been in the country. After informing the driver that his family had been in the United States for over a hundred years, Takaki muses over the significance of the encounter. 'Somehow,' he writes, 'I did not look 'American' to him; my eyes and complexion looked foreign"” (13). Takaki identified himself as "American," yet, he may have also identified with a particular ethnic group. He may have been both "American" and . Thus, because of the necessity to encourage students not to see ethnicity in black/white binaries, the concept of hybridity needs to be discussed in the classroom. To provoke their preconceived notions of race and "expectations," I placed a picture of James Earl Jones on the overhead and asked them what ethnicity they think he identifies with and why. Most of the students expressed that he is "black" and as such he identifies as "African American." My students were shocked to learn that James Earl Jones identifies as Choctaw, Cherokee, and African American. They were shocked because, according to one student, he is "supposed to be just African American" because he "looks black."

Examples like the above are part of the reason why it is so vital to encourage students to understand issues with representation and imposed expectations for identity. Further, it is because of the reason that most of my students could not fathom how Jones is both American Indian and African American that our discussions of race and ethnicity led into an enlightening discussion about hybridity. I wrote the following on the board for my students to note: "Cyrus Patell posits that not only are all identities hybrid, but also that every 'American' identity is, in fact, necessarily hybrid, though mainstream US culture has worked hard to deny that fact. They know that ethnic Americans are taught to deny the parts of themselves that are outside of mainstream US culture"” (65-66). This concept of hybridity I presented to my students immediately, as I prompted them to think about their own ethnicities. I had the students consider 
Patell's viewpoint at the beginning of the semester, through my lecture, as well as group work on defining ethnicity and considering their own "two-ness", in order to allow them to build upon their understanding of hybridity and ethnicity throughout the semester. A few students opted to text their parents and grandparents and shared that they were "this" and "that," i.e. one student explained that he was Asian American and English, but he "identifies as just American."

I cautioned my students that when we imagine ethnicity or culture in terms of specific, homogenous divisions (my culture, your culture, his culture, her culture), this binary is a very static view, as it does not challenge anyone's idea of who can/should be defined as "American," and it does not allow for ethnicity and identity to be plural or hybrid. Investigating the complexities surrounding the terms of culture, race and ethnicity allowed my students to understand not only hybridity, but also what constitutes the "mainstream." One issue that was considered was the idea of racializing whiteness, and the connotations that surround being labeled "white," which included the investigation of what is meant by "white privilege," and its function in society. Michael Kreyling asserts that "whiteness in the United States is, of course, a cornucopia of unearned and unacknowledged privileges and outlooks, with an ongoing and selfreplicating cultural life. There is no way not to be a part of this cultural organism" (37). I used Kreyling as a basis for a discussion on whiteness and how prominent it is in our American society, as well as in our academic society. Keith Gilyard also advocates the value in composition teachers' presenting whiteness as a concept that imposes on everyone "a default identity relative to whiteness formation, which was in itself a carefully calculated social maneuver" (51). "Whiteness," then, must be questioned just as much as any other category of race when we talk about the "discipline and classroom practice" (48). My students noted that this focus on the privileging of "whiteness" is hard for many to see in society, as according to 
Richard Dyer, "white power secures its dominance by seeming not to be anything in particular" (qtd. in Lipsitz 1). However, it can be seen through political and cultural power struggles, assimilation, forced removal, wars, internment, racism, as well as through intersections of gender, class, race, and sexuality (72), which the students agreed with and added that it can even be seen in certain classrooms among their peers.

When discussing ethnicity, I also encouraged the students to consider that the idea of multiple identities and ethnicities is difficult to accept for the white mainstream; for, though the issue of being multiracial, "while painful on the personal level, people want 'the real thing,' [for example]...a 'real' Indian" (Fowler 29). In other words, the mainstream calls for a definitive group or groups in which to "place" people. Thus, it is necessary to challenge the ideologies that impose restrictions on peoples' identities, and break out from the monolithic view of the white mainstream, which falls between two extremes: "white and black" (Forbes 93). These extremes of either/or are problematic not only because of the binaries, but because no one person is actually “white." In Africans and Native Americans: The Language of Race and the Evolution of Red-Black Peoples, Jack Forbes states that: "white is a blank color...no color at all," which is impossible (95). I used this viewpoint, as discussed above, to present to my students why checking a box (when filling out a form) to identity one's race and ethnicity is problematic, as are the choices that are provided. (This book also assisted in explaining to my students the idea of hybridity in terms of "red-black peoples"). Discussing the issues of hybridity and exposing my students to the diverse experiences within American literature was, hopefully, a step in educating them about resistance and oppression, as well as the plethora of literature by those of color that are often "swept under the rug." Most importantly, however, it challenges their notions of "expectations" surrounding those of color. 
The motivation for distinguishing ethnic literature from other literary traditions is complex and contestable, which is why it was essential that the students first established the history behind the literary canon, and how particular peoples and literatures were excluded; for, identifying literature as "ethnic," as opposed to canonical, was historically an act of exclusion. Because of the emphasis on history's significance and influence within the texts, it was imperative for the students to be privy to the historical context surrounding each text and ethnic group that were discussed. Changing the canon over the past few decades, however, "has become a major objective of literary practitioners of women's studies, black studies, and other 'ethnic' studies-the academic wings of the social movements of the 1960s and 1970s" (Lauter 436). In turn, the definition of "American literature" has consequently been called into question, along with the idea of a cultural melting pot. In 1979, Herbert Gans asserted that the idea of ethnicity would end in a "totally melted pot" is not considered possible by anyone in the twentieth century (454). It is still not possible today in the twenty-first century. Discussions of the changing canon, what defines the canon, problematizing the canon, and disrupting the idea of America being named a "cultural melting pot" were all focal points in the classroom, in order to encourage students to consider other viewpoints and to problematize various ideologies surrounding race, ethnicity, and nationality. One particular work that assisted the students with identifying the problematic nature of the homogenizing structure of the "melting pot" is LeAna B. Gloor's article "From the Melting Pot to the Tossed Salad Metaphor: Why Coercive Assimilation Lacks the Flavors Americans Crave," which emphasizes a tossed salad metaphor to demonstrate the necessity and positivity of having a heterogeneous view of the many cultures, societies, ethnicities, beliefs, religions, and languages that are all prevalent in North America. Ultimately, regardless of the "inclusion" or lack thereof in the literary canon, I wanted my students to 
understand that "inclusion" is not the issue, but rather the silencing of the diverse American Indian authors' voices is the issue, which is something that needs to be addressed when discussing literary contributions and sovereignty. ${ }^{70}$

Understanding American Indian struggles with assimilation, forced relocation, and removal is important for the students' overall comprehension of American Indian literature and its themes of sovereignty. Andrew Wiget argues that

to open a discussion of any single Native American text is to immediately invoke in one's students and one's self a tangled web of issues that will never become fully sorted out in the limited time available in the classroom.... There is no substitute for adequate preparation, which must include a general knowledge of the history of Indian-white relations, yet transcend it to focus on particular tribal cultures and literatures. (5)

Educating students about American-Indian specific issues, such as sovereignty, land rights, alcoholism, blood quantum, histories of oppression, and language and culture loss, in regards to colonialism's effects of oppression, allows them to see society's (both historical and present) expectations for what constitutes "ethnic" and the treatments of those of various races, especially those who identify as American Indian.

To emphasize the multitude of voices and representations in literature, I focused on authors of various ethnicities and backgrounds. In addition, I emphasized numerous theories, historical contexts, the texts, various articles, current events, interviews with the author(s), and short clips of film/videos to be used in the classroom. Because it is such a long list, I placed the texts and articles that I used in my course in Appendix A of this dissertation. The texts were "put in relation with one another (historically, rhetorically, and ideologically), not simply included 
side by side in a smorgasbord of diverse experiences" (Hames-Garcia 33). I did not want to simply "group" the texts by ethnicity of the authors, but by the concepts, ideas, histories, rhetoric, and ideologies informing them. AnaLouise Keating states that instructors should note a similarity in terms of theme, background, or message and trace its journey through different texts, as this will "educate students about the many differences among us," as well as the literature (103). Since I did not want to "clump" the texts to "represent" ethnic groups, I sectioned them based on the following: Defining America/Who is "American," American Dream vs. Internment/Migration/Immigration, America as Contact Zone, Place and Home, and Looking Forward.

I listed the theories, definitions, and in-class workings above in order to show that while I had a "game plan" for my introductory to American ethnic literature classroom - the "game plan" was to start directly into analyzing the various works - but the students' needs changed my plans. I found that it was necessary to educate the students about such complex concepts as ethnicity, race, and the literary canon and so forth in order to prepare them for the multifaceted and diverse texts we would be investigating. Further, this necessity was spurred by the need to provide my students a foundation from which they could build their understanding of American ethnic literature, most specifically, American Indian literatures. The overall, purpose of this course was to examine how ethnic American ethnic literatures, specifically American Indian literatures and rhetorics, can help college students better understand social and cultural beliefs, varying ideologies, problems, and social systems from a variety of time periods, specifically through the twentieth and twenty-first centuries. The goal of the course was to make familiar works by groups of color, and to find ways to help students better understand literary texts and their social, cultural, and historical contexts. 


\section{A Glimpse Into the Classroom}

In order to determine the needs of the students' for their understanding - as Powell argues above that knowing students' needs is how we can further their understanding in the classroom - I started the beginning of the course with discussions of what types of literature the students have read in their high schools and any previous college courses. I asked the students if they had read any works by American Indian authors, such as the more prominent authors, which include Sherman Alexie, Luci Tapahonso, Leslie Marmon Silko, Simon Ortiz, N. Scott Momaday, Louise Erdrich, or Joy Harjo. None of my students had read works from any of the above-mentioned authors, nor any other American Indian authors. I next asked my students if they had read any works by African American, Latino/a American (Mexican, Spanish, Dominican, etc), and Asian American authors, or any Holocaust texts. Only four students in my class of 25 had read works from authors of color. These authors included African American authors Langston Hughes and Alice Walker, and Holocaust survivor Ellie Wiesel. When I followed up with the question of which authors the remaining students have read, students were best read in works that represented their own ethnicity, in most cases, as most students listed William Shakespeare as an author they read in high school, along with American authors John Steinbeck, F. Scott Fitzgerald, and Ernest Hemingway in their other college courses. Next, we had a discussion about the authors that are synonymous with American literature, to which they listed: Shakespeare (interesting!), Fitzgerald, Steinbeck, Hemingway, George Orwell, Harper Lee, Henry David Thoreau, and Kurt Vonnegut. Leading the discussion forward, I asked: "what do all of these authors seem to have in common?" Most students mumbled "men," as well as “white." Some just looked blankly. So, I asked the follow-up question: "Why do we associate white male authors with American literature? Why not authors of color?" One student answered 
that "whites are the majority," to which another student replied, "whites control everything." This discussion then led to discussions about "dominant culture" and "the mainstream," as well as white privilege, which are topics that were revisited throughout the duration of the course. I asked my students the aforementioned questions because I wanted to know the extent of each student's background with literature; I knew that my students' previous reading experiences would influence their approach and attitude toward American Indian literature, a literature none of them had ever experienced and read. After I started my course with the above-mentioned questions to orientate my students' previous knowledge of literature, I then had my students read Vine Deloria's (Standing Rock Sioux) “Indians Today,” Philip Deloria's (Dakota) “I Am Not a Mascot,” and Louise Erdrich's (Turtle Mountain Band of Chippewa) “American Horse.” I wanted my students to read these works because they emphasize stereotypes and expectations. My students quickly picked up on the stereotypes used in the texts and made connections to the issues in society, such as issues surrounding team mascot names, like the Red Skins and the Chiefs. I also encouraged my students to share any stereotypes that they had heard or seen in regards to American Indian peoples. These stereotypes included the following: all American Indians "are alcoholics," American Indians “ do not exist anymore," all American Indians wear "feathers of some sort," all American Indians "live on a reservation," all American Indians "mostly speak their own language," and all American Indians "go to pow-wows and dance in a circle." It is because of these internalized assumptions and negative preconceived notions that I stress American Indian literature in my introduction to ethnic American literatures classroom. The students' assumptions and stereotypes were learned and they, sadly, went unchallenged throughout a significant duration of their educational journeys. 


\section{Focusing On American Indian Literature in the Classroom}

While I focused on contemporary ethnic American literatures in my course, I had a strong emphasis on American Indian texts, as these texts were the most "new" to the students. (Most of the students at the predominantly white institution at which I taught were not familiar with any American Indian authors or texts that spoke about American Indians and their various nations). One reason that I teach literature by American Indians, and emphasized such in my introduction to ethnic literature course, is to inspire students to see the world from indigenous perspectives, and to broaden their perceptions of American history, colonialism, and imperialism. In her essay "Native American Storytelling," American Indian scholar Karen Redfield argues that "we are all living in a contact zone, and the healthy future of this country depends on mutual understanding among all the nations and communities within our borders" (162). It is because of the students' lack of experience with American Indian texts that I felt it was necessary to focus on an area in which many students were not privy, especially an area that is vital to the students' acceptance and awareness as burgeoning citizens. As mentioned above, I started the course with Vine Deloria’s “Indians Today,” Phillip Deloria’s “I am Not a Mascot” and Louise Erdrich's “American Horse." When discussing these readings with my students, I discovered through student feedback and the discussion that the focus on American Indian works was both intriguing and confusing for the students because they were not familiar with American Indian texts; intriguing because the content was so new, and confusing because they did not understand the complex and unique historical backgrounds of the varying nations (qtd. in Hoover 173). None of my students had ever encountered an American Indian text, nor had they any knowledge about "real" American Indian peoples. Zitzer-Comfort asserts that many students come with little to no background knowledge of Native peoples and rely on stereotypes they have learned. She 
explains that two of the most significant barriers to consider when teaching American Indian literature are “combating stereotypes of American Indians, which come from students' internalized assumptions, and students' lack of background knowledge or their beliefs in aspects of American history that ignore American Indians" (Zitzer-Comfort 162). While not one of my students had ever read a piece of literature by, about, or for American Indian peoples, they did have knowledge of the stereotypes surrounding American Indian peoples. For example, when discussing the demonstration of stereotypes in Sherman Alexie's (Spokane-Coeur d'Alene) The Absolutely True Diary of a Part-Time Indian (more specifically about expectations of "who is American Indian"), one student made the comment that "American Indians only play powwow music, or drums" (qtd. in Hoover 173). Upon hearing this, I brought up Youtube.com and played "Still On Da Rez" by Rez Life Boi - Carradine Billie, a Seminole hip hop music artist. My students were shocked to hear an American Indian music group singing hip-hop. The realization that one, American Indians are present in our everyday lives, not fictional characters in the movies and in history books, and two, that they were a part of pop culture, was shocking to them. Their surprise was satisfying, as they were being confronted with their assumptions surrounding American Indian peoples (173). After watching the hip-hop video, most of my students immediately expressed that their expectations of American Indians "were different." This sharing of their viewpoints enabled me to list their "expectations" on the board, and the following is what they came up with: "feathers, Indian dress, face paint, long hair on men and women, stoic, old, wise, and drum music.” My students shared that they envisioned most "Indians to be old" and "mythic storytellers."

Perhaps the most worrying realization I had when teaching this course was that my students did not have any previous background on the violent history of assimilation, relocation 
and removal of American Indian peoples. Because my students reported a lack of exposure to basic history about the relocation and removal of American Indian peoples, I have incorporated lecture and videos on colonialism and relocation and removal into my present course planning in order to emphasize the history of violence, relocation, removal, assimilation, and alienation that took place during the 1800s. In the initial semester, however, I addressed that lack of history with exercises involving guided internet research prompts during class time in a computing lab. Many of my students had no understanding of the struggle for sovereignty that American Indian nations continue to survive against; so, to encourage their awareness, I had them research current events by using the terms "Native American," "American Indian," and "American Indian sovereignty." ${ }^{, 71}$ Students could use additional terms during their search but I found that these terms provided them a strong starting point from which they could expand their own research. In the following class session, I had the students explain to the class what he/she had found. Some current events included mascot prejudice, adoption issues, tribal citizenship, Victoria's Secret using American Indian ceremonial dress for their models, and the filming of the Lone Ranger that was taking place at the Navajo Nation's Canyon de Chelly (Hoover 174).

The students' unawareness surrounding the uniqueness of invidual Native Nations also showed when discussing Tracks by Louise Erdrich; students kept using generalisms like "all American Indian people" or "all American Indian groups" (174). Though I made it a point to lecture to the students about the different beliefs, philosophies, traditions and cultures between the various American Indian nations as we read works by different American Indian authors, I also wanted them to learn the unique histories and cultures on their own; for, simply telling them that "Sherman Alexie identifies as Spokane/Coeur d'Alene and Luci Tapahonso identifies as Diné, would not help the students to understand the immense differences between the nations, 
nor the differing histories" (174). To promote their own learning, I took my students to a library computer lab and encouraged them in researching the authors' backgrounds that we had previously read (up until that specific time in the course) - these included: Sherman Alexie, Louise Erdrich, Luci Tapahonso, and Vine Deloria. These backgrounds consisted of location of the authors' Nation, identifications, and affiliations. This exercise enabled the students an opportunity to learn about the autonomy of the individual nations, as well as aided in their learning process as they acquired this information on their own, rather than through lecture (174).

Though my students were unaware of the distinction of American Indian authors, ultimately, they had no understanding as to the significance of the term "sovereignty" when encountering works by Native authors or otherwise. Encouraging students to be able to identify and become aware of sovereignty in not only current events, but also in texts about and by American Indians is essential in their understanding of the historical and personal contexts surrounding works by, for, and about American Indian peoples. Before students can fully appreciate the significance of a piece of work authored by an American Indian author, it is necessary for them to recognize and understand rhetorical sovereignty, as according to King, this recognition "asks that students dig deeper and try to understand what they do not know and what is not 'about' them" (223). To provide the students with the opportunity to identify sovereignty in manageable texts, I used excerpts from Sarah Winnemucca's Life Among the Piutes and Charles Eastman's From the Deep Woods to Civilization as both works are "approachable and effective, and demonstrate rhetorical sovereignty for the students" (Hoover 175). After reading these works, I encouraged my students to discuss how Winnemucca and Eastman demonstrate sovereignty through their rhetoric, including code switching. Some students researched 
"rhetorical sovereignty" through their laptops and cell phones to ensure they were understanding the term "sovereignty" correctly, and they brought in these definitions of rhetorical sovereignty when discussing Winnemucca and Eastman and the authors' use of specific rhetorical choices. Their works prompted the students to question: "how and why is the act of writing this text considered rhetorical sovereignty?" Furthermore, I provided my students with excerpts from these texts to make them privy to the ways in which literature and rhetoric come together and to help demonstrate the power of the rhetoric used in the storytelling of both Winnemucca and Eastman, as well as the history of the United States that both texts exhibit. The students quickly noticed the different audiences that each author was addressing, the strategy of story telling, and how both authors used their words and language with specific purpose - to attain a rhetorical goal (175).

When discussing rhetorical choices, I also wanted my students to understand the action of code switching. To encourage their acknowledgement of code switching, I asked my students to go to the library and locate an American Indian author that uses both English and another language in his/her works. This assignment allowed us to spend a class period discussing code switching and the plethora of examples they had found, as well as showed the students that different American Indian authors use language in varying ways. The students also noted how some authors included translations and others did not, which led to further discussion about rhetorical sovereignty. Finally, after much discussion of code switching, as well as "what is rhetorical sovereignty," I then had my students read Tohe's book Tséyi' / Deep in the Rock: Reflections on Canyon de Chelly. Another reason I chose Tohe's text to teach the students about rhetorical sovereignty is because, according to Elizabeth Yeager Washington and Stephanie Van Hover in their article "Din'e Bik'eya: Teaching about Navajo Citizenship and Sovereignty," 
Tohe's book is argued to be one of most prominent resources for teaching about American Indian identity, more specifically, Diné identity. Furthermore, the Navajo Nation comprises the largest land area allocated "mainly to a Native American jurisdiction" in the United States and so it offers a distinctive opportunity to develop students' understandings of citizenship rights and sovereignty (Washington and Van Hover 80).

\section{Focusing on Tohe's Text}

Before starting any new piece of literature, my students were provided with some background of the author. The author's background information (ethnicity, history, etc) was accomplished through my lecture and their own research on the author's agency. In this case, it was Diné Laura Tohe. Before engaging with her poetry, I discussed with my students the Diné history, more specifically, the Navajo Long Walk, as the Long Walk is a significant image in the text. I then had my students read Tohe's poem "Many Horses" and, while in groups, come up with a reason for her code switching in that poem. Not only did this generate discussions about why Tohe "used certain words" in "certain spots" of her poem, but it also prompted students to wonder: "why horses?" Investigating Tohe's poem also led into a discussion of rhetorics of alliance, as well as sovereignty. Another exercise with Tohe's text was to have the students go through her book of poetry, and pick out where they found examples of rhetorics of survivance (after we discussed "what are rhetorics of survivance") and alliance. As explained in my essay "Rhetorical Sovereignty in Written Poetry," I first encouraged my students to find examples on their own, and then in small groups (about 3-4 students in each group). This activity allowed them time to read the poetry once more (they had read it before class as well) and engage with Tohe's use of rhetorics of survivance and alliance. I placed them into small groups to discuss this in more detail as it provided them with a level of comfort as none of my students had any 
knowledge of the Navajo Long Walk, which, as I mention above, is a strong focus in Tohe's text (176). Furthermore, rhetorics of survivance and alliance can be difficult to not only understand, but also identify, when undergraduate students have not had any previous experience with American Indian texts and/or authors, or any knowledge of the terms alliance, survivance, or sovereignty in a rhetorical focus. The small groups also allowed them a chance to express and better articulate their ideas before coming together to discuss their findings as a whole class. As to not stress the individual students, I had the students share their findings as a group; this led to interesting dialogue both within and among the groups of students.

By analyzing Tohe's text, my students learned about cultural and rhetorical sovereignty, as well as survivance and alliance, and they began to see how and why Tohe reflects on what Canyon de Chelly means for the Diné, in terms of their roots and deep historical and personal connections to the canyon, as well as the impact of the Navajo Long Walk. In my case study of Tohe's work, found below, I provide an analysis of Tohe's Tséyi' to establish how her rhetorical choices and demonstration of rhetorical and cultural sovereignty can aid in students' understandings of survivance and alliance, through the usage of her code switching.

\section{A Short Case Study of Tohe's Work}

Sharing History and Demonstrating Survivance

One way that survivance is demonstrated and employed in works by and about American Indian peoples is through storytelling (Vizenor "Survivance"). It is through her poetic stories of the Navajo Long Walk and the struggles and tragedies surrounding the Navajo Nation - or rather Diné bikéyah $^{72}$ - that Tohe employs her rhetorical sovereignty by using rhetorics of survivance through her use of the Navajo language by code switching and using translation (Hoover 176). It is through Tohe's story telling, via rhetorical sovereignty, that my students learned more about 
the Diné and their land, than through non-Native rhetorics of fugitive poses. My students learned the history of the Navajo Nation through Tohe's focus on the history and significance of the land, more specifically Tséyi, or Canyon de Chelly - as it is known, according to Tohe, on "tourist maps" (xiii). In her introduction, Tohe explains to the reader that Tséyi' housed the Diné, and both the Diné and the land accepted each other (xiii). This "kinship" was threatened in 1864 when the U.S. Calvary, led by Kit Carson, forced the Diné from their home - from their land (Hoover 177). Tohe educates the reader about the Navajo Long Walk and about the Navajo Nation through her references to relocation and removal. She accomplishes this education through her reflections while visiting Canyon de Chelly. Canyon de Chelly, "the rock," is in the heart of "Dinetah," or rather the Navajo Nation. It is also the place where many Diné hid from the United States during the "round-up" of the Diné that was led by Kit Carson from 1863-1868. My students noted the "history lesson on the Navajo Nation" that Tohe provides in the beginning of her work. It is significant that my students realized this use of history, as Tohe's "educating" my students not only helped them to see the difference in histories between the varying Native Nations (in this case, specifically of the Navajo Nation), but her sharing of the Diné history also helped my students to "see" the importance of the stories shared within her poetic compilation.

Further, I noted above how Powell asserts that we need a "new language" in order to accept each other and learn from each other. Tohe attempts to promote this new language through her poetry as she uses the Navajo language with the English language. She does not use one or the other; she uses both. More specifically, she uses both to teach the reader about the Diné's history, land, culture, beliefs, and traditions, and give voice to both past and contemporary Diné peoples. Moreover, code switching provides her with a tool to not only re-tell a history that has been skewed or ignored by the Western culture, but also a tool through which 
she can encourage allies, ones that will learn about and appreciate the Diné's continued existence. It is the dynamic relationship between languages in which Tohe shows empowerment through language. Harjo and Bird emphasize that using English can be a form of empowerment in the face of destruction when used for "Native" purposes: "In our tribal cultures the power of language to heal, to regenerate, and to create is understood. These colonizers' languages, which often usurped our own tribal languages, or diminished them, now hand back emblems of our cultures, our own designs: beadwork, quills if you will. We've transformed these enemy languages" (21). So, it is through Tohe's use of two languages in her works that discussions of language, its connectedness to identity, and how "using the enemy's tools" is indicative of continued sovereignty reclamations. As my students read Tohe's book of poetry, I encouraged them to discover the Navajo language and consider its function in the text. Below are a few ways that Tohe uses the Navajo language to send a message to the reader.

\section{Code Switching}

The Diné's presence, instead of the imposed absence suggested by Western rhetorics, is significantly depicted in Tohe's poem "On the Round Belly of the Earth" as she encapsulates the invasion of the unwanted visitors on the Diné land. She writes:

The Germans, Swedes, Danes, and Eastern Europeans that / flooded this country brought with them the fury to own the land. First by the force / of themselves, opening the earth and dropping seeds into her, they realized the / abundance of the land and wanted more. The plane turns southward and toward / home, where my mother buried my umbilical cord so that my spirit would remain / tied to Nahasdzáán, the earth. (1) 
Tohe translates "Nahasdzáán, the earth" for the reader because she is not only sharing the history of the Diné land and establishing the continued presence of the Diné in a land that was "flooded" by those trying to take the land and eradicate the Diné, but she also emphasizes the Diné's deep connection to Nahasdzáán, the earth. Tohe's explanation of the "invasion" onto the Diné's land was a strong foundation from which to teach my students about the tragic relocation and removal of the late 1800s, and its impact even into the twenty-first century. Further, Tohe's reference to the Diné's connection to the earth helped to focus discussions of how different nations respect the land and their cultural connections to it. This emphasis on the Diné's connection to the land, in turn, helped to quell the stereotype that "all Indians like the land."

As shown in "Rhetorical Sovereignty in Written Poetry," it is also through her poetry that Tohe teaches both non-Native and Native students about the Diné's rich culture and values, as well as uses rhetoric of survivance to demonstrate a strong nation and land that endured relocation and removal, as she directly or indirectly translates terms that are significant to the nature and land of the Navajo Nation (Hoover 177). One example of her translation is in the poem "Deep in the Rock." Tohe writes: "Deep in the rock, crows make echoes, gáagii, gáagii. Their name is pure /onomatopoeia. Gáagii / are everywhere" (9). The Navajo word "gáagii," is connected to the English term "crows." In Navajo Land, Navajo Culture, Robert S. McPherson explains that, "a medicine man, said that coyote, wolf, crow, and mountain lion were all hunters and friends of Navajo hunters. The crow cries ahead and tells the hunter where the game is located" (25). Thus, the above example shows Tohe's use of rhetorics of survivance through not only her use of the Navajo language in her English-dominant text, which makes her a "subject within [the dominant discourse], not just a victim subject to it" (Powell "Rhetorics" 425), but she also depicts survivance through the image of the crow and her engagement in trickster rhetoric 
through her code switching. Tohe asserts her active, Diné presence through the representation of the crows, and is, in a sense, telling the reader: "like the crows, we are still here." Tohe's connection between the Diné and the crows' and trees' sustained presence in the land represents a continued and active presence by the Diné; for, according to Vizenor, "the presence of animals, birds, and other creatures in native literature is a trace of natural reason, by right, irony, precise syntax, literary figuration, and the heartfelt practice of survivance" ("Survivance" 12). This survivance can further be seen in the following line: "Deep in the rock, the tamarisk and monkey-egg trees have dug in to prevent / erosion. Like the Diné, they refuse to leave" (Tohe 9). This line appears simplistic in its imagery of the trees being rooted in the earth; however, this is a very complex line that denotes the survival and the "roots" of the Diné in the past and in the present. "Like the Diné" who hid within the canyon to evade relocation and removal, or rather the "erosion" of their culture and home, the "tamarisk and monkey-egg trees" are symbolic of the Diné of the past who did not leave the canyon, as well of those who were forced to physically leave, but whose culture remained intact to teach and share stories with the Diné of the present. This continued existence was an important concept for my students to identify in Tohe's text: that American Indians are not only in the past and absent - they are both present, and in the present.

Tohe's expertise in dual-languages allows her to teach the non-Diné reader not only about the land of the Navajo Nation, but also about the traditions and beliefs of the Diné, which are "rooted" in the canyon. These traditions can be seen in the poem "Jiní," when Tohe directly translates the Navajo term "jiní" to the English phrase "they say," as she writes: "Jiní, they say. We accept jiní as part of our stories on simple faith. It's not important who said it, but that it was said" (11). While Tohe is retaining the Diné connection to the word "jiní," she is also letting the 
non-Diné speaking reader see that "they say" is the English equivalent. The "they" are the Diné who were not allowed to have a voice during the 1860s. This poem demonstrates that regardless if they were heard in the past, they have stories that influence the present. They have history and they should be heard. Tohe's explanation of "they say" is housed within a poem that remembers the past and demonstrates a respect for what was said by Diné ancestors - it is nostalgic of a precolonial nation. She is demonstrating the Diné as a people that have not only endured hardship, but also a nation that has great strength. Tohe seems to not only be educating the non-Diné reader, but also the Diné, as she engages in sharing Diné stories about the past (Hoover 180).

Concepts such as being present and sharing emotional issues is further seen in Tohe's poem "Refugees in Our Own Land," as she translates the following for the reader: "Shiyáázh, my son, fusses in his cradleboard" (17). She continues: "Shhh, shee'awéé', shiyázhí, shhh." Hush baby, my beloved, hush," as she translates for the non-Navajo speaking reader once again. It is important that Tohe translates for the reader, as she is teaching the non-Diné speaking reader the Navajo language, as well as the context in which these translations and code switches are used. This emphasis on language is significant because it encourages students to wonder why the baby is fussing and why the mother is so concerned with "being heard" by the enemy. These inquiries by the students furthered discussions of forced removal and eradication, as well as discussions surrounding the idea of the "enemy" in the text.

\section{Promotion of Alliance}

Another important element of Tohe's translations, or rather her teaching the reader the Navajo language, is her promotion of alliance. This use of alliance is seen in her poem "Many Horses." On the surface, it seems as if the speaker visits the mountain and then leaves. While this can be indicative of Tohe being called to the canyon by her ancestors, it is the use of her code 
switching and translation that is most important, as Tohe emphasizes the Diné creation story and repeats the English version of "mountain" six times and the Navajo version five times. (These versions change, depending on the action, as can be seen below). The following excerpt shows her code switching and full translation of these code switches:

Dził bich 'ị’ yishááł...I am approaching the mountain

Dził bikáá' haashā...I am ascending the mountain

Dził bikáá' naashá...I am walking on the mountain

Dził bąąhdōō ‘adaashááh...I am descending the mountain

Dził bits'ąaji dah diishááh...I am leaving the mountain. (7)

Tohe uses ellipses to guide the reader to a translation of the Navajo phrases. As the action changes (i.e. walking, descending, leaving, etc), as does the Navajo translations, while the English versions of "the mountain" remain the same. Tohe clearly knows that her audience includes non-Diné speaking, or rather reading, readers, as she is outwardly teaching them the Navajo language. These teachings can be for the non-Diné reader, or it is also accurate to assume that she may also be teaching other Diné the language as well, as the younger generations use the Navajo language less and less. This example clearly demonstrates rhetoric of alliance, as Tohe is sharing knowledge with her audience, be they Diné or non-Diné, as she is encouraging the reader to become an "ally"; one whom works "toward the survival" of his/her community and the Navajo Nation (Powell "Down" 42). Tohe continues her promotion of alliance in her poems "Female Rain" and "Male Rain." What makes these poems unique is that they are both written entirely in the Navajo language and then a translation of these poems is written entirely in English. Again, Tohe is demonstrating her awareness of both audiences, Diné and non-Diné by 
including both languages, which aids in her teaching the Navajo language. Her instances of code switching in this type of context not only helped to emphasize the conscious decision of her code switching and translation, but also why she decides to do that in those particular poems.

As I made my students privy to the concept of code switching, a few students noticed that she does not translate the term "Hwéeldi." She uses this term one time in her entire book of poetry. The only time she uses the term is in her short poem, "What Made This Earth Red?" as she writes:

What made this earth red? These rocks red? Was it the light from earth / and sky to remind us at day's end of the color of our births? Is it all the / trails we took upon ourselves or that were forced upon us, beginning / with our blood trails to Hwéeldi and back? (3)

"Hwéeldi" is what the Diné call their relocation place of Bosque Redondo, also known as Fort Sumner. However, Tohe does not share the meaning of this term; meaning, she does not guide the reader with a comma or an ellipsis to the translation of "Hwéeldi." My students (excitedly!) noticed this exclusion of translation and we had a discussion about the meaning of Hwéeldi. I did not offer them the definition of the term; rather, I allowed them to use their laptops, iPhones and iPads to research the definition. My decision to have them research the term was my modeling of how to take the time to research a piece of information if one does not know its meaning. After discussing the meaning behind the term, we had a discussion about why she does not translate it for the reader. One student noted: "Maybe she doesn't want us to know," to which another student responded: "Then why would she include it in the poem?" This back and forth was a positive discussion about meaning in the poem and the author's autonomy as a Diné woman. 
Tohe's code switching, or rather her use of both English and Navajo languages, helped my students to "see" the "new language" that Powell stresses, as both propose their meanings and translations for the audience. The discussion about language's function in the poems also enhanced the students' understanding that the Navajo language is in decline. This discussion, in turn, provided a transition into the topics of assimilation and American Indian boarding schools. Furthermore, Tohe realizes her audience of non-Natives and thus is presenting to them the idea that in addition to listening to one another, we "must share some understanding of one another's beliefs. We don't have to believe one another's beliefs, but we do have to acknowledge their importance, understand them as real, and respect/honor them in our dealings with one another" (42). Respect and acknowledgement are both demonstrated through Tohe's conscious decision to translate the Navajo language for the non-Navajo speaking reader - she is aiding non-Diné students in learning about the Diné culture, and demonstrating that these languages can coexist. Lastly, Tohe's lack of translation for specific terms and demonstration of sovereignty not only encouraged my students to understand how the Diné are different from other American Indian nations, but also question what the terms that she does and does not translate, represent.

\section{Questioning Representations}

Tohe's work also helped to clarify issues of representation and fugitive poses, which can be seen in her poem, "A Tree Grows near the Road.” The poem has two stories. The first story gives voice to a past Diné woman, enduring the Navajo Long Walk in the canyon in 1864 The second story gives voice to a present day (2005) Diné woman who watches tourists tromp on the very ground where Diné blood was spilt by the US government in the 1860s. Tohe begins her poem with a depiction of the tourists that visit the canyon: “...trucks and jeeps used to run tourists / in and out of the canyon - half-day, all-day tours, cameras click, / coconut sunscreen / with SPF 30 
fills the air" (Tohe 13). While the tourists are clicking their cameras, taking pictures of the beauty of the rock, they are oblivious to the stories embedded in the stone. Tohe, however, reminds the reader, disrupts the tourists' narrative, and gives voice to the "woman who got away" (13). She tells the woman's story for her, since she was silenced during the Navajo Long Walk; this can be seen in the following excerpt: "Someone shudders in that tree that reaches across the dirt trail. It is a woman / driven from her home. Her husband and children scorched, along with the corn / and peach orchards. The sheep slaughtered. Below the horse soldier paces / back and forth, back and forth. She sees horse prints in the sand burying hers" (13). This back and forth of past and present-day images stimulated a discussion about the Diné's continued presence as well as discussions about the Navajo Long Walk, an event in which students were already made privy from Tohe's introduction. We also discussed, as a class, the filming of "The Lone Ranger" at Canyon de Chelly. My students had a difficult time understanding why Johnny Depp and the rest of the cast of the movie were allowed to shoot a film where "so many people died" during the forced removal of the Navajo Long Walk. The empathy and concern my students exhibited prompted me to discuss with them situations of appropriation, such as Halloween costumes and mascots. While my students admitted that mascots were "wrong," most admitted that they never even considered Halloween costumes to be "offensive." However, many students claimed that now, after realizing American Indians are "real" and are "here," they would "feel weird" wearing an "Indian mask" or "headdress." Therefore, Tohe's short poem was also very effective in encouraging discussions of appropriation and representation.

Further, in the same poem, Tohe also depicts the canyon as a present-day, tourist "hotspot," as she writes: "Brown Diné women sell soda and turquoise jewelry / near the grove of cottonwoods at Antelope House / Tourists must love the authenticity of "Real Indians" (13). "A 
Tree Grow near the Road" is the only poem in which Tohe emphasizes representation and stereotypes surrounding the Diné, or even American Indians writ large, as she writes: "Tourists must love the authenticity of 'Real Indians."” This singular mention of "Real Indians" was a fantastic foundation from which the students examined the common stereotypes surrounding the "realness" of American Indians.

\section{What They Learned}

As my analysis and case study above displays, Tohe's poetry provides non-Diné students, or even Diné students, with a glimpse into the Diné culture, while also displaying her rhetorical sovereignty. It is through her poetry that she shows students, through "Diné eyes," the history and culture of the Diné, and it is through her "teaching" about her culture, language, and history that she engages students in rhetorics of alliance - she creates allies through her poetry, her storytelling, and her teaching. Analyzing Tohe's text was significantly beneficial to my students' understanding of sovereignty and about the Navajo Nation, as is evidenced below.

To conclude our focus on Tohe's work, I required my students to write a 3-5 page response paper on their understanding of Tohe's text and their ideas as to what Tohe is "choosing" to "do" and include in her poetry and why. Not only had we focused on code switching, rhetorical sovereignty, and rhetorics of survivance and alliance in that part of our literature course, but we had also discussed Tohe's display of cultural sovereignty and ideas of cultural continuance. With all of the topics that we had covered while discussing Tohe's text, these response papers provided students with an opportunity share their understanding and reflections of Tohe's demonstration of her own, as well as the Navajo Nation's, survivance - in addition to the other rhetorical moves in her work, such as rhetorical sovereignty, code switching, translation, and cultural sovereignty, as well as rhetorics of alliance. Some students 
focused on Tohe's rhetorics of alliance, noting her teaching the non-Navajo speaking audience the Navajo language. One student wrote: "I had no idea that the Navajo had their own language. However, I am glad that Tohe taught me the difference between English and Navajo. I feel like I am in a privileged group - learning how to read Navajo." Another student noted: "My favorite part of Tohe's poetry was learning how to read Navajo. Seeing the two languages next to each other made me realize how we say things differently in our different languages. I wonder how the meanings change" (qtd. in Hoover 183). These examples of my students' writing demonstrate that the students appreciated and acknowledged learning about the differences in languages, cultures and meaning-making, and that they recognized and enjoyed Tohe's decision to teach them the language of the Diné. This learning process promotes not only discussions about alliance, but also encourages allies.

Some students also noted Tohe's ability to write in both the Navajo language and the English language, but one student wrote that: “Tohe's use of both English and Navajo [languages] is a weapon in her arsenal of survival strategies that help her show her presence in literature" (qtd. in Hoover 183). Also focusing on sovereignty, another student reflected on the following: "In history class we never learned about the Navajo Long Walk, nor did we learn about American Indians struggling with their sovereignty. What does this tell us about sovereignty today? Leaving out this vital information tells us that there is still a struggle for sovereignty - to be heard" (183). The student's realization that the visibility of the Long Walk is limited or non-existent in some history classes/textbooks, as well as the student's recognition of rhetorical sovereignty was one of my goals in teaching Tohe's work.

In the words of Powell, "maybe as allies, we can spur one another on to even more disruptive tactics" ("Down" 57). By this, I mean that we need to disrupt our students' 
preconceived (and sometimes misinformed) notions about American Indian peoples and works authored by American Indians. Moreover, for those students who have never been privy to these texts, we can form a "pedagogical framework that both encourages and teaches students to be allies, and I believe texts like Tohe's can help us do just that" (Hoover 184). Before students can wholly appreciate and understand the complexities of works authored by American Indian peoples, they must understand the meanings of political, intellectual, cultural, and rhetorical sovereignty, as Lyons asserts that no student should "encounter a Native American text without having learned something about Indian peoples' historical and ongoing struggles for sovereignty" (464). By bringing into focus the continued struggles for sovereignty, it helps to clarify the continued existence of American Indians, their significant contributions to society, including literature, and helps the students to call into question their own preconceived notions surrounding expectations, representation, and colonialist views.

The above-mentioned discussions and classroom activities surrounding the above works, including Tohe's Tséyi", does not represent a course in its entirety; rather, "I am providing a potential stepping-stone for beginning the necessary and complex journey into assisting our students in understanding sovereignty as well as rhetorics of survivance and alliance" (Hoover 185). Further, as King posits,

the need for Native texts in the classroom connects in part to a larger ongoing discussion regarding multiculturalism and the recognition of multiple voices in the composition classroom. While multiculturalism in pedagogy has made some progress via bringing those voices habitually marginalized to the attention of students, the rhetorical 'hows' and 'whys' of these voices and the texts through which they speak are not frequently addressed. (210) 
In order to successfully understand and appreciate Native works, students must understand sovereignty. Lyons posits that the "pursuit of sovereignty is an attempt to revive not our past, but our responsibilities" (448). For those of us who are non-Native, or even Native, allies, "teaching our students about American Indian nations, the various nations' historical backgrounds, and the significance of and struggle for sovereignty, is our responsibility" (Hoover 185). The promotion of alliance between American Indian authors and their works and the introductory literature classroom, provides a means of listening to (and hearing!) each other, contributes to each other's ability to maintain a balance of growth and respect for each other's communities, and a place in which future alliances and a respect for sovereignty (intellectual, cultural, and rhetorical) can be actuated and respected (185).

Colonial educational systems have endorsed and promoted problematic ways for both non-American Indians and American Indians to engage with literatures and rhetorics authored by, for, and about American Indians (184). Thus, making students privy to indigenous works that contain these rhetorical moves is significant because many students do not understand, or even acknowledge, that American Indians struggle for sovereignty; further, many do not have any experience with American Indian texts or knowledge about indigenous populations. By using Diné writer Laura Tohe's Tséyi'/Deep in the Rock: Reflections on Canyon de Chelly as an example, educators can encourages students to discuss the importance of language, the reasons for how/why shifting languages is critical, and how different American Indian nations may use language in various ways to affirm their cultural and intellectual sovereignty.

Tohe's text is a useful tool through which educators can teach students how American Indian authors maintain and (re)claim their rhetorical sovereignty. Further, using a text such as Tohe's is beneficial to not only the promotion of American Indian texts in the classroom, but the 
necessity of disrupting, adding to, and maintaining our students' acknowledgement, awareness, and understanding of the significance of rhetorical sovereignty and the power of those voices of American Indian authors in claiming that sovereignty and resisting colonial attempts to silence them (185). Analyzing and reading these texts in the introductory literature classroom (or even the writing classroom) will not only "encourage our students to hear these voices, but to possibly acknowledge, grow, and change their own voices" (185). This encouragement of growth, respect, and awareness not only promotes alliance but also creates allies. 


\section{NOTES}

1. In this dissertation, I use the terms "American Indian," "Native American," "Native" and "Indigenous" interchangeably because I quote from a variety of scholars who use the various terms. However, I will promote the term "American Indian," instead of "Native" or "Native American" to privilege the term American Indian authors are using in their works, so as to privilege and respect their rhetorical sovereignty on the rhetoric of identity issue. Most

importantly, though, I will also use tribal identifiers, when appropriate and/or available, to name tribal affiliation.

2. The biggest tragedy and struggle surrounding America Indian Nations and their allies during 2017 is the Standing Rock Sioux / No DAPL situation. For information about this, since the mainstream media coverage is both lacking and misrepresentational, see the following: Indian Country Today Media Network and Indianz.com, as well as Democracy Now's excellent coverage on the situation.

3. I use both "Navajo" and "Diné" in this dissertation. Navajo is an imposed title, but has been widely used by non-Navajo scholars and is therefore the most recognizable term in mainstream institutions to refer to this group of people. The word Diné, when translated into English, means "the people." The Navajo commonly refer to themselves this way.

4. Storytelling, as an act, will be further discussed in subsequent chapters.

5. The background and history I provide is limited in scope and by no means represents the breadth and depth of the complexities surrounding the American Indian - U.S. history, nor the unique historical contexts within the various sovereign Nations' and the United States' events, cultures, and societies. 
6. In "Rhetorical Sovereignty: What Do American Indians Want from Writing," Leech Lake Ojibwe rhetorician Scott Lyons tells us that what American Indians want from writing is the ability to pursue rhetorical sovereignty, or the "inherent right and ability of peoples to determine their own communicative needs and desires, to decide for themselves the goals, modes, styles, and languages of public discourse" (449-50).

7. In Tribal Secrets: Recovering Native Intellectual Traditions, Osage Robert Allen Warrior explains intellectual sovereignty as a means for one, who is a part of an American Indian nation, to promote community renewal, keep alive the American Indian tradition, and also allows nonAmerican Indians to see "the importance of choosing carefully whom we invite into the sovereign space that is... [American Indians'] intellectual praxis" (123).

8. In her article "The National Museum of the Native as Cultural Sovereignty" Chickasaw Amanda Cobb explains cultural sovereignty as engaging in an "act of self-definition" and to protect one's "cultural continuance" (502).

9. "Survivance" denotes the need for both resistance and survival; to resist an imposition of being absent and invisible in the colonial imaginary and to survive the ongoing colonial attempts to define, quiet, and ignore American Indian peoples. See Malea Powell or Gerald Vizenor.

10. Rhetorics of alliance, according to Malea Powell, encourages the reader to become an ally - one who works toward the survival of his/her community and that of the American Indian nations. In "Rhetorics of Survivance: How American Indians Use Writing," Powell states that to become allies, we "must share some understanding of one another's beliefs. We don't have to believe one another's beliefs, but we do have to acknowledge their importance, understand them as real, and respect/honor them in our dealings with one another" (42). 
11. According to Jennifer Nez Denetdale, "there are different meanings attached to Dinétah and Diné Bikéyah. Dinétah most often refers to the sacred ground that lies between the four sacred mountains as well as the region where the ancestors emerged from the lower worlds" ("Reclaiming" 190). Diné Bikéyah, on the other hand, means "Navajo Land," and is used to "refer to our [Diné] territory and usually refers to lands within the four sacred mountains and to the present Navajo Nation" (190).

12. Diné Rex Lee Jim explains that the Navajo way of life, when entering into the present world, was moved from chaos to order. This notion is referred to as "Są' ah naagháí bik'eh hózhóón,” which translates as “May I be everlasting and beautiful living” (qtd. in Denetdale 10). Jim explains that this is representational of the Diné's "declaration to live a healthy and wealthy lifestyle and the practice of applying its teachings to life" (qtd in Denetdale 10).

13. This fort is present-day Fort Defiance in Fort Defiance, Arizona.

14. For further explanation surrounding the discussions of the political aspects of sovereignty, please see Clara Sue Kidwell and Alan Velie's Native American Studies. Source is referenced in Works Cited.

15. See an additional explanation for "storytelling" in chapter three of this dissertation.

16. See the following for more on Anthony Webster's work in code switching: "CodeSwitching in Navajo Orthographic Poetry: On Places, the Mythic, and Mythic Places.” Texas Linguistic Forum 50 (2004); “From Hóyéé to Hajinei”: On Some Implications of Feelingful Iconicity and Orthography in Navajo Poetry. Pragmatics 16.4 (2006); Explorations in Navajo Poetry and Poetics. Albuquerque: U of New Mexico P, 2010. 
17. Other significant texts in this tradition include Elizabeth Cook-Lynn's Why I Can't Read Wallace Stegner and Other Essays, Robert Warrior's Tribal Secrets, Jace Weaver's That the People Might Live, Daniel Heath Justice's Our Fire Survives the Storm, and Lisa Brooks' The Common Pot.

18. I am using the author's use of "Native." While I privilege using "American Indian" in my dissertation, when referring to American Indian literature in general, I will also use "Native," if the author from which I am quoting or paraphrasing uses that title.

19. See the works of Jennifer Nez Denetdale and David E. Wilkins for more information on the connection between the Diné language and the Navajo cultural identity.

20. "Dinetah" or "Diné bikéyah," according to Tohe, is what the Diné call "their homeland" (2005, xiv).

21. While this explanation that she provides is in the preface of another of her works, it is applicable to my discussion of Tséyi'/Deep in the Rock: Reflections on Canyon de Chelly. Although I am not analyzing this particular work in this chapter of my dissertation, it is necessary to include an explanation of this preface in a discussion of Diné storytelling because Tohe's assertion reflects the tone of memory in all of her works.

22. I use the term "fugitive poses" in reference to Gerald Vizenor's theory that museums, photographs, anthropology and archaeology were deeply entrenched in a Western epistemological framework and have histories that are inherently colonial. The American Indians are "posed" in a particular view, a certain visual representation, that is afforded by Western and colonial thought. They are "posed" in silence and Western representations. Survivance works against these poses. For further discussion about "fugitive poses," see Vizenor's Fugitive Poses: Native American Indian Scenes of Absence and Presence. 
23. Sometimes authors shift the tribal designator of Diné to Dine, without the accent over the “e." Both mean the same, as both titles demonstrate a person's connection to the Navajo Nation. 24. For an article that provides visuals of the fashion designer's t-shirts, view the May2016 Huffington Post article "Wear These Native Designs Instead of Urban Outfitters" by Sarah RulzGrossman. Moreover, to purchase one of Yazzie's designs, visit his online store OXDX Clothing.

25. The examples I provide in this section are limited in scope and represent only a small percentage of the significant injustices that are continuing to be impinged upon American Indian peoples, most specifically, the Diné. Additional, recent articles that address this ongoing issue which affects all American Indian peoples, include Lauren Pelly’s “'Indian Giver’ Confronting Cultural Appropriation Through Artwork” in the Toronto Star and Denise Ryan's “"Just Watch Me': Challenging the 'Origin Story' of Native Americans" in the Vancouver Sun.

26. To learn more about what other American Indian tribes and nations are doing in order to preserve their languages, see: "Revitalizing Native Cultures" in Indian Country Diaries.

27. See a full explanation of the Navajo Long Walk in Chapter One of this dissertation.

28. In his essay "Diné Culture, Decolonization, and the Politics of Hózhǫ," Larry W. Emerson explains: "How one names Diné country seems to relate to how one views history, politics, and culture." Neocolonialists tend to call Dinétah the "Navajo Reservation." Contemporary Navajo officials call Diné country the "Navajo Nation." Traditionalists still call it "Diné Bikéyah" in a sacred way.

29. See Steve Russell's article “Huge Navajo Win for All Tribes: Exploiters of Tribal Names Slapped Down," which explains how Urban Outfitters used the name "Navajo" to further their clothing brand. Moreover, to see the numerous appropriations of the Diné culture, through the 
use of Halloween costumes, I Googled "Navajo Halloween Costumes." The results are disheartening, as there are 402,000 results for this search, and the costumes are sold by large stores such as Walmart, Ebay, and other numerous internet companies. For a specific article, with visuals of appropriated American Indian Halloween costumes, view the October $2015 C B C$ News article "First Nations Urge Against Wearing Offensive ‘Indian' Halloween Costumes” by Marina Von Stackleberg; this article provides visuals of the "American Indian" costumes, such as "Queen of the Tribe," "Native Knockout," and "Reservation Royalty." The research for this is very limited in scope; I included the results to emphasize my point about the continued appropriation of the Diné culture.

30. I will go into further depth and analysis, in regards to code switching and trickster, in the next chapter. I am only touching on it here, as to demonstrate the connection between the crows and trickster because Tohe code switches the Navajo word "gáagii" for "crow."

31. Some Diné argue that in order to be a part of the Navajo Nation, one must speak the Navajo language. See Tristin Ahton's article “Navajo Presidential Race Shaken By Language Gap.”

32. For more information about Navajo Skinwalkers, consult Joanne Teller's and Norman Blackwater's The Navajo Skinwalker, Witchcraft, \& Related Spiritual Phenomena: Spiritual Clues: Orientation to the Evolution of the Circle.

33. To read the Diné creation story, in its entirety, consult Paul Zolbrod's Diné Bahane': The Navajo Creation Story. Zolbrod privileges the elements of Diné oral storytelling and translates the creation story from Navajo into English. 
34. I use the English version for my analysis because I am not fluent in the Navajo language, and so I do not want to misinform or misinterpret any analysis surrounding the Navajo version of the poems.

35. To learn more about the relevance behind "Diné," and the meaning of "Navajo," see the article "Name Change Not On Navajo Agenda" from the Deseret News.

36. For more about Indira Karamcheti, who has discussed the practice of "insufficient" translation: a moment of "not-naming," and how that not-naming resists conventional English, see her article “Aimé Césaire’s Subjective Geographies: Translating Place and the Difference It Makes." In Between Languages and Cultures: Translation and Cross-Cultural Texts. Ed. Anuradha Dingwaney and Carol Maier.

37. The "entangled history" to which I am referring is the relocation and removal of the Diné, including the Navajo Long Walk, from 1863-1868.

38. I make the clarification here about "insiders," as even a Diné who cannot speak the Navajo language is still an insider to the Diné culture.

39. For further understanding in regards to keeping elements of the Diné culture "secrets" sacred, or how one must be Diné to understand some elements of the Diné culture, see Kyle Macmillian's article “Celebrating Navajo Stories" in the Denver Post.

40. For a discussion about male versus female tricksters, see Jay Cox's "Dangerous Definitions: Female Tricksters in Contemporary Native American Literature.”

41. For further discussion about border rhetorics, see Gloria Anzaldúa's Borderlands/La Frontera: The New Mestiza

42. Other Diné authors, both men and women who employ the use of trickster and trickster discourse in their works include Luci Tapahonso and Rex Lee Jim. 
43. Similarly to Chapter Two, I use the term "fugitive poses" in reference to Gerald Vizenor's theory (in his work titled Fugitive Poses) that museums, photographs, anthropology and archaeology were deeply entrenched in a Western epistemological framework and have histories that are inherently colonial. The American Indians are "posed" in a particular view, a certain visual representation, that is afforded by Western and colonial thought. They are "posed" in silence and Western representations.

44. For more on the silencing of American Indian women's stories and experiences, read John Wunder's Native American Cultural and Religious Freedoms and Sarah Deer's, Bonnie Clairmont's, and Carrie Martell's Sharing Our Stories of Survival: Native Women Surviving Violence.

45. For more about the silencing of American Indian histories, see Donald Fixico's Rethinking American Indian History and Clifford Trafzer et al's Boarding School Blues: Revisiting American Indian Education Experiences.

46. For more on the Diné naming systems, see Anthony Webster's “"Plaza 'Góó and Before He Can Respond....': Language Ideology, Bilingual Navajo, and Navajo Poetry.” 47. For further discussion of the boarding school systems naming system, see Clifford Trafzer et al's Boarding School Blues: Revisiting American Indian Education Experiences.

48. Two foods likely introduced to the students while at the boarding school. Louis Erdrich's "American Horse" too focuses on the use of food (a chocolate bar) in the persuasion of “assimilating" students in boarding schools.

49. See Frank G. Speck's Cherokee Dance and Drama, James Mooney's Myths of the Cherokee, and Gayle Ross's How Rabbit Tricked Otter and Other Cherokee Trickster Stories, as well as Richard Erdoes American Indian Trickster Tales. 
50. For information about African American trickster Brer Rabbit and Brer Rabbit's connection to American Indian trickster folktales, see Jay Hansford C. Vest's "From Bobtail to Brer Rabbit: Native American Influences On Uncle Remus.”

51. For additional information on Bugs Bunny as trickster, see NPR's JJ Sutherland's article "Bugs Bunny: The Trickster, American Style."

52. See Jonathan Brennan's edited collection When Brer Rabbit Meets Coyote: African-Native American Literature.

53. The rabbit, in other folklore traditions, is not always a strong figure, however. One example is Tar Baby, as the fox traps Bre'r rabbit. In that story, the rabbit is pretentious, and that pretension leads to his downfall.

54. Tricksters in the Diné culture act as representations and reminders of Diné "values, language and cultural history" (Ballinger 62). Trickster also is used as an "educative tool" from which young Diné learn (62). For more on Diné tricksters and the role of trickster rabbit in American Indian folklore, see Franchot Ballinger's Living Sideways: Tricksters in American Indian Oral Traditions, Paul Radin's The Trickster: A Study in American Indian Mythology, and Gary Varner's Creatures in the Mist: Little People, Wild Men and Spirit Beings Around the World.

55. According to Anthony Webster, "Puebloan peoples, historically, spoke a variety of Keresan and Kiowa-Tanoan languages, neither of which is related to Navajo (a Southern Athabaskan language)" ("Imagining" 54).

56. Ma'ii plays a large role in the Diné creation story, as can be read in Richard Howells' $A$ Critical Theory of Creativity. Coyote, ma'ii, is also used in Diné children's stories to teach about 
society and cultural values, as can be seen in Shonto Begay's Ma'ii and Cousin Horned Toad: A Traditional Navajo Story.

57. See Franchot Ballinger's Living Sideways: Tricksters in American Indian Oral Traditions.

58. Italics used by the author.

59. For more about the role of the matriarchy in the Navajo Nation, see Jennifer Nez

Denetdale's work on decolonizing the Diné history through storytelling in Reclaiming Diné History: The Legacies of Navajo Chief Manuelito and Juanita and Denetdale's article about the Diné traditions in "Chairmen, Presidents, and Princesses: The Navajo Nation, Gender, and the Politics of Tradition.”

60. For more about the history and prominence behind the bouffant hairstyle during the 1950s and 1960s, see Margaret K. Powell's and Joseph Roach’s "Big Hair.”

61. See Jacqueline Keeler's article “Why Navajo Hair Matters: It's Our Culture, Our Memory, and Our Choice" in Indian Country Today.

62. See also Tohe's poem "The Mane Story” in No Parole Today.

63. I use the term "American Indian," instead of "Native" or "Native American" when referring to general American Indian literature; however, tribal designations are preferred when possible.

64. See Scott Richard Lyon's “Rhetorical Sovereignty: What Do American Indians Want from Writing?"

65. Another important source is Tanya Lee's "America Indians Go Ivy League” from Indian Country Media Network, which explains that the percentage of American Indian and Alaskan Natives, at Ivy League schools, as of December 2013, was only around $0.5 \%$. 
66. See Ernest Stromberg's American Indian Rhetorics of Survivance: Word Medicine, Word Magic.

67. For more about language loss issues within the Native Nations, see Joanie Harmon's "Reclaiming a Native-American Language" and Hoskie Benally's "Lands and Language." To learn more about what other American Indian tribes and nations are doing in order to preserve their languages, see: "Revitalizing Native Cultures" in Indian Country Diaries.

68. See John McWhorter's “How Americans Have Re-Shaped Language” and Jonah Engel Bromwich's December 2016 news article "YouTube Stars Say They Were Removed From Delta Flight for Speaking Arabic," and Chris Fuchs "Politicians, Asian Americans Respond After New York Times Editor Told to 'Go Back to China."”

69. This is referencing Ronald Takaki's A Different Mirror, in which he recounts an incident with a taxi driver as he heads to a conference on multiculturalism in Norfolk, Virginia.

70. I am referencing Craig Womack here when, in Red on Red: Native American Literary Separatism (1999), he argues that "tribal literatures are not some branch waiting to be grafted onto the main trunk. Tribal literatures are the tree, the oldest literatures in the Americas.... We should not allow ourselves, through the definitions we choose and the language we use, to ever assume we are outside the canon" (6-7). While I do not go so far as to argue for the separatism of canons that he ultimately does, I do agree that individual Native nations' rhetorical traditions must be recognized, which is why I emphasized the differing nations, and their rhetorical contributions, in my course.

71. When I had the students conduct their own research in the computer lab, I guided them to specific sites that would provide credible sources, i.e. scholarly journal sources, newspaper and magazine sources, using .ORGs, .GOVs, .EDUs, and so forth. 
72. Diné bikéyah," according to Tohe, is what the Diné call "their homeland" (2005, xiv). 


\section{WORKS CITED}

Anzaldúa, Gloria. Borderlands/La Frontera: The New Mestiza. $3^{\text {rd }}$ ed. Aunt Lute Books, 2007.

Archambault, David. "Standing Rock Sioux Tribe Thanks Many Allies.” Indianz.com, 5 Dec. 2016, http:/www.indianz.com/News/2016/12/05/dave-archambault-standing-rocksiouxtri.asp. Accessed 5 March 2017.

Archuleta, Elizabeth. "'I Give Your Back': Indigenous Women Writing to Survive.” SAIL, vol. 18, no. 4, 2006, pp. 88-104.

Babcock-Abraham, Barbara. “'A Tolerated Margin of Mess’: The Trickster and His Tales Reconsidered." Journal of the Folklore Institute, vol. 11, no. 3, 1975, pp. 147- 186.

Babcock, Barbara, and Jay Cox. "The Native American Trickster." Handbook of Native American Literature. Ed. Andrew Wiget. New York: Garland, 1996.

Ballinger, Franchot. Living Sideways: Tricksters in American Indian Oral Traditions. Norman: U of Oklahoma P, 2004.

Bataille, Gretchen M. and Lori Lisa. eds. Native American Women: A Biographic Dictionary. $2^{\text {nd }}$ ed. New York: Routledge, 2001.

Bear, Charla. “American Indian Boarding Schools Haunt Many.” NPR 12 May 2008, http://www.npr.org/templates/story/story.php?storyId=16516865. Accessed 4 June 2016.

Begaye, Russell. "Federal Government Lets Navajo Nation Down After EPA Mine Spill.” The Daily Caller. 2 Nov 2015, http://dailycaller.com/2015/11/02/federal-government-letsnavajo-nation-down-after-epa-mine-spill/. Accessed 4 July 2016.

Benally, Hoskie. "Lands and Language.” PBS.org. 13 March 2016, http://www.pbs.org/circleofstories/wearehere/. Accessed 13 July 2016. 
Bighorse, Tiana. Bighorse the Warrior. U of Arizona P, 1994.

Blaeser, Kimberly. “Trickster: A Compendium.” Buried Roots and Indestructible Seeds: The Survival of the American Indian Life in Story, History, and Spirit. Eds. Mark A. Lindquist and Martin Zanger. Madison: U of Wisconsin P, 1994.

Blau, Max, Kait Richard, and Marisa Russell. "North Dakota Pipeline: Protestors Vow to Stand Ground." CNN, 30 November 2016, http://www.cnn.com/2016/11/29/us/dakota-pipelineprotests. Accessed 5 December 2016.

Boeschoten, Riki Van. "Code-Switching, Linguistic Jokes, and Ethnic Identity: Reading Hidden Transcripts in a Cross-Cultural Context." Journal of Modern Greek Studies, vol. 24, no.2, 2006, pp. 347-377.

Brave Heart, Maria Yellow Horse, and Lemyra M. DeBruyn. "The American Indian Holocaust: Healing Historical Unresolved Grief." American Indian and Alaska Native Mental Health Research, vol. 8, no.2, 1998, pp. 56-78.

Brill, Susan. “Alk'idaa'jini Luci Tapahonso, Irvin Morris, and Della Frank: Interweaving Navajo and English in Their Poems and Stories." Cimarron Review, vol. 121, 1997, pp. 135-153.

Bruchac, Joseph. Navajo Long Walk: Tragic Story Of A Proud Peoples Forced March From Homeland. National Geographic Children's Books, 2012.

Buell, Marcia. "Code-Switching and Second Language Writing: How Multiple Codes Are Combined in a Text." What Writing Does and How It Does It. Eds. Charles Bazerman and Paul Prior. Mahwah, New Jersey: Lawrence Erlbaum Associates, 2004.

Callahan, Laura. Spanish/English Code Switching in a Written Corpus. Philadelphia: John Benjamins Publishing Co., 2004.

Carmean, Kelli. Spiderwoman Walks This Land: Traditional Cultural Properties and the Navajo 
Nation. Walnut Creek: Alta Mira P, 2002.

Cheek, Lawrence W. The Navajo Long Walk. Tucson, AZ: Rio Nuevo P, 2004.

Cobb, Amanda. "Understanding Tribal Sovereignty: Definitions, Conceptualizations, and Interpretations. “American Studies, vol. 46, no.3-4, 2005, pp. 115-132.

---. "The National Museum of the Native as Cultural Sovereignty." American Quarterly, vol. 57, no. 2, 2005, pp. 485-506.

Cooper, Guy H. "Coyote in Navajo Religion and Cosmology." The Canadian Journal of Native Studies VII. 2, 1987, pp. 181-193.

Cutter, Martha. ."Translation and Alternative Forms of Literacy." MELUS, vol. 34, no.4, 2009, pp. 5-13.

De Fina, Anna. "Code-switching and the Construction of Ethnic Identity in a Community of Practice.” Language in Society, 2007, pp. 371-392.

Deloria, Vine, and Clifford Lytle. The Nations Within: The Past and Future of American Indian Sovereignty. Austin: U of Texas P, 1984.

Deloria, Vine. Spirit and Reason: The Vine Deloria, Jr. Reader. Golden, CO: Fulcrum Publishing, 1999.

---. Custer Died For Your Sins. Norman, OK: U of Oklahoma P, 1988.

Denetdale, Jennifer Nez. "Chairmen, Presidents, and Princesses: The Navajo Nation, Gender, and the Politics of Tradition." Wicazo Sa Review, vol, 21, no.1, 2006, pp. 9-28.

---. "Remembering Our Grandmothers: Navajo Women and the Power of Oral Tradition." Indigenous People's Wisdom and Power: Affirming Our Knowledge through Narratives. Eds. Julian Kunnie and Nomalungelo Ivy Goduka. Burlington, Ashgate Publishing Co, 2006. 
---. Reclaiming Diné History: The Legacies of Navajo Chief Manuelito and Juanita. Tucson: U of Arizona P, 2007.

---. The Long Walk: The Forced Navajo Exile. New York, NY: Infobase Publishing, 2008.

Derosa, Robin. "Critical Tricksters." American Indian Rhetorics of Survivance: Word Medicine, Word Magic. Ed. Ernest Stromberg. U of Pittsburgh P, 2006.

“Dine Bikeyah.” Facebook. 4 March 2016. Web. 9:00am.

Dunn, Carolyn. “The Trick is Going Home: Secular Spiritualism in Native American Women's Literature." Reading Native American Women: Critical/Creative Representations. Ed. Inés Hernández-Avila. New York: Altamira P, 2005.

Emerson, Larry. "Diné Culture, Decolonization, and the Politics of Hózhǫ." Diné Perspectives: Revitalizing and Reclaiming Navajo Thought. Ed. Lloyd E. Lee. Tucson: U of Arizona P, 2014.

Fagan, Kristina. "What's the Trouble With Trickster?: An Introduction.” Troubling Tricksters: Revisiting Critical Conversations. Wilfrid Laurier U P, 2010.

Farella, John R. The Main Stalk: A Synthesis of Navajo Philosophy. Tucson, AZ: U of Arizona P, 1984.

Fast, Robin. "This Land is Full of Stories: Navajo Histories in the Works of Luci Tapahonso." Women's Studies, 38, 2007, pp. 185-211.

Fixico, Donald L. The American Indian Mind in a Linear World: American Indian Studies \& Traditional Knowledge. New York: Routledge, 2003.

---. Treaties with American Indians: An Encyclopedia of Rights, Conflicts and Sovereignty, 3 volumes, ed, (2007).

Forbes, Jack. "Intellectual Self-Determination and Sovereignty: Implications for Native Studies 
and for Native Intellectuals.” Wicazo Sa Review, vol. 13, no.1, 1998, pp. 11-23.

---. Africans and Native Americans: The Language of Race and the Evolution of Red-

Black Peoples. Chicago: U of Illinois, 1993.

Fowler, Shelli B, et al. "Negotiating Textual Terrain: A Conversation on Critical and Pedagogical Interventions in the Teaching of Ethnic Autobiography." Frontiers: A Journal of Women Studies, vol. 17, no.2, 1996, pp. 4-49.

Gans, Herbert J. "Symbolic Ethnicity: The Future of Ethnic Groups and Cultures in America." Theories of Ethnicity. Ed. By Werner Sollors. New York: New York UP, 1996.

Gibson, Caitlin. "J.K. Rowling Borrowed a Navajo Legend for Her New Story. Is That Okay?" Washington Post, 9 March 2016.

Gilbert, Matthew Sakiestewa. "I Learned to Preach Pretty Well, and Cuss, Too.” Ed. MariJo Moore. Eating Fire, Tasting Blood: An Anthology of the Great American Holocaust. New York, NY: Thunder's Mouth P, 2006.

Gilyard, Keith. "Higher Learning: Composition's Racialized Reflection." Race, Rhetoric and Composition. Portsmouth, NH: Boynton/ Cook, 1999.

Grande, Sandy. Red Pedagogy: Native American Social and Political Thought. Lanham, MD: Rowman \& Littlefield, 2004.

Gross, Lawrence W. "Cultural Sovereignty and Native American Hermeneutics in the Interpretation of the Sacred Stories of the Anishinaabe.” Wicazo Sa Review, vol. 18, no.2, 2003, pp. 127-134.

Hames-Garcia, Michael Roy. "Which America is Ours?: Martí's "Truth" and the Foundations of "American Literature." Modern Fiction Studies, vol. 49, no.1, 2003, pp. 19-53.

Hannon, Gerald. "Tomson Highway and the Trickster: Scenes from the Life of Playwright 
Tomson Highway." Toronto Life, vol. 25, no.4, 1991, pp. 28-44.

Harjo, Joy, and Gloria Bird. “Introduction.” In Reinventing the Enemy's Language:

Contemporary Women's Writings of North America, ed. Joy Harjo and Gloria Bird. New York: Norton, 1998.

Hogg, George Thomas. An Introduction to Indian Nations in the United States. Ithaca, NY: National Congress of American Indians, 2015.

Hoover, Jessica Safran. "Rhetorical Sovereignty in Written Poetry: Survivance Through CodeSwitching and Translation in Laura Tohe's Tséyi'/Deep in the Rock: Reflections on Canyon de Chelly." Survivance, Sovereignty, and Story: Teaching American Indian Rhetorics, edited by Lisa King, Rose Gubele, and Joyce Rain Anderson, Utah State U P, 2015, pp. $170-187$.

Hyde, Lewis. Trickster Makes This World Mischief, Myth and Art. New York: North Point P, 1998.

"Illinois State University.” Forbes. 2017, https://www.forbes.com/colleges/illinois-stateuniversity. Accessed 8 Feb. 2017.

"Indian Boarding Schools." Indian County Diaries. PBS. Sept. 2006, http://www.pbs.org/indiancountry/history/boarding.html. Accessed 12 January 2017.

Iverson, Peter. Dine: A History of the Navajos. Albuquerque, NM: U of New Mexico P, 2002. Keating, AnaLouise. “"Making New Connections”: Transformational Multiculturalism in the Classroom." Pedagogy, vol. 4, no.1, 2004, pp. 93-117.

Kidwell, Clara Sue, and Alan Velie. Native American Studies. UK: Edinburgh U P, 2005.

King, Lisa. "Rhetorical Sovereignty and Rhetorical Alliance in the Writing Classroom: Using American Indian Texts.” Pedagogy, vol 12, no.2, 2012, pp. 209-233. 
Kluckhohn, Clyde, and Dorothea Leighton. The Navaho. Cambridge: Harvard U P, 1958.

Kreyling, Michael. "Teaching Southern Lit in Black and White.” Southern Cultures, vol. 11, no.4, 2005, pp. 47-75.

Landis, Barbara. "Putting Lucy Pretty Eagle to Rest." Boarding School Blues: Revisiting American Indian Educational Experiences. Eds Clifford E. Trafzer, Jean A. Keller, and Lorene Sisquoc.Lincoln: U of Nebraska P, 2006.

Lauter, Paul. "Race and Gender in the Shaping of the American Canon: A Case Study from the Twenties." Feminist Studies, vol. 9, no.3, 1983, pp. 435-463.

Lee, Kimberli. "Heartspeak from the Spirit Songs of John Trudell, Keith Secola, and Robbie Robertson." Studies in American Indian Literatures, vol. 19, no.3, 2007, pp. 89-114.

Lee, Lloyd. "Reclaiming Indigenous Intellectual, Political, and Geographic Space: A Path for Navajo Nationhood." The American Indian Quarterly, vol. 32, no.1, 2008, pp. 96-110.

---. "The Future of Navajo Nationalism.” Wicazo Sa Review, vol. 22, no.1, 2007, pp. 53-68.

---. "Navajo Cultural Identity: What Can the Navajo Nation Bring to the American Indian Identity Discussion Table?” Wicazo Sa Review, vol. 21, no.2, 2006, pp. 79-103.

Lipsitz, George. The Possessive Investment in Whiteness. Philadelphia: Temple UP, 1998. Lo, Adrienne. "Code Switching, Speech Community Membership, and the Construction of Ethnic Identity." Journal of Sociolinguistics, vol. 3, no.4, 1999, pp. 461-479.

Lyons, Scott. "Body: Peyotism and the Pan-Indian Public, 1911-23." Eds. C. Jan Swearingen and Dave Pruett. Rhetoric, the Polis, and the Global Village: Selected Papers from the 1998 Thirtieth Anniversary Rhetoric Society of America Conference. Mahwah, NJ: L. Earlbaum Associates, 1999.

--- "Rhetorical Sovereignty: What Do American Indians Want From Writing?" CCC, vol. 51, 
no.3, 2000, pp. 447-468.

Martin, Holly E. “Code-Switching in US Ethnic Literature: Multiple Perspectives Presented Through Multiple Languages." Changing English, vol. 12, no.3, 2005, pp. 403-415.

McCarty, Teresa L. A Place to be Navajo: Rough Rock and the Struggle for Self-Determination in Indigenous Schooling. Mahwah, NJ: Lawrence Erlbaum Associates, Publishers, 2002.

McPherson, Robert S. Navajo Land, Navajo Culture: The Utah Experience in the Twentieth Century. U of Oklahoma P, 2013.

"Mille Lacs Band State of the Nation Focuses on Cultural Sovereignty." Indian Country Today. 17 January 2015.

Miller, Ryan W. "How the Dakota Access Pipeline Battle Unfolded." USA Today, 4 December 2016.

Montoya, Isaiah. "Remembering the 'Pueblo Training School.” Navajo Times 9 July 2009.

Morales, Laurel. "Backlash After Referee Bans Traditional Navajo Hairstyle.” NPR. 14 Feb. 2016, http://www.npr.org/2016/02/14/466720705/backlash-after-referee-bans-traditionalnavajo-hairstyle. Accessed 5 March 2016.

Moyers, Bill. "The Absence of Native American Power." Moyers and Company. 9 April 2013. “Navajo Nation Government.” Navajo Nation, 2011, http://www.navajo-nsn.gov/govt.htm. Accessed 11 November 2016.

Omi, Michael, and Howard Winant. Racial Formations in the United States. $2^{\text {nd }}$ ed. New York: Routledge, 1994.

Ortiz, Simon. "Towards a National Indian Literature: Cultural Authenticity in Nationalism." MELUS, vol. 8, no.2, 1981, pp. 7-12.

Owens, Louis. Mixedblood Messages: Literature, Film, Family, Place. U of Oklahoma P, 2001. 
---. Other Destinies: Understanding the American Indian Novel. U of Oklahoma P, 1994.

Parsons-Yazzie, Evangeline. "Perceptions of Selected Navajo Elders Regarding Navajo Language Attrition.” Journal of Navajo Education, vol. 13, no.2, 1996, pp. 51-57.

Patell, Cyrus R. K. "Representing Emergent Literatures.” American Literary History, vol. 15, no.1, 2003, pp. 61-69.

Powell, Malea. "Down by the River, or How Susan La Flesche Picotte Can Teach Us About Alliance as a Practice of Survivance." College English, vol. 67, no.1, 2004, pp. 38-60.

---. "Rhetorics of Survivance: How American Indians Use Writing." College

Composition and Communication, vol. 53, no.3, 2002, pp. 396-434.

---. "Blood and Scholarship: One Mixed-Blood's Story." Race, Rhetoric and Composition. Ed. Keith Gilyard New Hampshire: Boynton/Cook P, 1999.

Powell, Margaret K. and Joseph Roach. "Big Hair." Eighteenth-Century Studies, vol. 38, no.1, 2004, pp. 79-99.

Pratt, Mary Louise. “Arts of the Contact Zone." Profession, 91, 1991, pp. 33-40.

Pratt, Richard H. Battlefield and Classroom: Four Decades With the American Indian, 18671904. Norman: U of Oklahoma P, 1964.

Prucha, Francis Paul. Documents of United State Indian Policy. $3^{\text {rd }}$ ed. Lincoln: U of Nebraska P, 2000.

---. Americanizing the American Indians: Writings by the "Friends of the Indian," 1880-1900. U of Nebraska P, 1978.

Radin, Paul. The Trickster: A Study in American Indian Mythology. Schocken, 1956.

Redfield, Karen A. "Native American Storytelling." American Indian Rhetorics of Survivance. Ed. Ernest Stromberg. Pittsburgh: U of Pittsburgh P, 2006. 
Report of the United States Bureau of Indian Affairs. Annual Report of the Commissioner of Indian Affairs to the Secretary of the Interior, 1886.

“Revitalizing Native Cultures.” Indian Country Diaries. PBS.org. Sept. 2006, http://www.pbs.org/indiancountry/challenges/cultures.html. Accessed 12 June 2016.

Said, Edward. Culture and Imperialism. Vintage, 1994.

Schecter, Sandra R., and Robert Bayley. "Language Socialization Practices and Cultural Identity: Case Studies of Mexican-Descent Families in California and Texas." TESOL Quarterly, vol. 31, no.3, 1997, pp. 513-541.

Shebala, Marley. “Universal Truths, Ancient Wisdom.” Navajo Times. 21 Feb 2008.

Sieg, Stina. “Navajo Fashion Designer Uses T-Shirts To Illustrate Native Life.” KJZZ 91.526 April 2016, http://kjzz.org/content/297780/navajo-fashion-designer-uses-t-shirtsillustrate-native-life. Accessed 15 May 2016.

Smith, Jeanne Rosier. Writing Tricksters: Mythic Gambols in American Ethnic Literature. Berkeley: U of California P, 1991.

Smith, Linda Tuhiwai. Decolonizing Methodologies: Research and Indigenous Peoples. Dunedin: U of Otago P, 1999.

“Storytelling Help Preserve Navajo Culture.” ASU News. Arizona State University, 2006.

Strayhorn, Terrell L., Fei Bie, Marjorie L. Dorime-Williams, and Michael Steven Williams. “Measuring the Influence of Native American College Students' Interactions With Diverse Others on Sense of Belonging."Journal of American Indian Education, vol. 55, no.1, 2016, pp. 49-73.

Stromberg, Ernest. American Indian Rhetorics of Survivance: Word Medicine, Word Magic. U of Pittsburgh P, 2006. 
Sutherland, JJ. "Bugs Bunny: The Trickster, American Style.” NPR 6 Jan. 2008, http://www.npr.org/templates/story/story.php?storyId=17874931. Accessed 17 June 2016.

Tan, Avianne. "Navajo Nation Mourning, Pleading for Help After Toxic Mine Spill Contaminates Rivers.” ABC News. 11 Aug 2015.

Tapahonso, Luci. Sáanii Dahataat: The Women Are Singing. U of Arizona P, 1993.

Toelken, Barre. "Life and Death in the Navajo Coyote Tales." Recovering the Word: Essays On Native American Literature. Eds. Brian Swann and Arnold Kupat. Berkeley: U of California P, 1987.

Toelken, Barre, and Tacheeni Scott. "Poetic Retranslation and 'Pretty Languages."” Traditional American Indian Literatures: Texts and Interpretations. Ed. Karl Kroeber. Lincoln: U of Nebraska P, 1981.

Tohe, Laura. No Parole Today. Albuquerque, NM: West End Press, 1999.

---. Sister Nations. Minnesota Historical Society Press, 2002.

---. Tséyi'/Deep in the Rock: Reflections on Canyon de Chelly. Tucson: U of Arizona, 2005.

---. "Hwéeldi Bééhániih: Remembering the Long Walk." Wicazo Sa Review, vol. 22, no.1, 2007, pp. $77-82$.

---. Personal Interview. 26 March 2009.

Toledo-Benalli, Eulynda. "Facing the Legacy of Boarding Schools." Cultural Survival, vol. 28, no.4, 2004.

Torres-Padilla, Jose L. "Death to the Originary Narrative! Or, Insurgent Multiculturalism and Teaching Multiethnic Literature.” MELUS, vol. 30, no.2,2005, pp. 13-30. 
Trafzer, Clifford E. "Introduction.” Boarding School Blues: Revisiting American Indian Educational Experiences. Eds Clifford E. Trafzer, Jean A. Keller, and Lorene Sisquoc.Lincoln: U of Nebraska P, 2006.

Trafzer, Clifford E., Jean A. Keller and Lorene Sisquoc (eds). Boarding School Blues: Revisiting American Indian Educational Experiences. Lincoln: U of Nebraska P, 2006.

"US Department of Education, National Center for Education Statistics." The Condition of Education. Washington, DC: U.S. Government Printing Office, 2013.

Vizenor, Gerald. Vizenor, Gerald. "Aesthetics of Survivance, Literary Theory and Practice.” Survivance: Narratives of Native Presence. Lincoln, NE: U of Nebraska P, 2008. 1-23.

---. Survivance: Narratives of Native Presence. Lincoln: U of Nebraska P, 2008.

---. Fugitive Poses: Native American Indian Scenes of Absence and Presence. Lincoln: U of Nebraska P, 2000.

--- "A Trickster Discourse: Comic and Tragic Themes in Native American Literature." Buried Roots and Indestructible Seeds: The Survival of American Indian Life in Story, History, and Spirit. Eds. Mark A. Lindquist and Martin Zanger, Madison: U of Wisconsin P, 1994.

---. Manifest Manners: Postindian Warriors of Survivance. Hanover: Wesleyan U P, 1994.

---. The Heirs of Columbus. $1^{\text {st }}$ edition. Wesleyan, 1991.

---. “Trickster Discourse.” Wicazo Sa Review, vol. 5, no.1, 1989, pp. 2-7.

---. Narrative Chance: Postmodern Discourse on Native American Indian Literatures. Norman: U of Oklahoma P, 1989.

---. The Trickster of Liberty: Native Heirs to a Wild Baronage. U of Oklahoma P, 1988. ---. Anishinabe Nagamon: Songs of the People. Nodin P, 1970. 
Warrior, Robert. Tribal Secrets: Recovering American Indian Intellectual Traditions. Minneapolis, MN: U of Minnesota P, 1994.

Washington, Elizabeth Yeager, and Stephanie Van Hover. "Din'e Bik'eya: Teaching about Navajo Citizenship and Sovereignty.” The Social Studies, 102, 2011, pp. 80-87.

Weaver, Jace, and Craig Womack and Robert Warrior. American Indian Literary Nationalism. Albuquerque: U of New Mexico P, 2006.

Weaver, Jace. Other Words: American Indian Literature, Law, and Culture. Norman: U of Oklahoma P, 2001.

---. “Trickster: The Sacred Fool.” Other Words: American Indian Literature, Law, and Culture. Norman, U of Oklahoma P, 2001.

Webster, Anthony K. "Code-Switching in Navajo Orthographic Poetry: On Places, the Mythic, and Mythic Places." Texas Linguistic Forum, 50, 2004.

---. “From Hóyéé to Hajinei’: On Some Implications of Feelingful Iconicity and Orthography in Navajo Poetry.” Pragmatics, vol. 16, no.4, 2006, pp. 535-549.

---. “'Tséyi’ First, Because Navajo Language was Here Before Contact': On Intercultural Performances, Metasemiotic Stereotypes, and the Dynamics of Place.” Semiotica, 181 1/4, 2010, pp. 149-178.

--- . “'Don’t Talk About It': Navajo Poets and Their Ordeals of Language.” Journal of Anthropological Research, vol. 68, no.3, 2012, pp. 399-414.

Weeks, Andrew, Kelsey Forkner, Susan George, and Josette Lorig. “Making Ends Meet Literature Pedagogy, Faculty - Graduate Student Teamwork, and Undergraduate Literacy." Pedagogy, vol. 16, no.2, 2016, pp. 229-250.

Wiget, Andrew. “A Talk Concerning First Beginnings: Teaching Native American Oral 
Literature." Essays on Teaching the American Literatures: From the Heath Anthology Newsletter, 9, 1993, pp. 4-7.

Wildcat, Daniel, and Vine Deloria. Power and Place: Indian Education in America. Golden, CO: Fulcrum P, 2001.

Wilkins, David. American Indian Sovereignty and the U.S. Supreme Court: The Masking of Justice. Austin: U of Texas P, 1997.

Wilson, Shawn. Research Is Ceremony: Indigenous Research Methods. Halifax: Fernwood, 2008.

Womack, Craig. “A Single Decade.” Reasoning Together: The Native Critics Collective. Eds. Craig S. Womack, Daniel Heath Justice, and Christopher B. Teuton. Norman: U of Oklahoma P, 2008.

---. Red on Red: Native American Literary Separatism. Minneapolis, MN: U of Minnesota P, 1999.

Yurth, Cindy. "Blackhorse to Grads: 'We're Not Going to Take It Anymore.”' Navajo Times 19 May 2016.

---. "Hwéeldi at 150: Making Peace With a Painful Past." Navajo Times 2 October 2014. Zitzer-Comfort, Carol. "Teaching Native American Literature: Inviting Students to See the World Through Indigenous Lenses.” Pedagogy, 8, 2008, pp. 160-70. 


\section{APPENDIX A: SUGGESTED TEXTS}

I used, just to name a few, the following larger texts and articles for my introductory to American literature course, with an emphasis on American Indian literatures:

\section{Books}

Laura Tohe's Deep in the Rock: Reflections on Canyon De Chelly

Laura Tohe's No Parole Today

Helena Maria Viramontes's Under the Feet of Jesus

Julia Alvarez's How the Garcia Girls Lost Their Accents

Sherman Alexie's Absolutely True Diary of a Part-Time Indian

Louise Erdrich's Tracks

Zora Neale Hurston's Their Eyes Were Watching God

Walter Mosley's 47

Elie Wiesel's Night

Art Spiegleman's Maus I

Beginning Ethnic American Literatures by Grice, et al

\section{Shorter Works}

Martin Luther King's “I Have a Dream” speech

Vine Deloria's "Images and Identities" and "Indians Today"

Philip Deloria’s “I am Not a Mascot”

Louis Erdrich’s “American Horse”

W.E.B. DuBois' "Double Consciousness"

Sui Sin Far's "In the Land of the Free"

Maxine Hong Kingston's “No Name Woman" 
Amy Tan's "Half and Half”

Mary Louise Pratt's "Contact Zone"

Nicholasa Mohr's “The English Lesson”

Maria Campbell’s “Halfbreed”

Luci Tapahonso's “What I Am 